NONGAME SPECHES

Of Special Interess or Concem

9

333.95

F $2 n$

1978

Mammals

Birds

Reptiles

Amphibians

Fishes

Prepared by

Demnis i. Flatin

Nongame Biologist

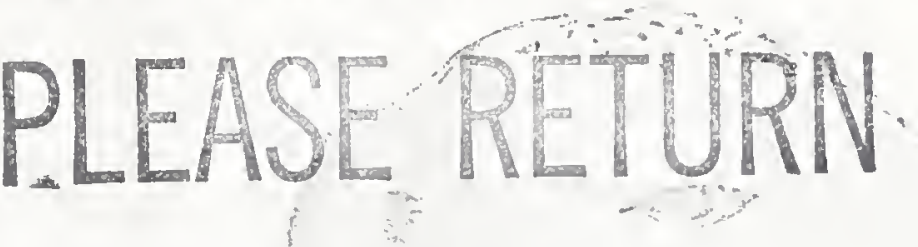

gIATE DOCUMENTS COLLECTION

SEP 301980

MONTANA STATE LIBRARY

930 E Lyndale Ave.

Hziend. Montana 59601

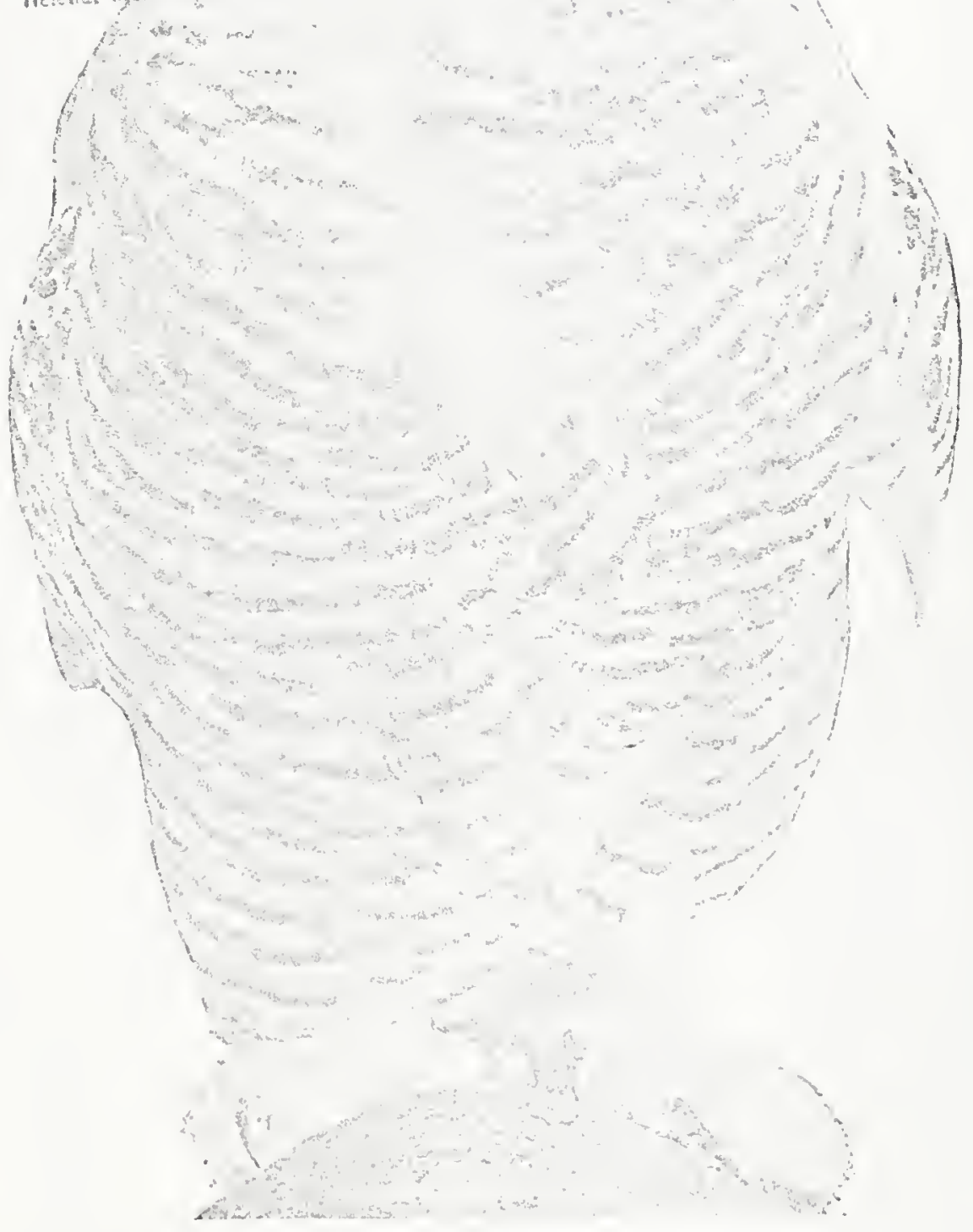

Photo by Gerry Atwell

Wilnile Division - Montana Department of Fish and Game - January, 1973 


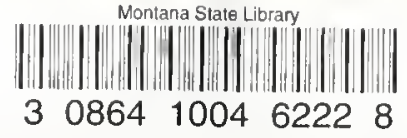


INTROHUCTION . . . . . . . . . . . . . . • . 1

LITERATURE CTTED . . . . . . . . . . . . . . . 4

\section{COUNTY INVENTORTES}

Silver Bow . . . . . . . . . . . . . . 5

Cascade ................... . . . . 6

Ye1lowstone................... . . . . 6

Nissoula . . . . . . . . . . . . . . . 7

Lewis \& Clark . . . . . . . . . . . . . . 7

Gallatin . . . . . . . . . . . . . . . 8

Flathead . . . . . . . . . . . . . . 8

Fergus . . . . . . . . . . . . . . . . 9

Jowder River . . . . . . . . . . . . . . 9

Carbon ................... . . 10

Phillips . . . . . . . . . . . . . 10

ilil1 . . . . . . . . . . . . . 11

Rava11i................... . 11

Custer. . . . . . . . . . . . . . 12

lake . . . . . . . . . . . . . . 12

bawson . . . . . . . . . . . . . . 13

Roosevelt . . . . . . . . . . . . . 13

Beaverhead .. . . . . . . . . . . . 14

Choteal. . . . . . . . . . . . . . 14

Valley. . . . . . . . . . . . . . 15

Toole..................... . . 15

Bighorn . . . . . . . . . . . . . . 16

Musselshell. . . . . . . . . . . . . 16

lilaine . . . . . . . . . . . . . 17

Madison . . . . . . . . . . . . . . 17

Pondera . . . . . . . . . . . . . . 18

Richlant . . . . . . . . . . . . . 18

Powell .. . . . . . . . . . . . . . 19

Rosebud. . . . . . . . . . . . . . . 19

Deer Lodge. . . . . . . . . . . . . . . 20

Teton ................... . . 20

Stillwater ................. 21

Treasure. . . . . . . . . . . . . 21

Sheridan................. . . 22

Sanders................ . . . 22

Judith Basin . . . . . . . . . . . 23

Daniels . . . . . . . . . . . . . 23

Glacier . . . . . . . . . . . . 24

Fa11on . . . . . . . . . . . . . 24

Sweetgrass. . . . . . . . . . . . . 25

liccone .................. . . 25

Carter . . . . . . . . . . . . . 26 
Proadwaler .. . . . . . . . . . . . . . . 26

Wheatland . . . . . . . . . . . . . . . 27

Prairit. . . . . . . . . . . . . . . 27

Granite. . . . . . . . . . . . . . . . . 28

Meagher.................... . . . . . . 28

Ljberiy . . . . . . . . . . . . . . . . . 29

Park . . . . . . . . . . . . . . 29

Garfield . . . . . . . . . . . . . 30

Jefferson . . . . . . . . . . . . . . 30

Wilaur . . . . . . . . . . . . . 31

Golden Villey. . . . . . . . . . . . . 31

Mineral . . . . . . . . . . . . . 32

Petroleum . . . . . . . . . . . . . . . 32

Lincoln . . . . . . . . . . . . . . 33

LATILONG INVENTORTES

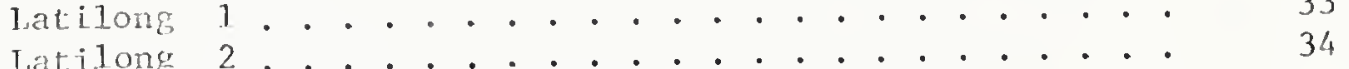

Latilong 3 ................... . . . . . . 34

Latilong 4 . . . . . . . . . . . . . . 35

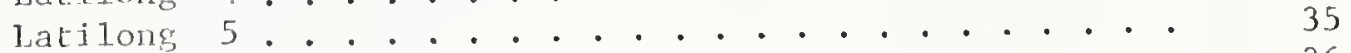

I.tilong 6................... . . . . . . 36

I.atilong 7 . . . . . . . . . . . . . . . 36

Latilong 8 . . . . . . . . . . . . . . . . . . . . . . . 37

Latilong 9.................. . . . . . . . . 37

Latilong 10. . . . . . . . . . . . . . . . . . . . . . . . . 38

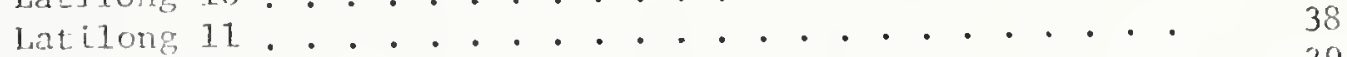

Latijong 12 . . . . . . . . . . . . . 39

Latitong 13 . . . . . . . . . . . . . 39

Latilong 14... . . . . . . . . . . . . . . . 40

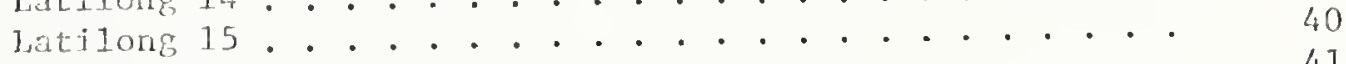

Latilong 16 . . . . . . . . . . . . . . . 4 4]

Latilong 17 . . . . . . . . . . . . . . 41

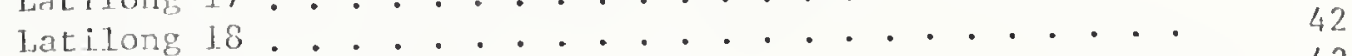

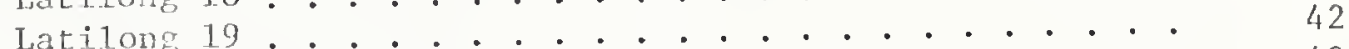

Iatjlon $20 .$. . . . . . . . . . . . . . . . . 43

Latilong 21 . . . . . . . . . . . . . . 43

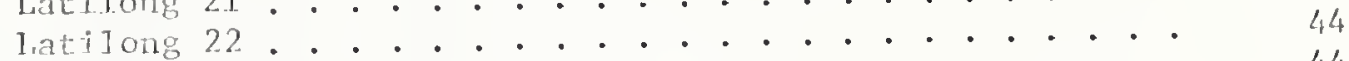

Latitong 23 . . . . . . . . . . . . . . . . 44

Latilong 24 . . . . . . . . . . . . . . . . . 45

latilong 25 . . . . . . . . . . . . . . . . 45

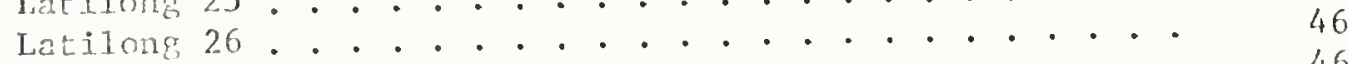

latilong 27 . . . . . . . . . . . . . . . . 46

latilong 28 . . . . . . . . . . . . . . . 47

Latjong 29 . . . . . . . . . . . . . . . . . . 47

Latilong 30 . . . . . . . . . . . 48

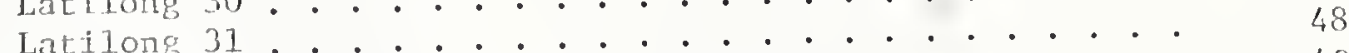

Latilong 32 . . . . . . . . . . . 49

Latilong 33 . . . . . . . . . . . 49

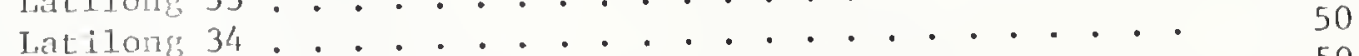

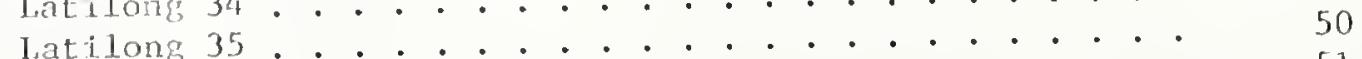

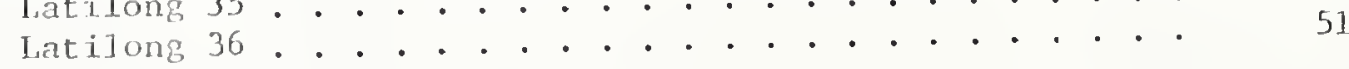


Latilong 37 . . . . . . . . . . . . . . . 51

Iatilong 38 . . . . . . . . . . . . • • 52

Latilong 39 . . . . . . . . . . . . . . 52

Jatilong 40 . . . . . . . . . . . • • • • • 53

Latilong 41 . . . . . . . . . . . . . • • 53

Latilong 42 . . . . . . . . . . . . . . . . . 54

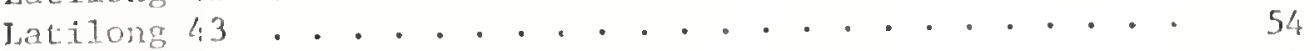

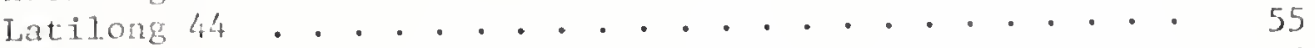

Latilong 45 . . . . . . . . . . • • • 55

Latilong 46 . . . . . . . . . . . . . . . . 56

Latilong 47 . . . . . . . . . . . . . . 56

APPENDTX

I. Montana Mamina 1. . . . . . . . . . . . 58

IT. Montana Birds . . . . . . . . . . . 63

III. Montana Reptiles. . . . . . . . . . . . . 66

IV. Montana Amphibians. . . . . . . . . . . . 67

V. Hontans Fishes . . . . . . . . . . . . 68 
-

0

○ 

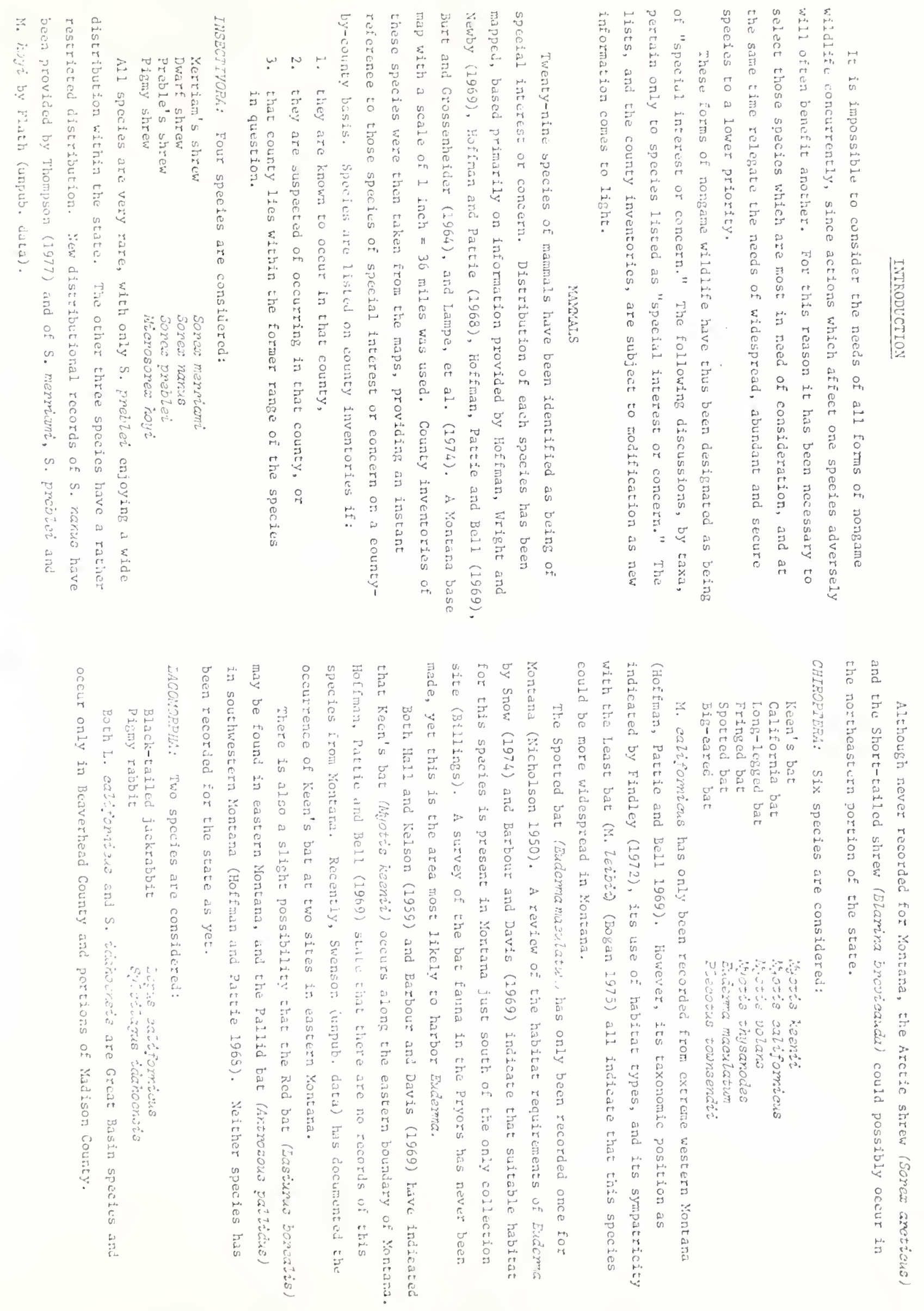


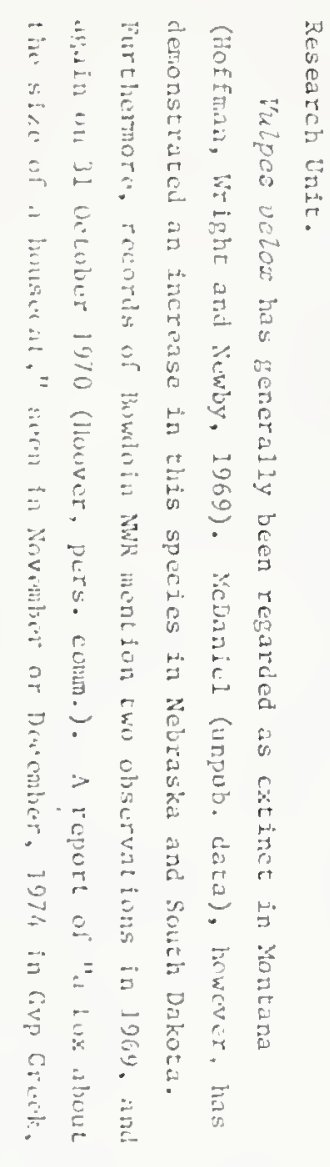

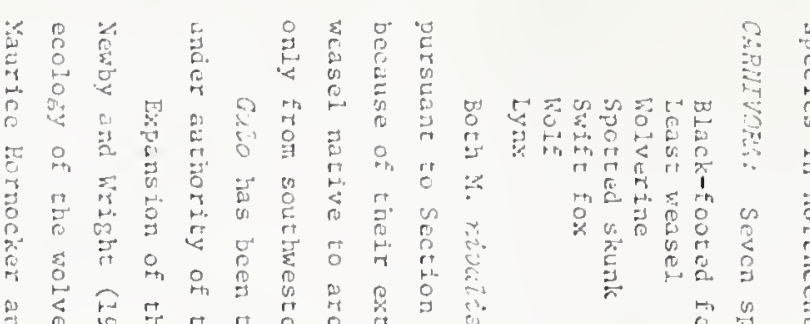

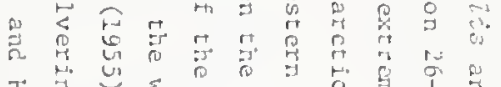

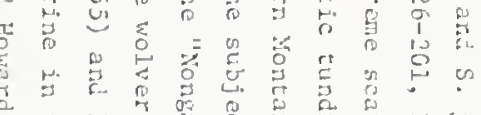

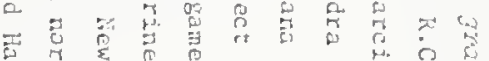

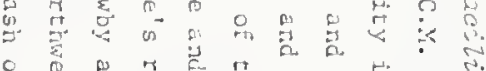

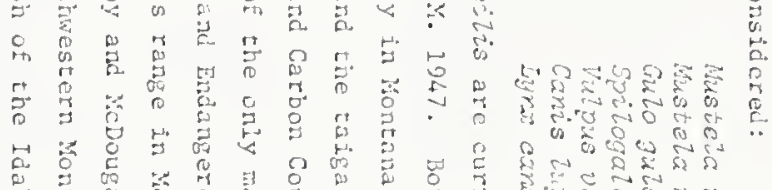

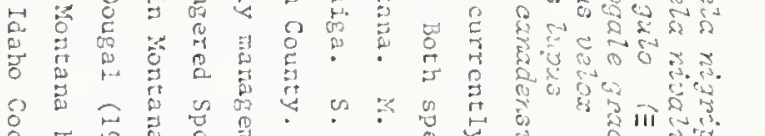

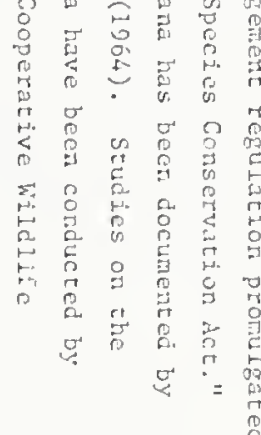

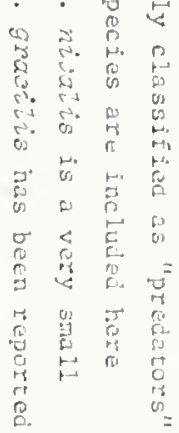

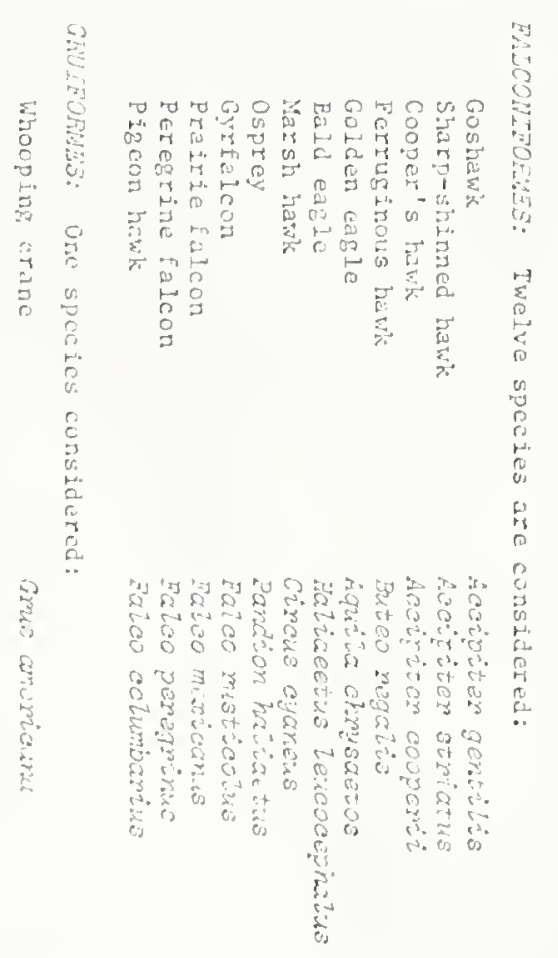$$
\text { पै }
$$

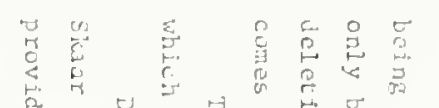

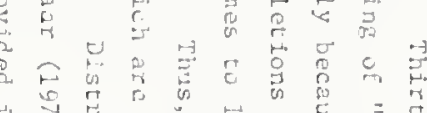

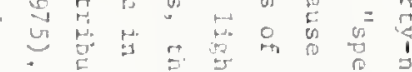

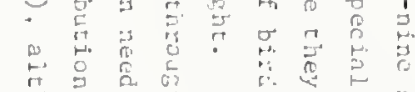

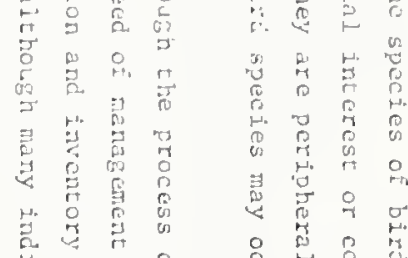

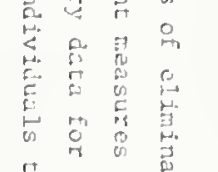

Pin

stis

tra

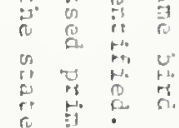

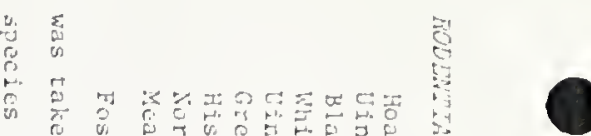

t)

马

0
0

年

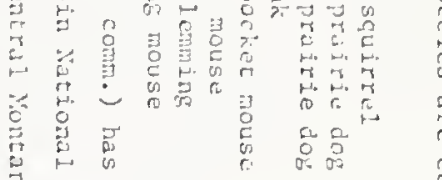

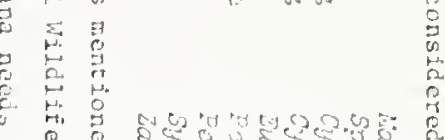

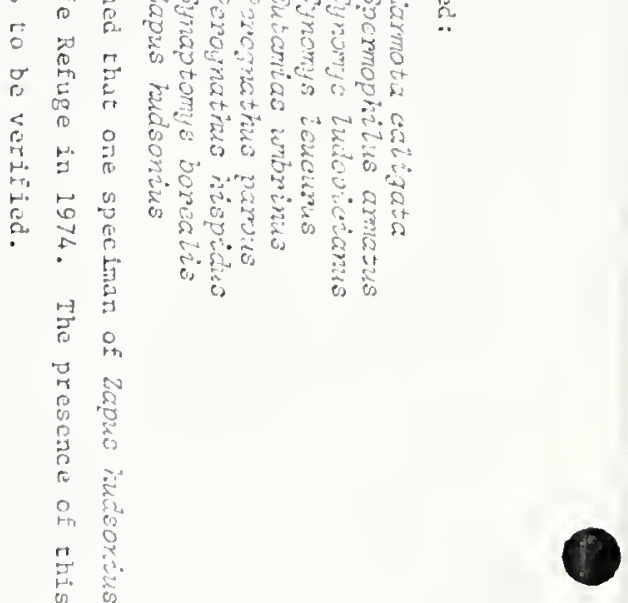

i.

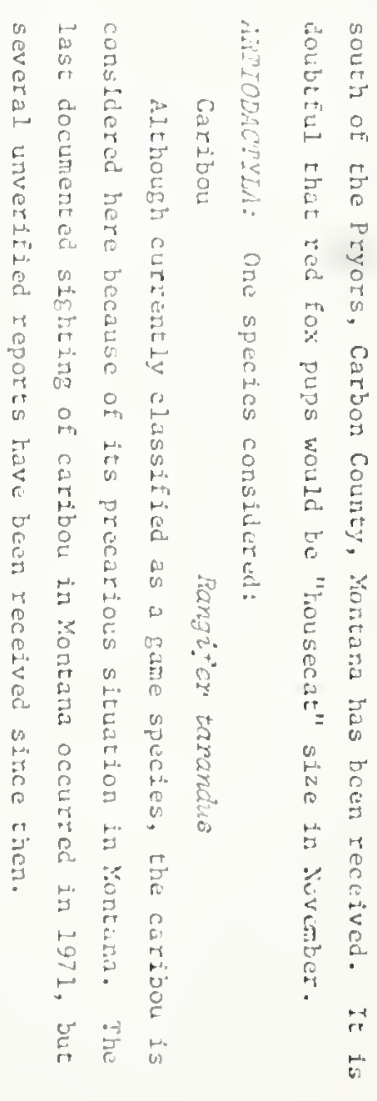



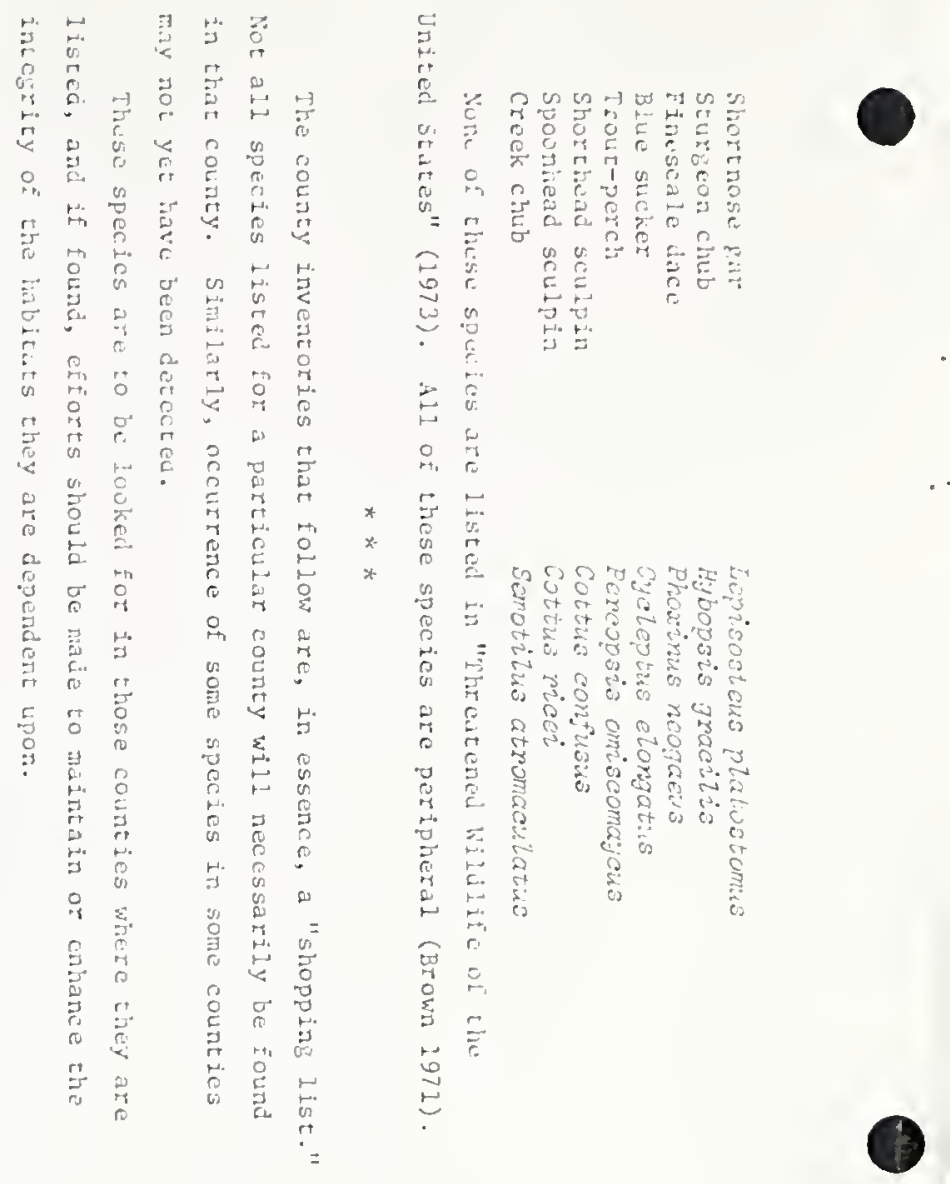

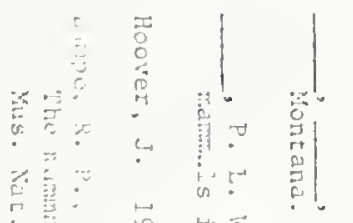

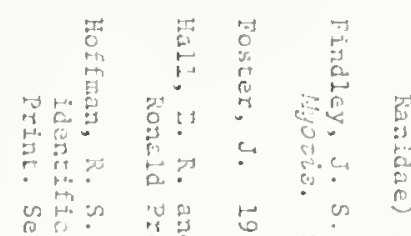

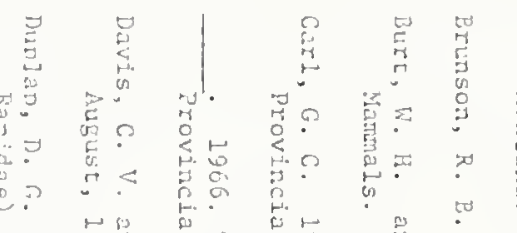

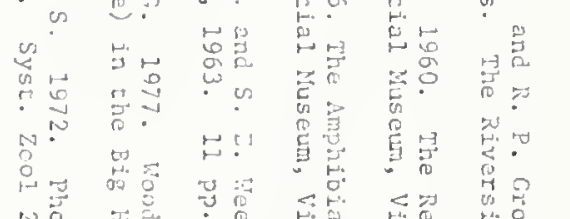

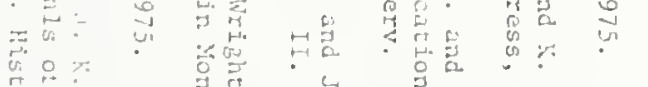

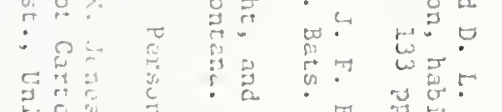

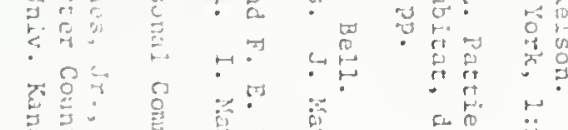

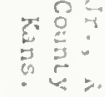

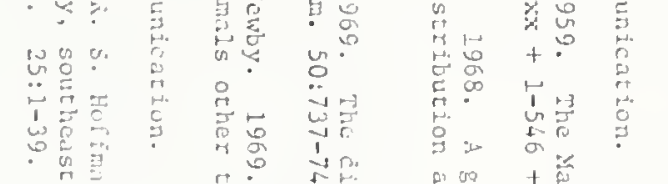

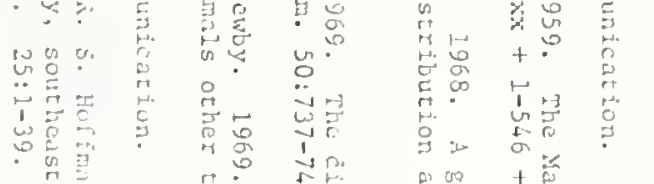

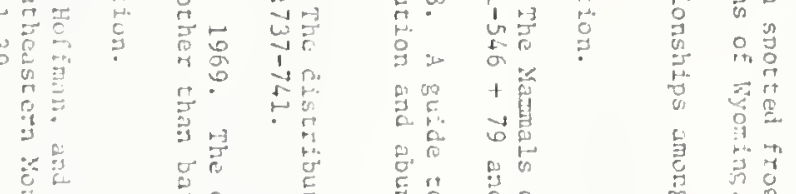

资

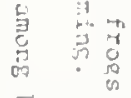

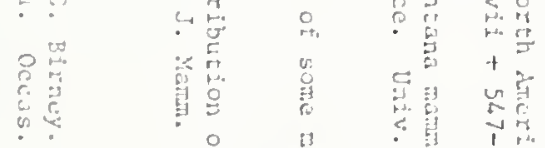

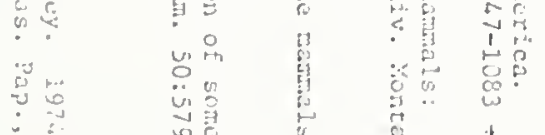

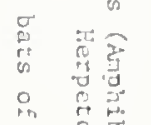

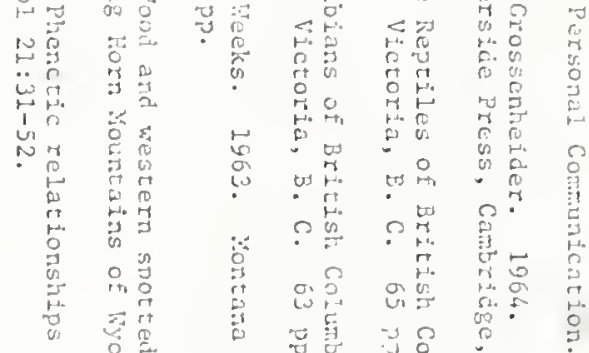

0
0
0
0
0
0
0
0
0
0
0
$\vdots$
0
0

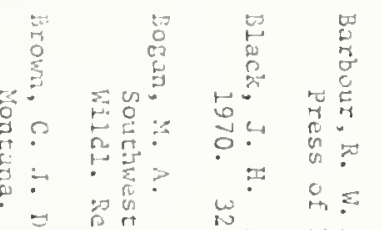

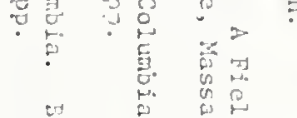

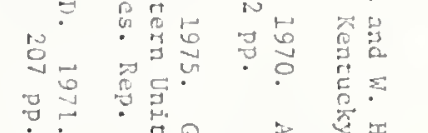

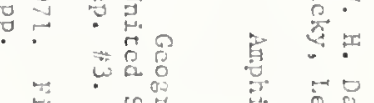

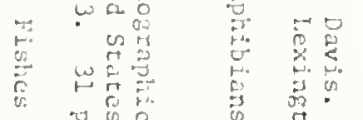

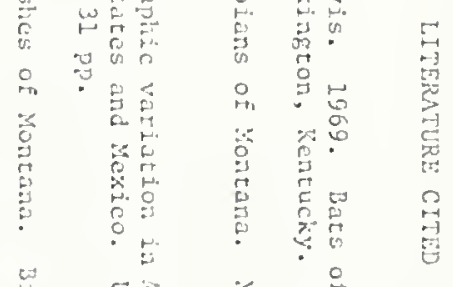

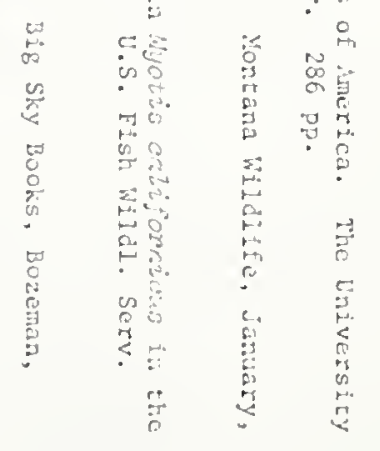


-
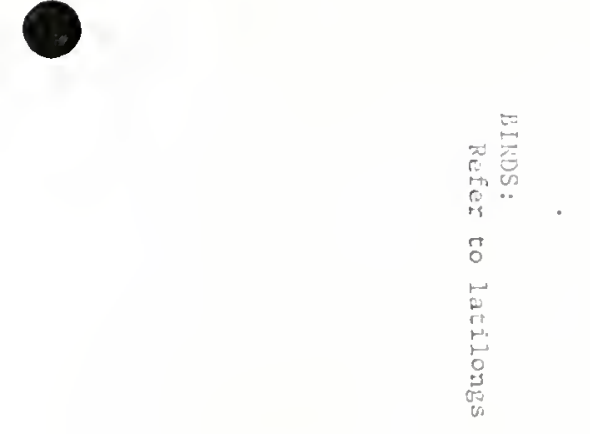<smiles>C1CCCC1</smiles> 

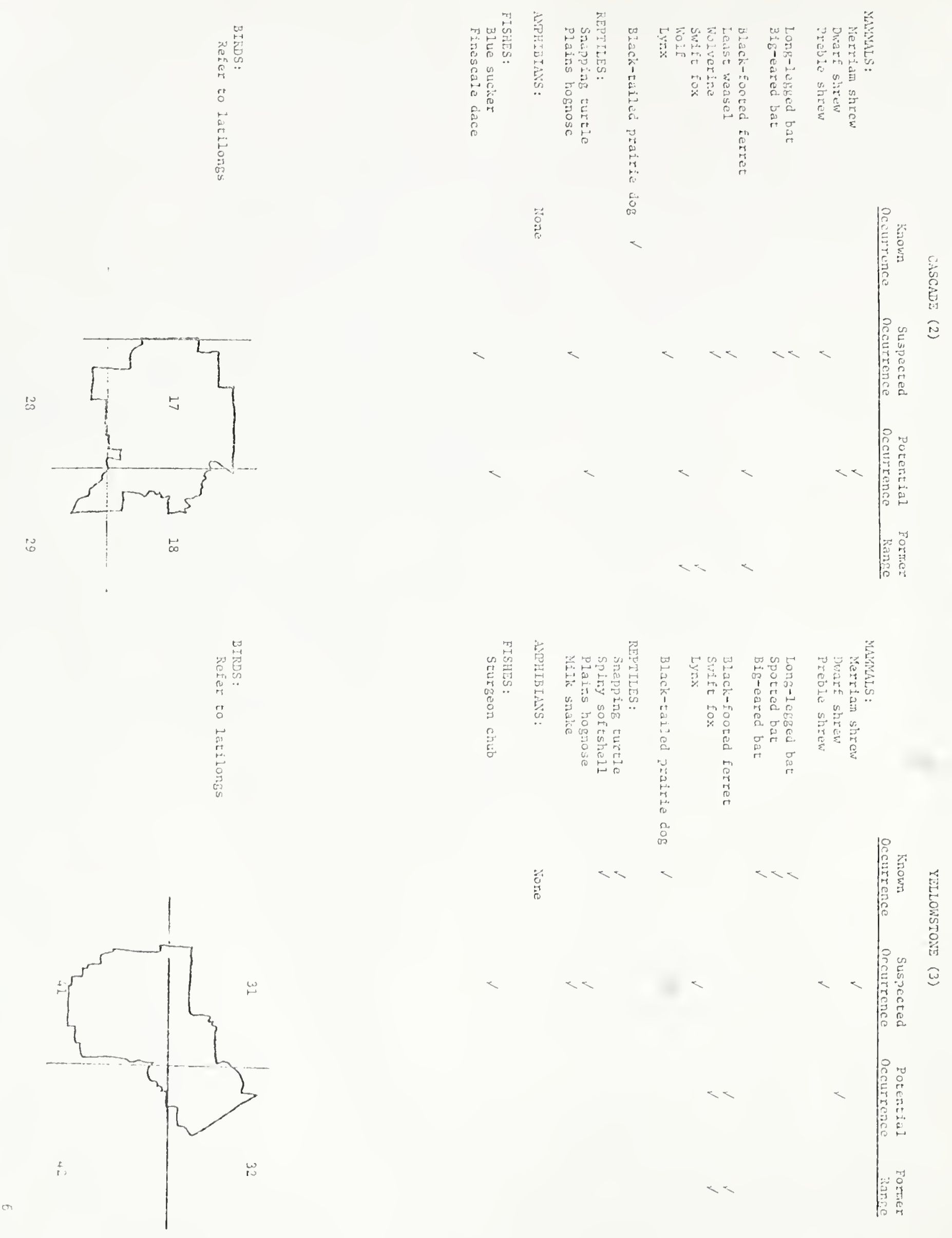


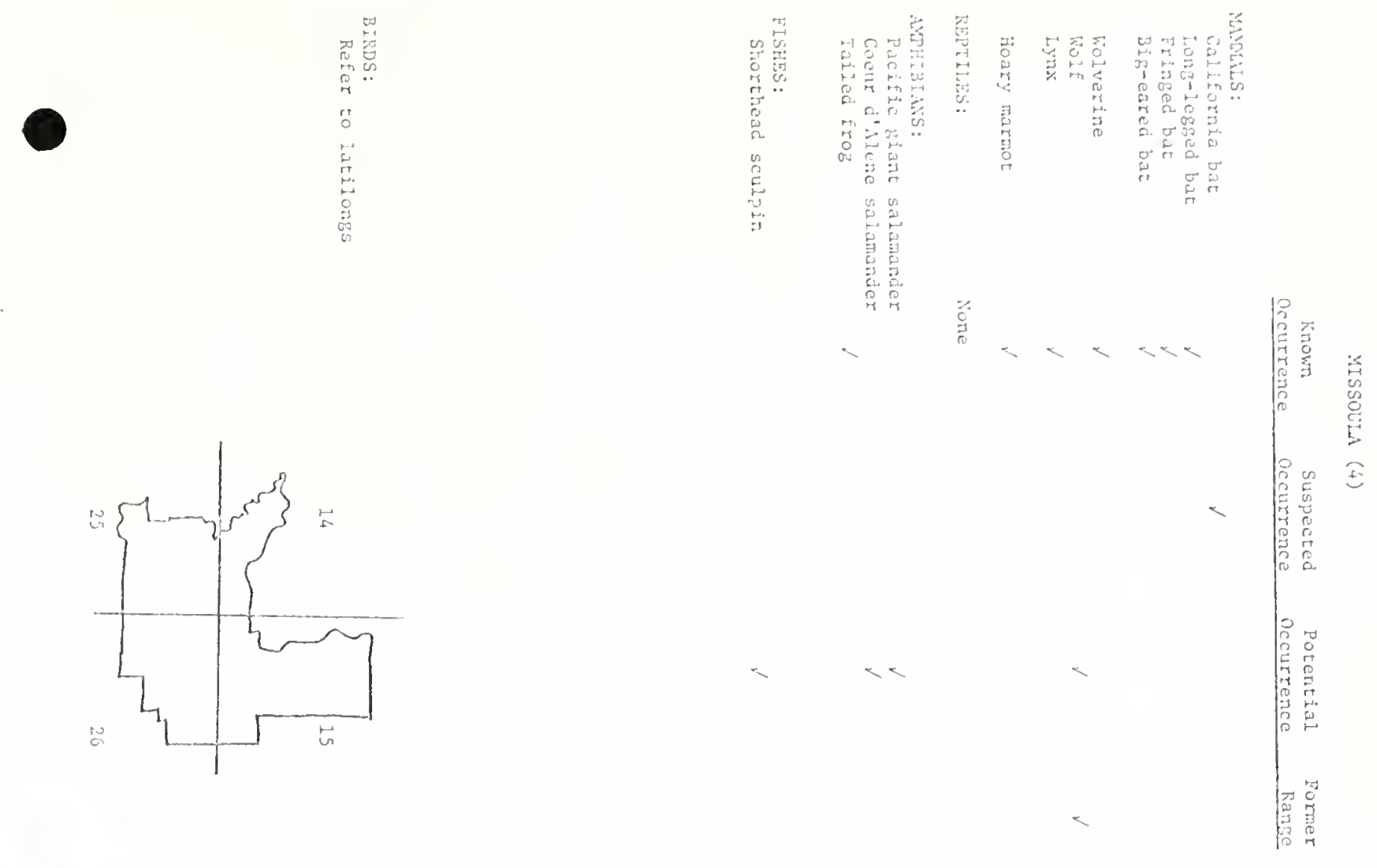

0
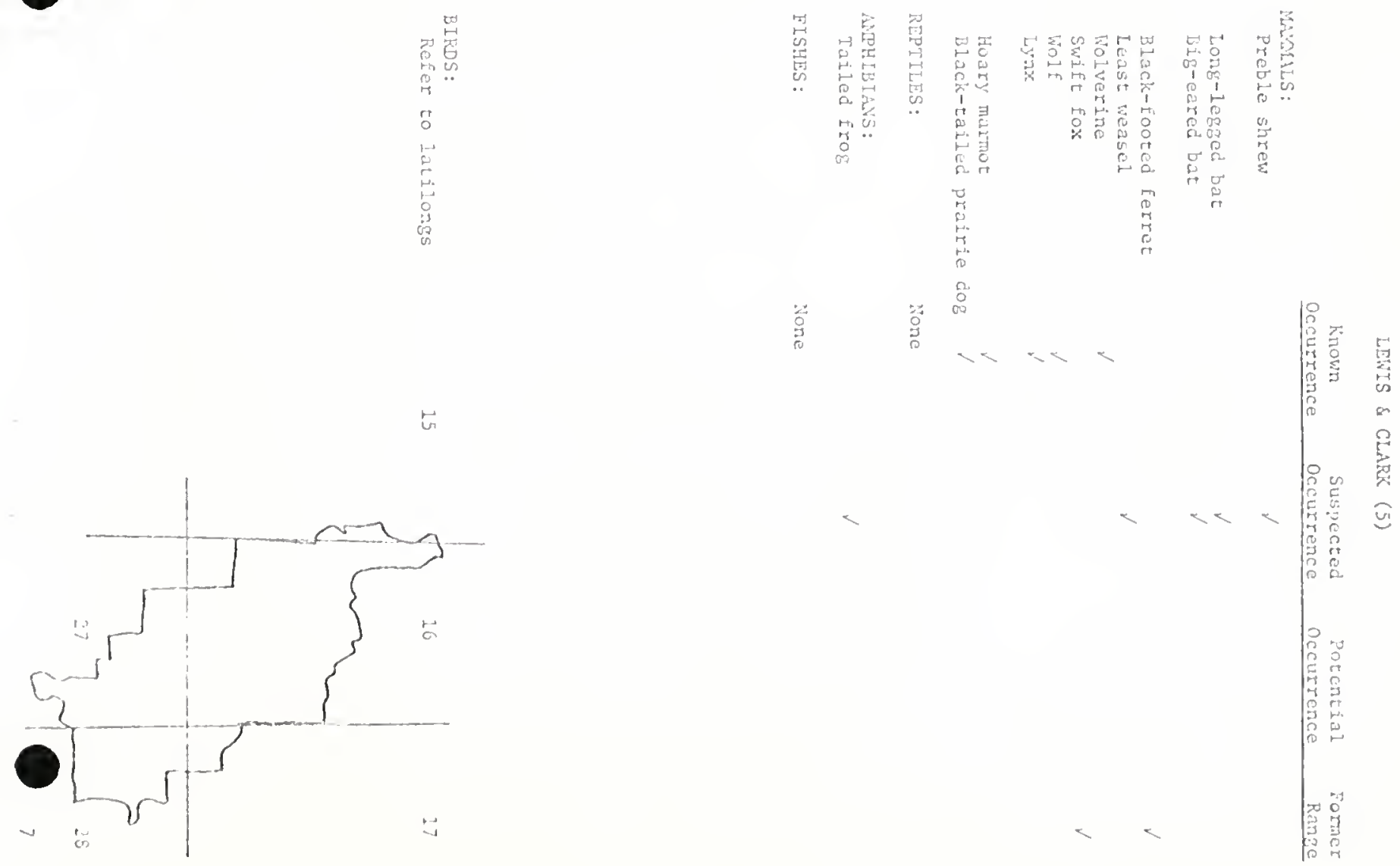

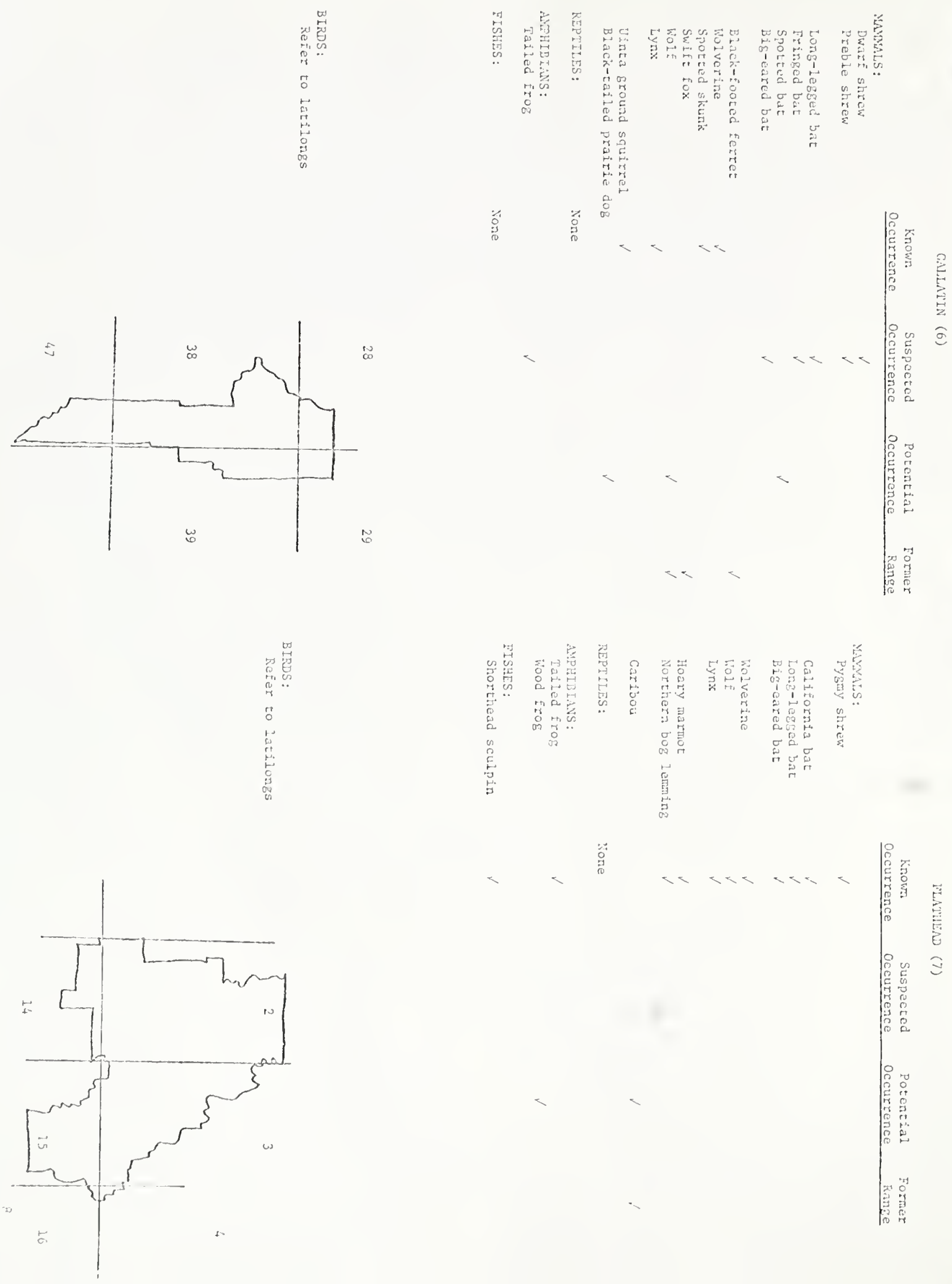

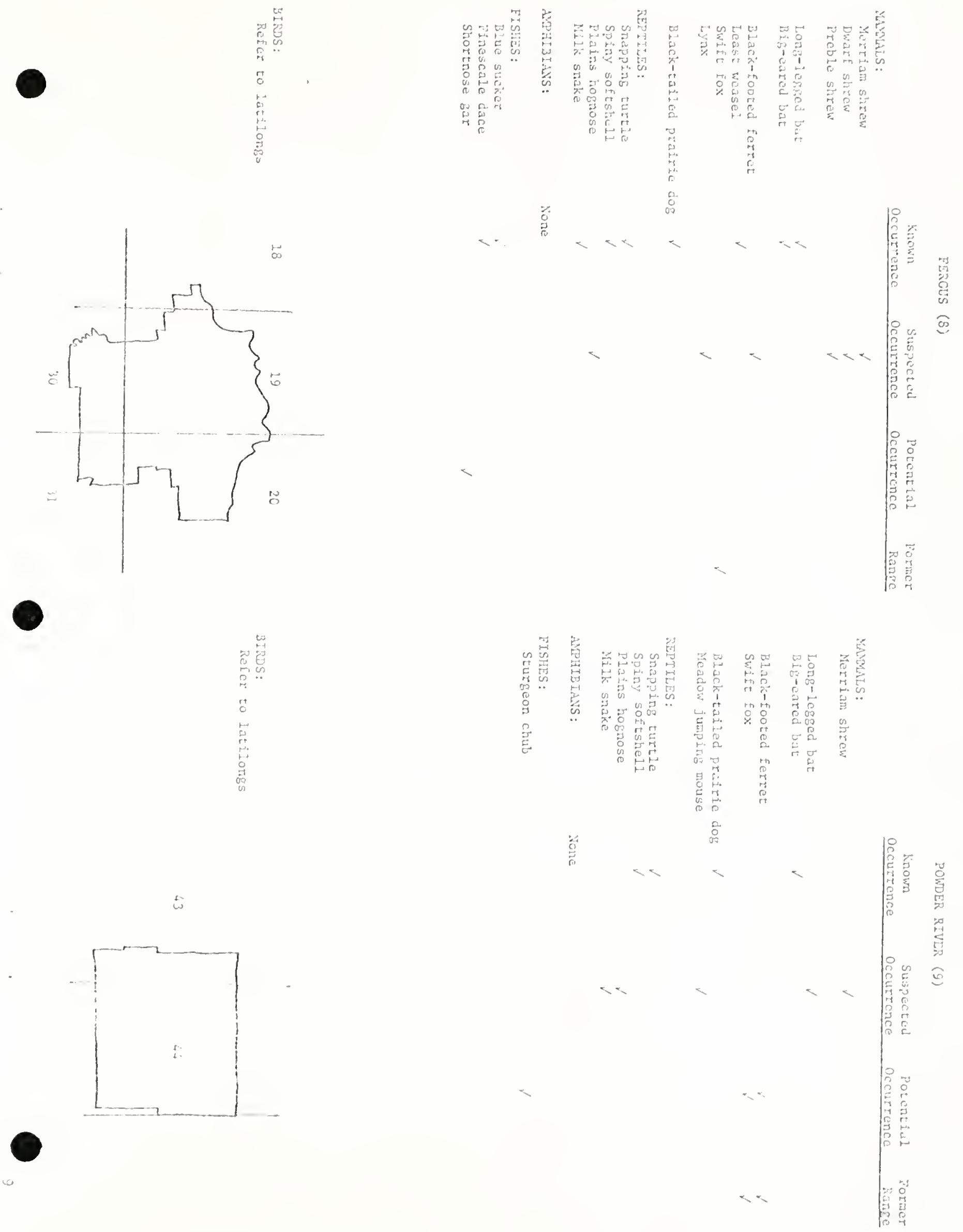

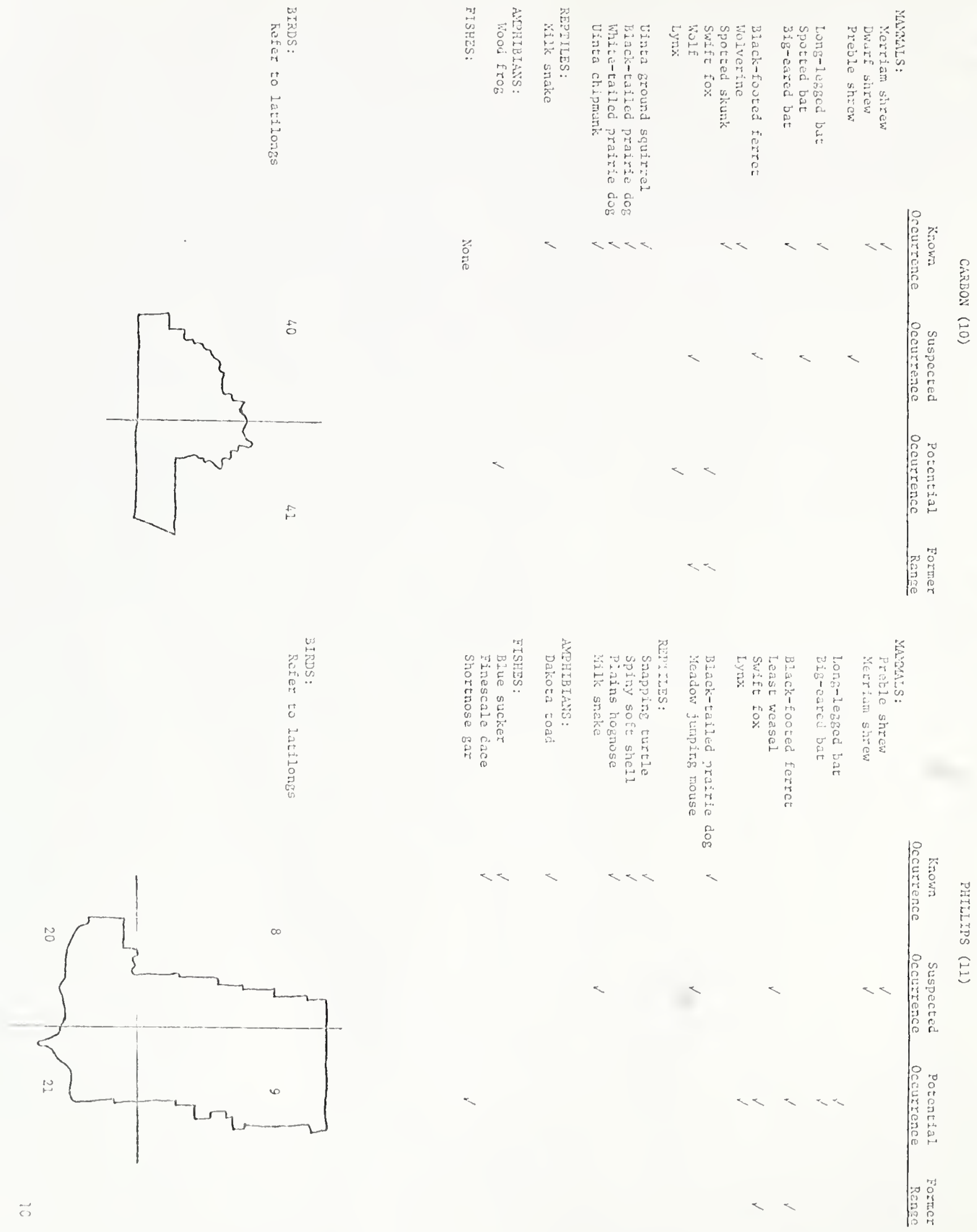

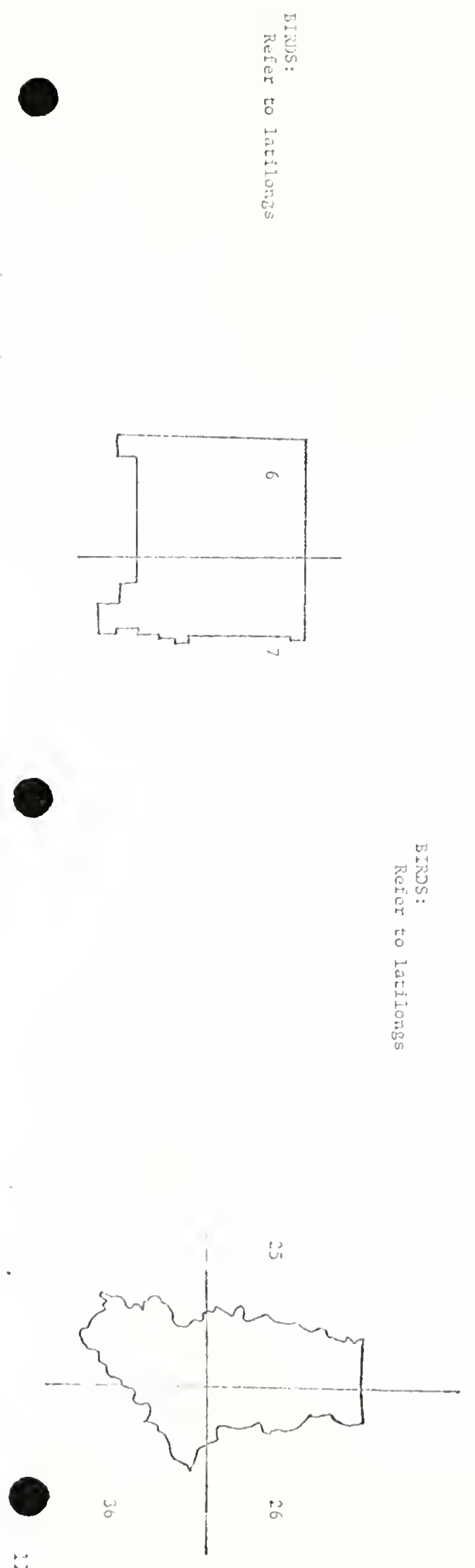

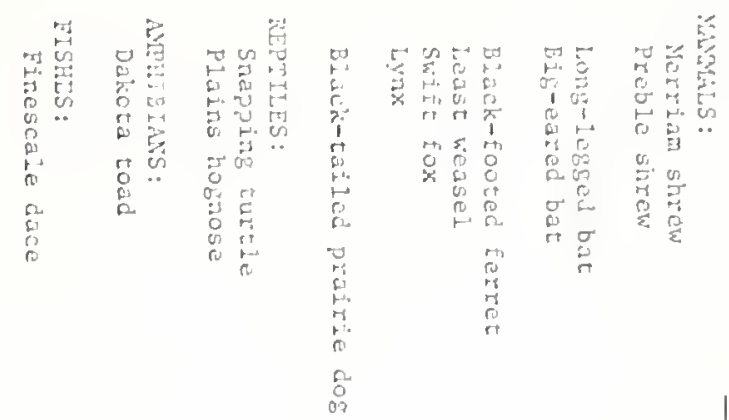

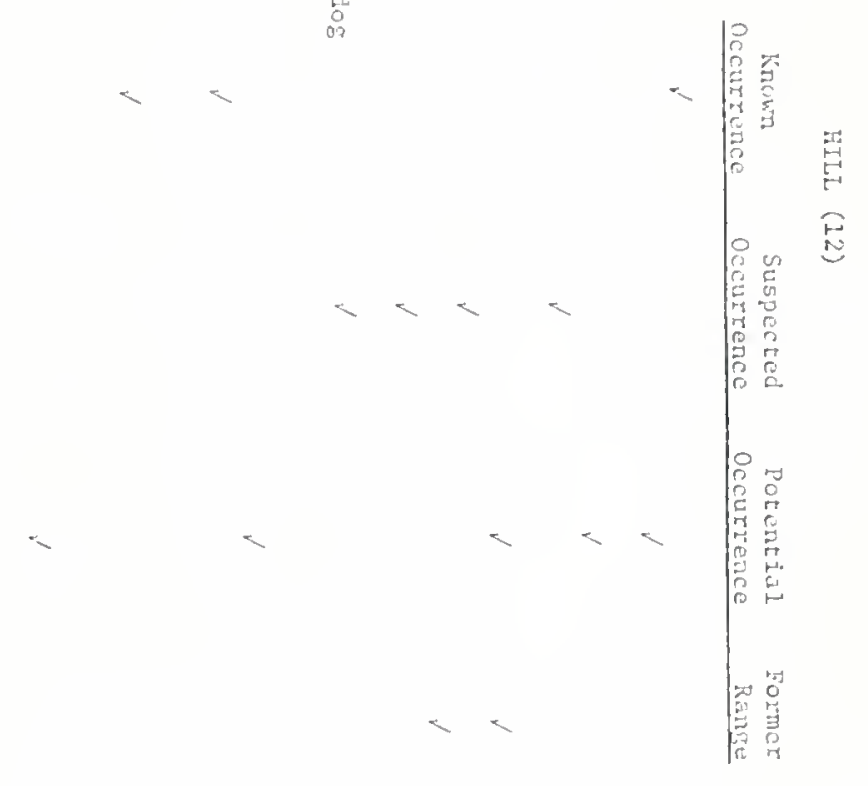

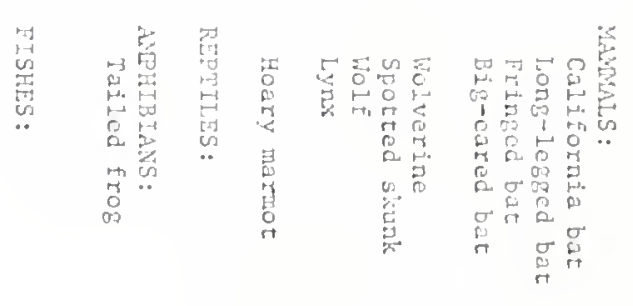
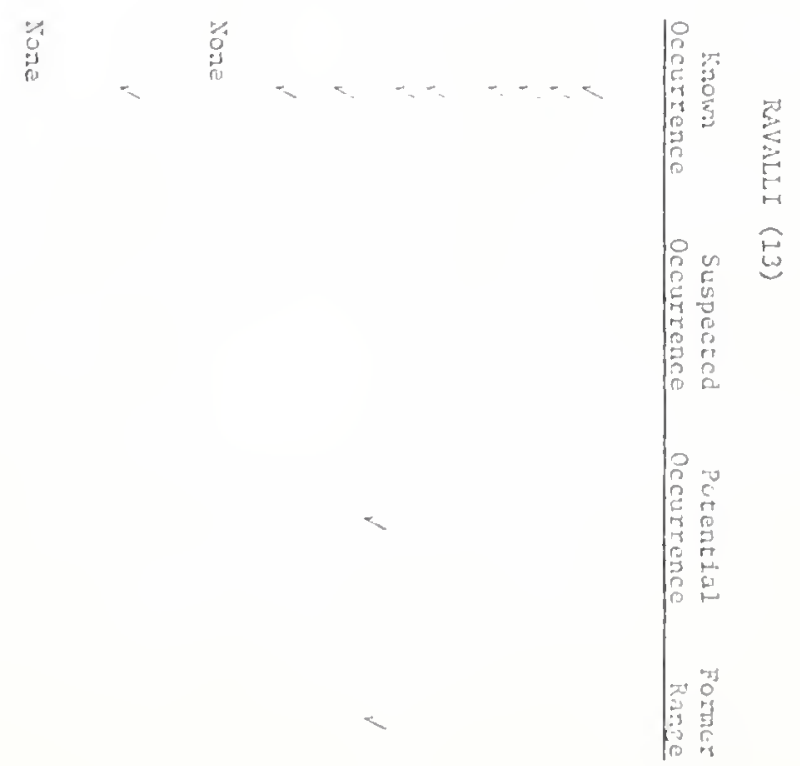

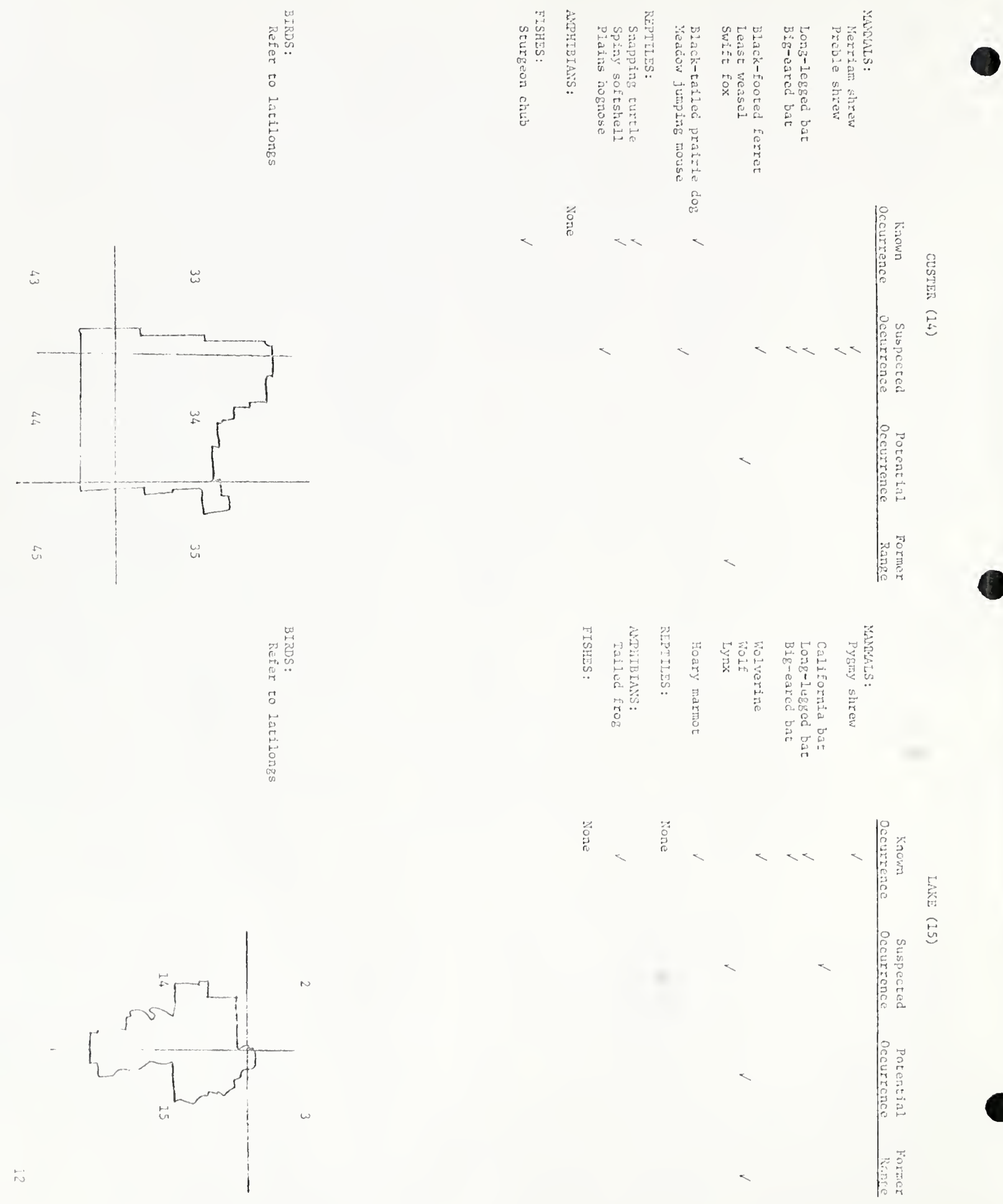

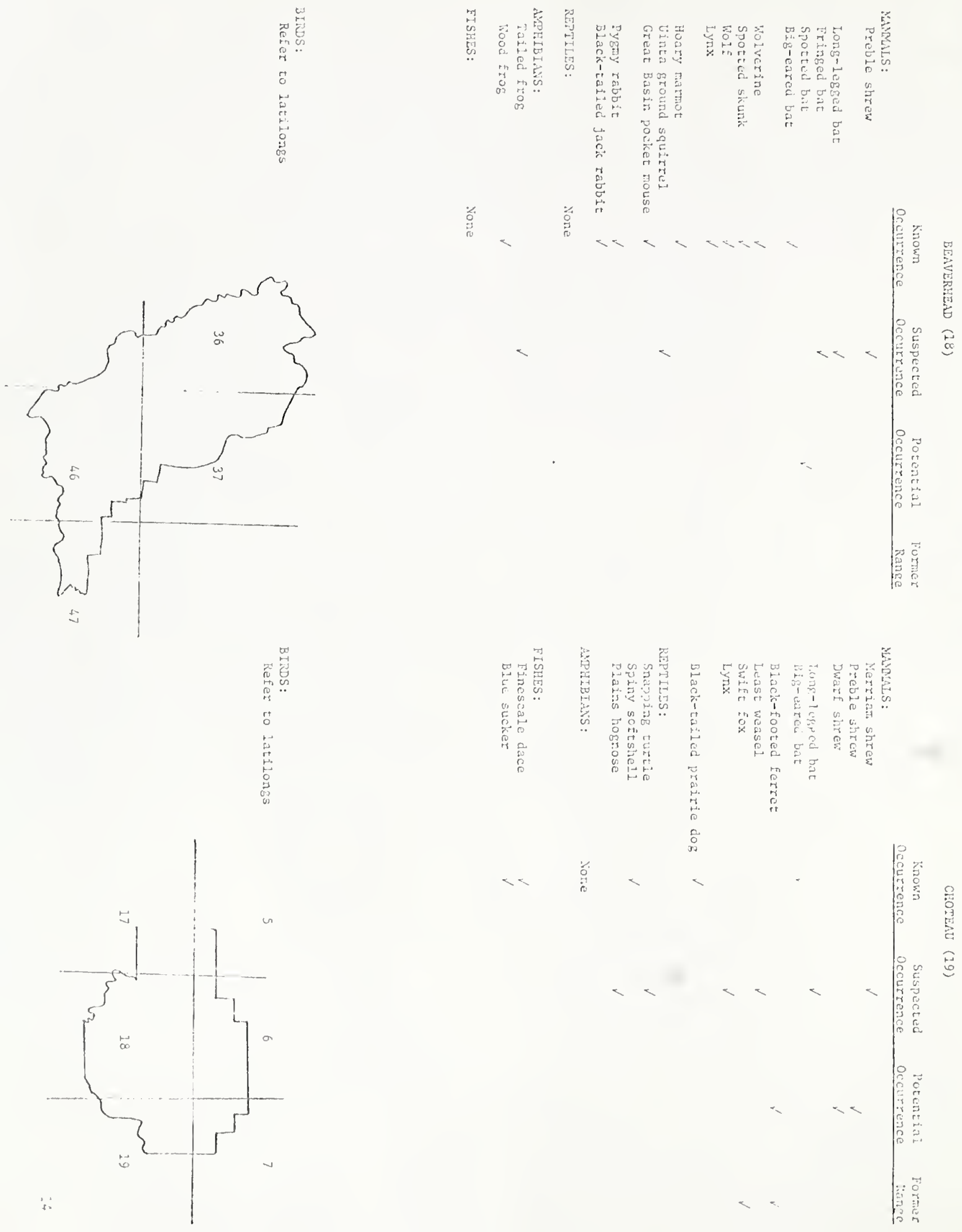

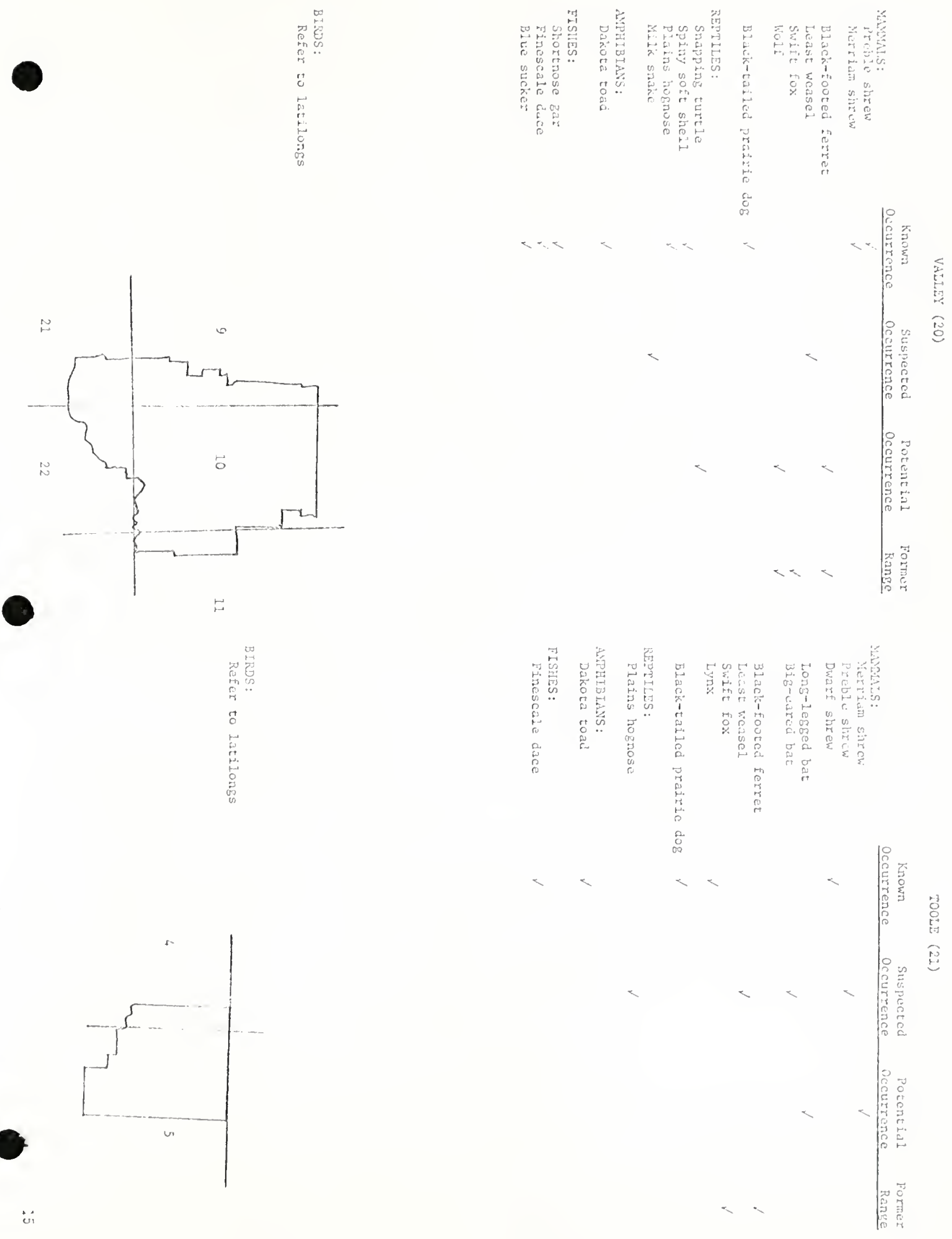

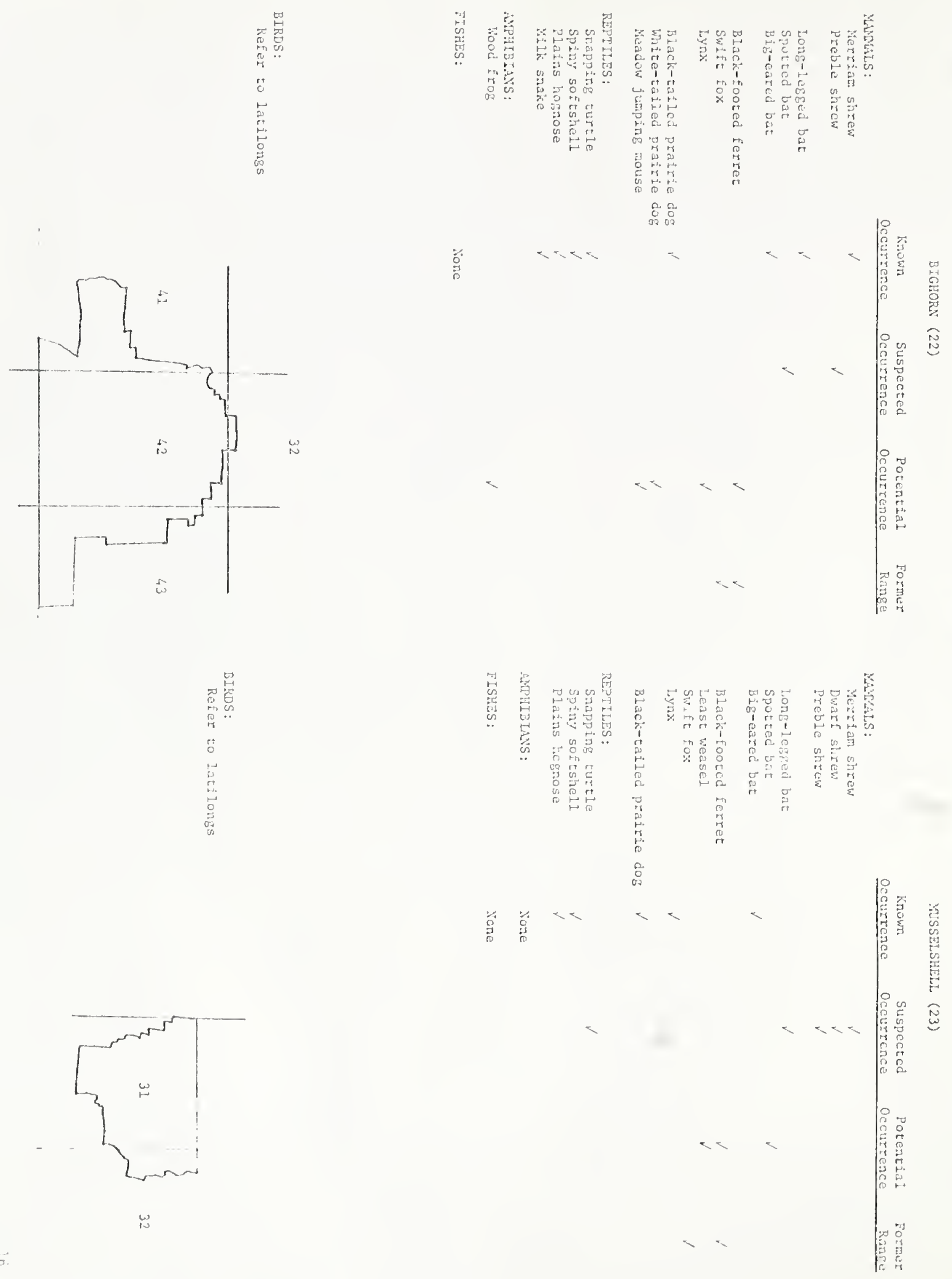

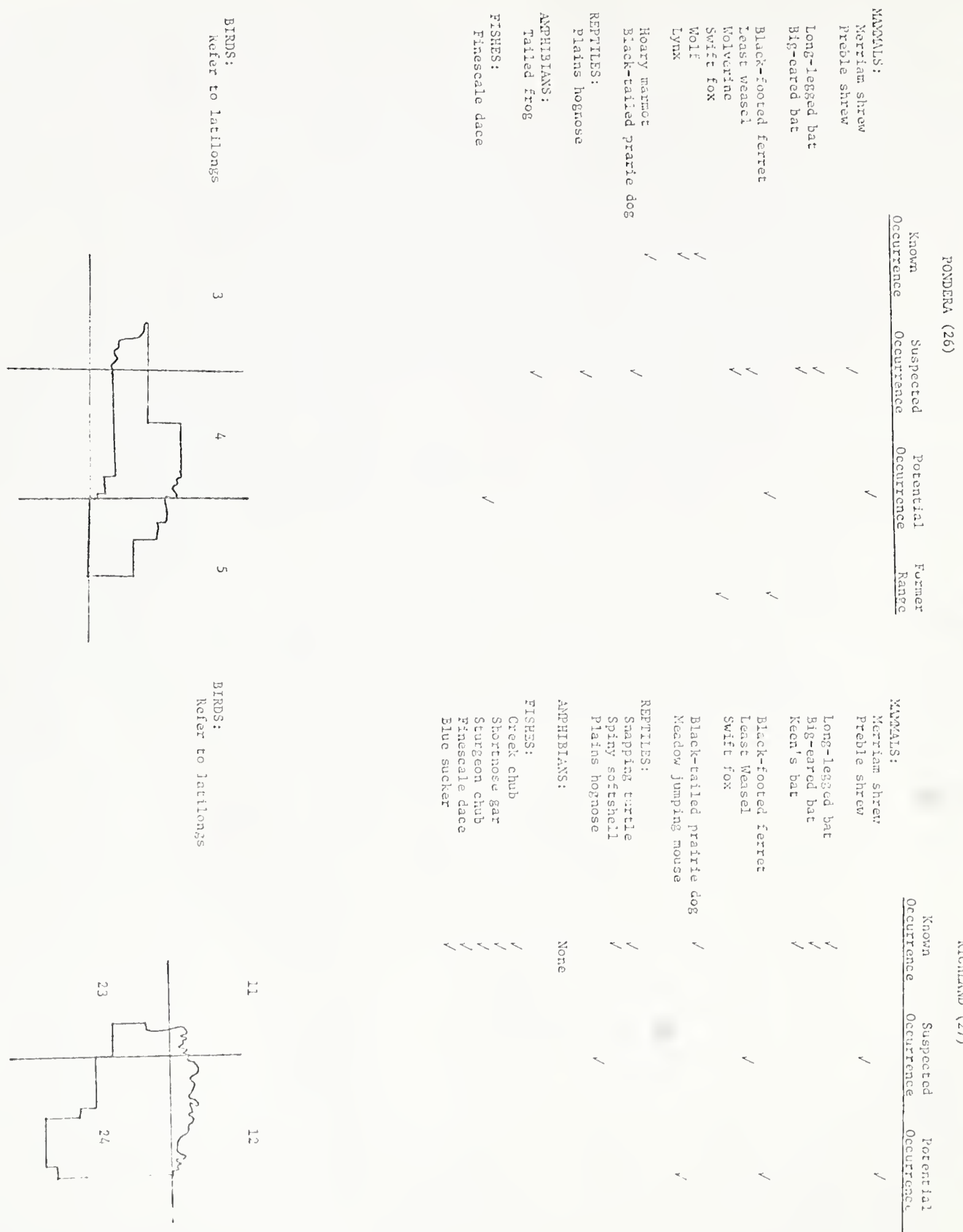

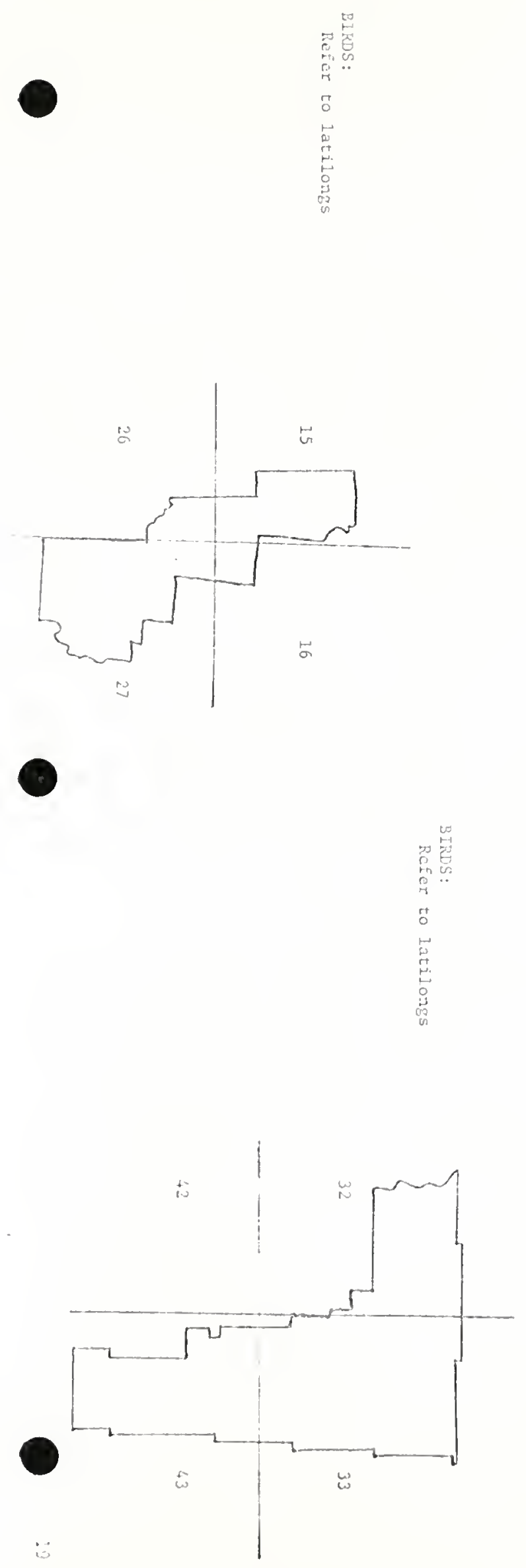

My

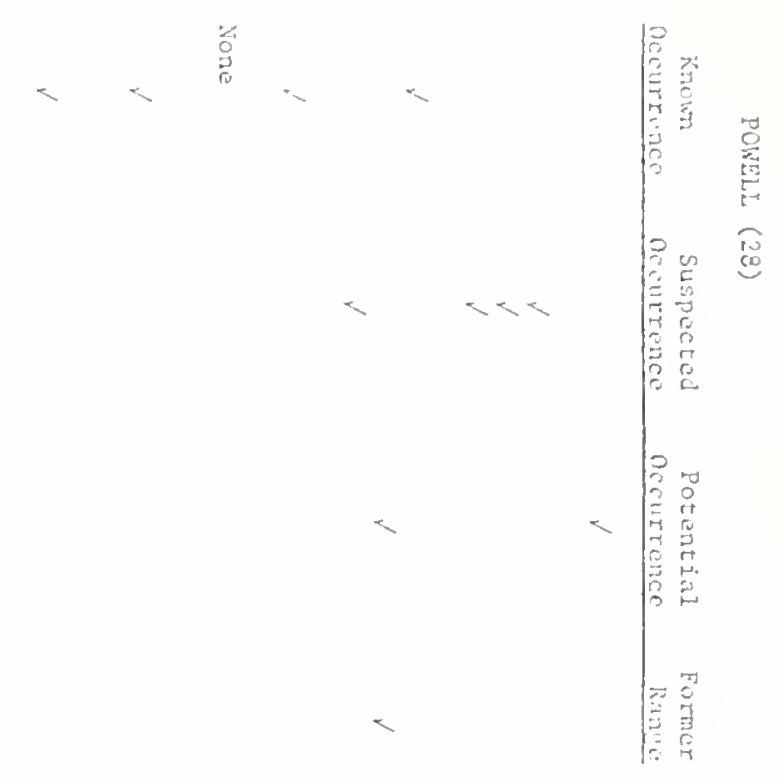

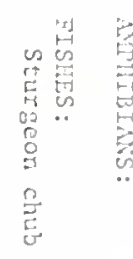
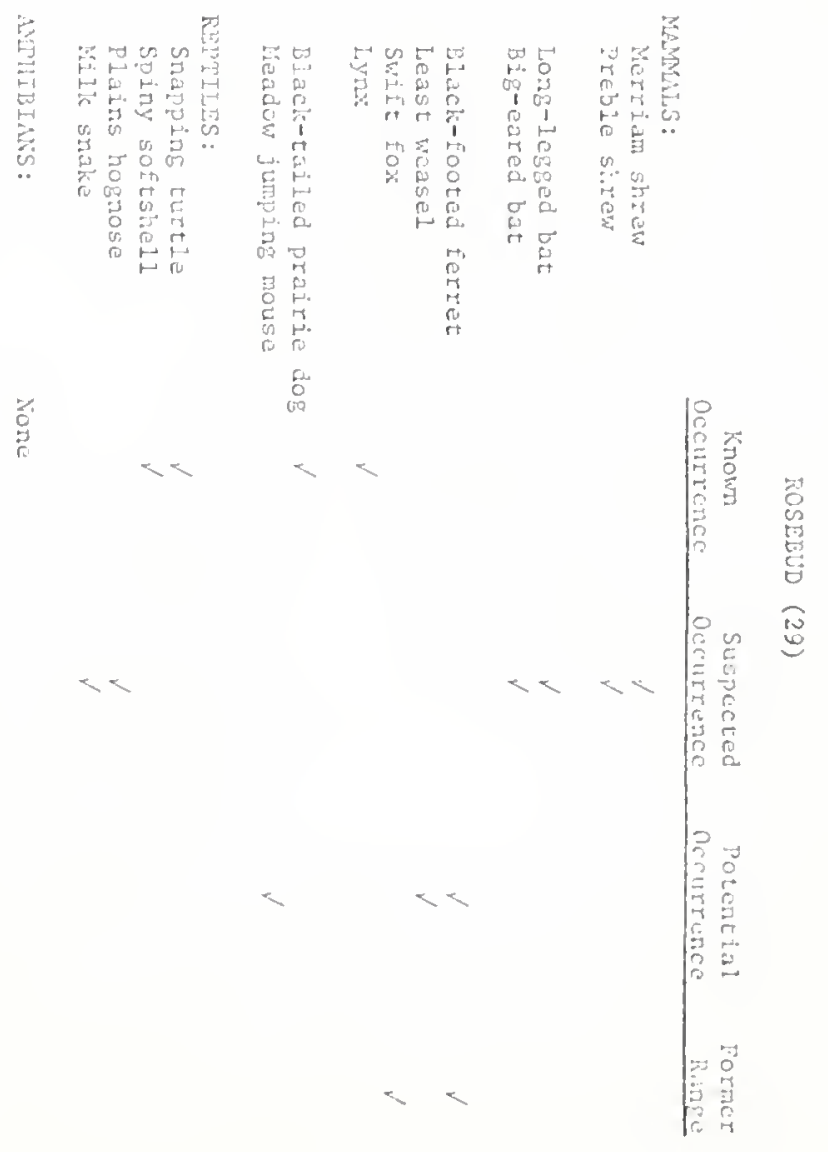

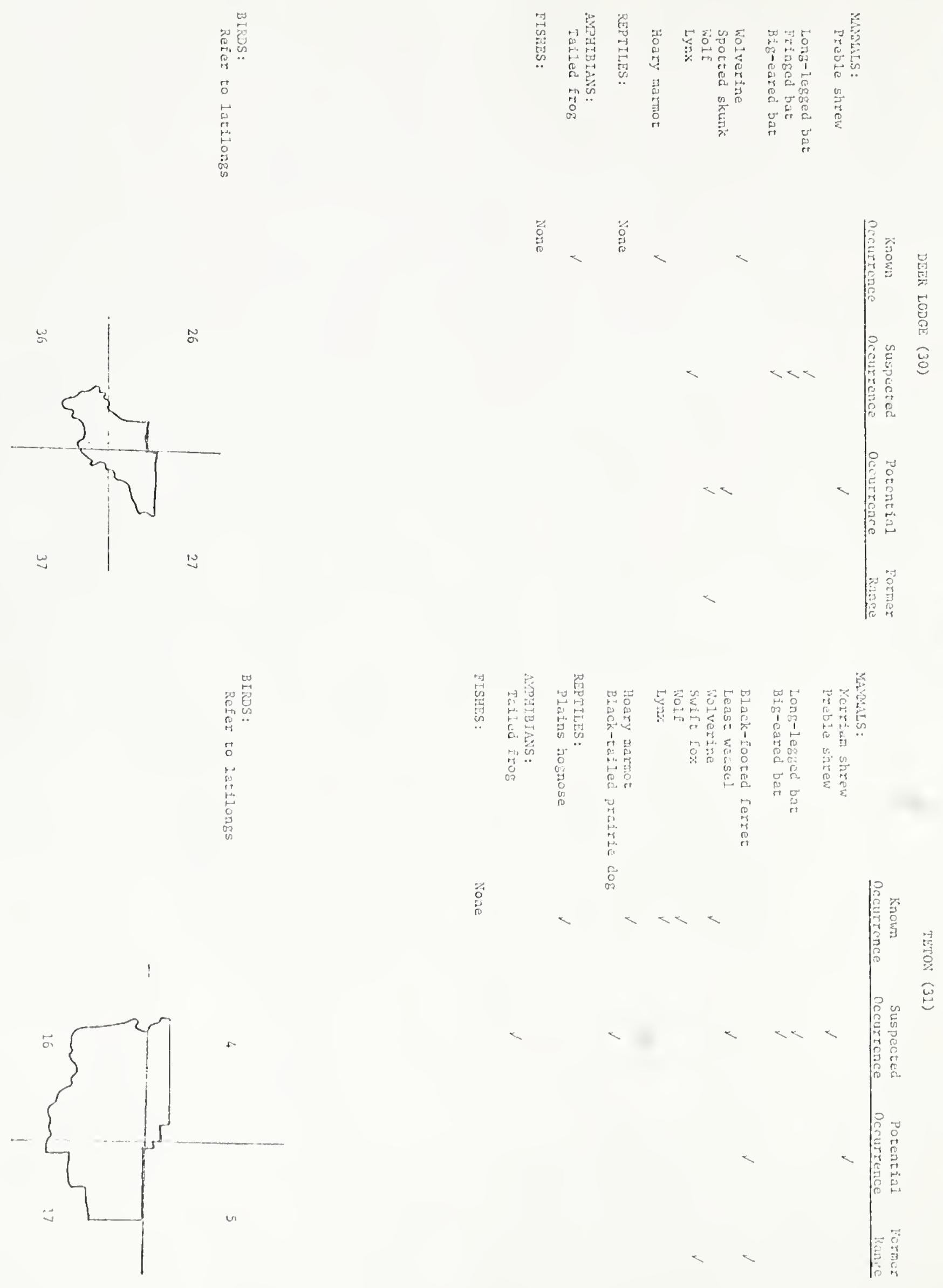


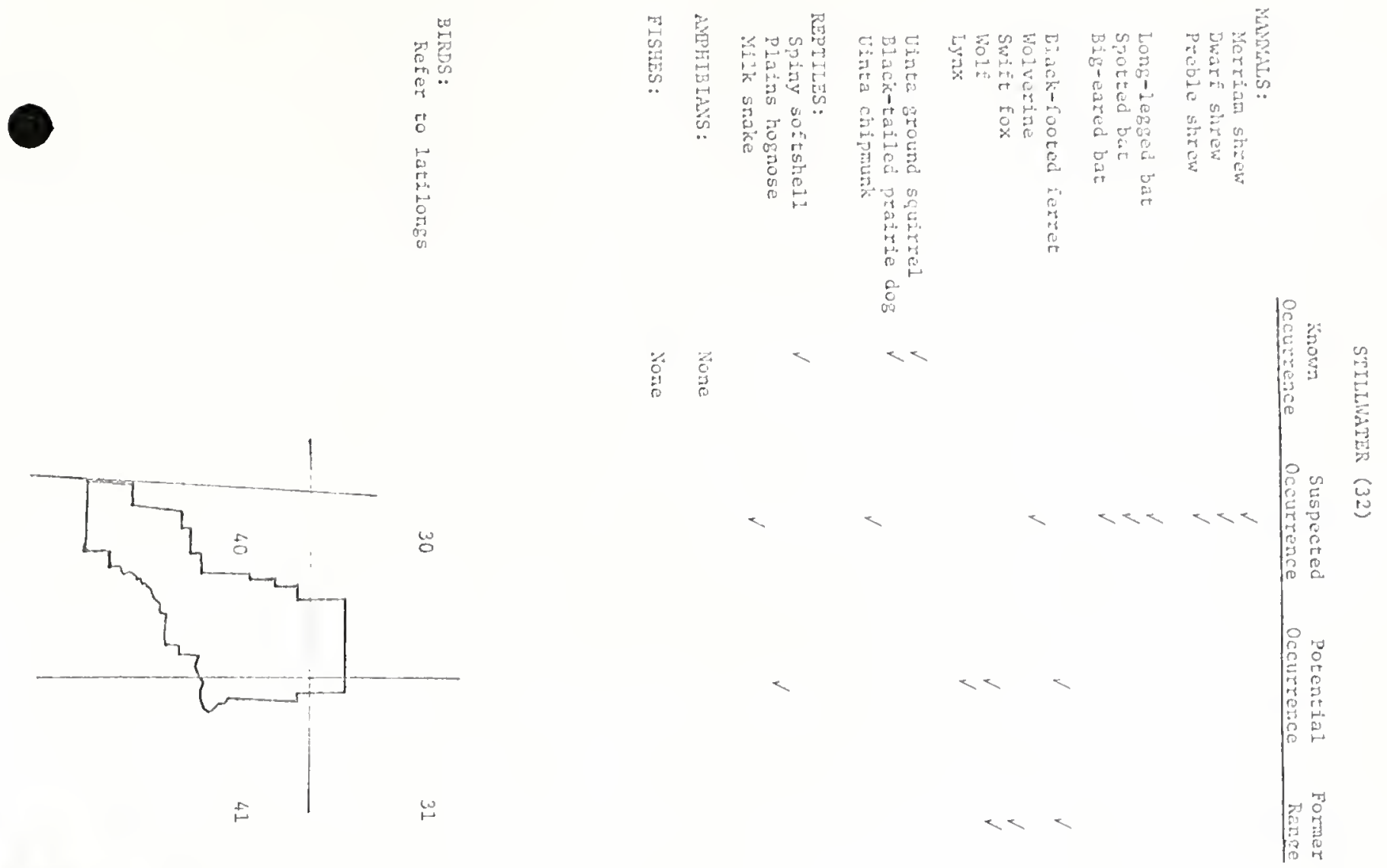

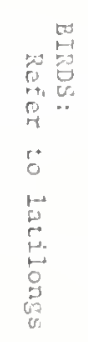

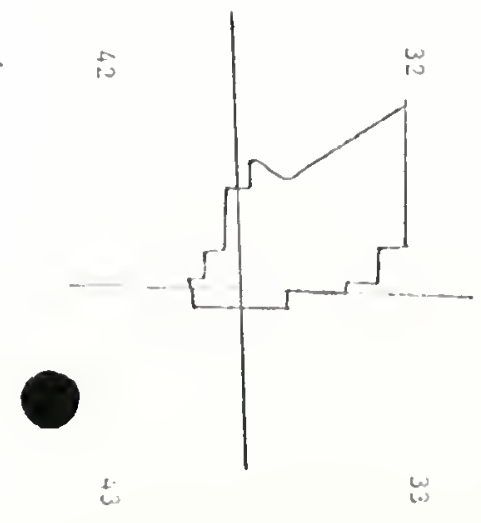

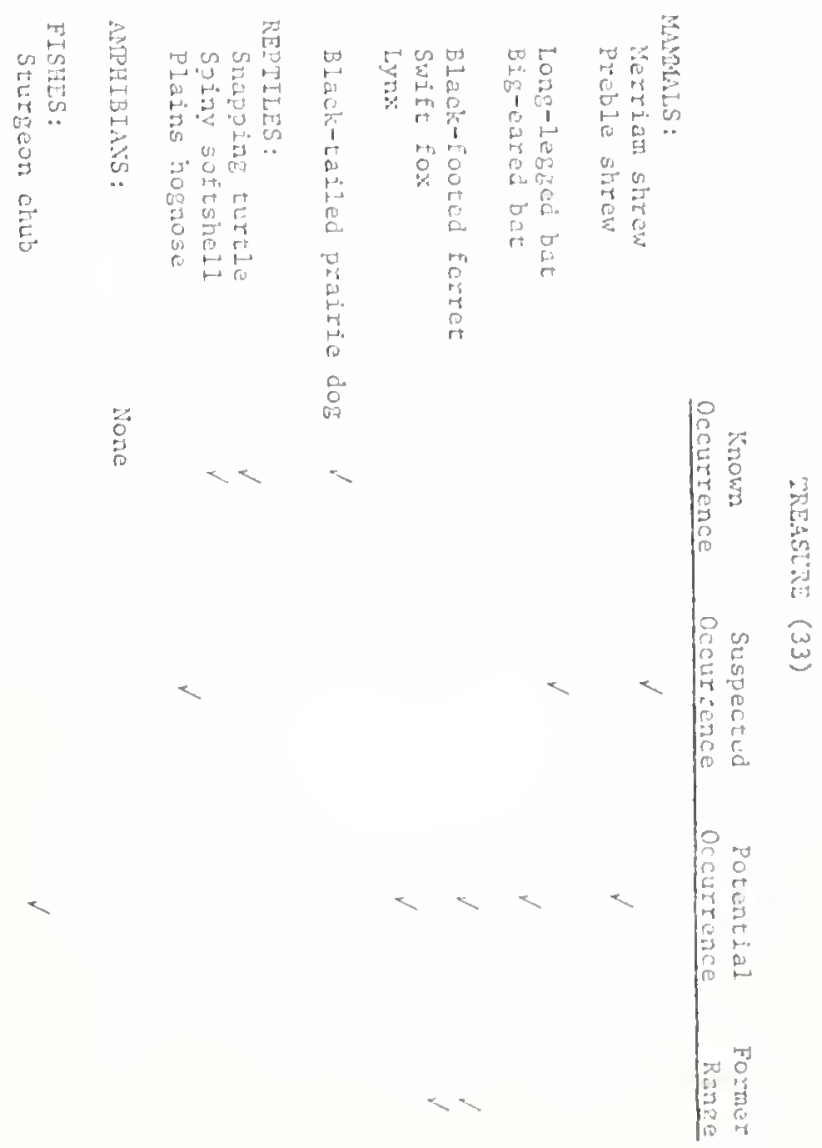

D 


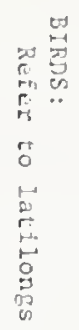
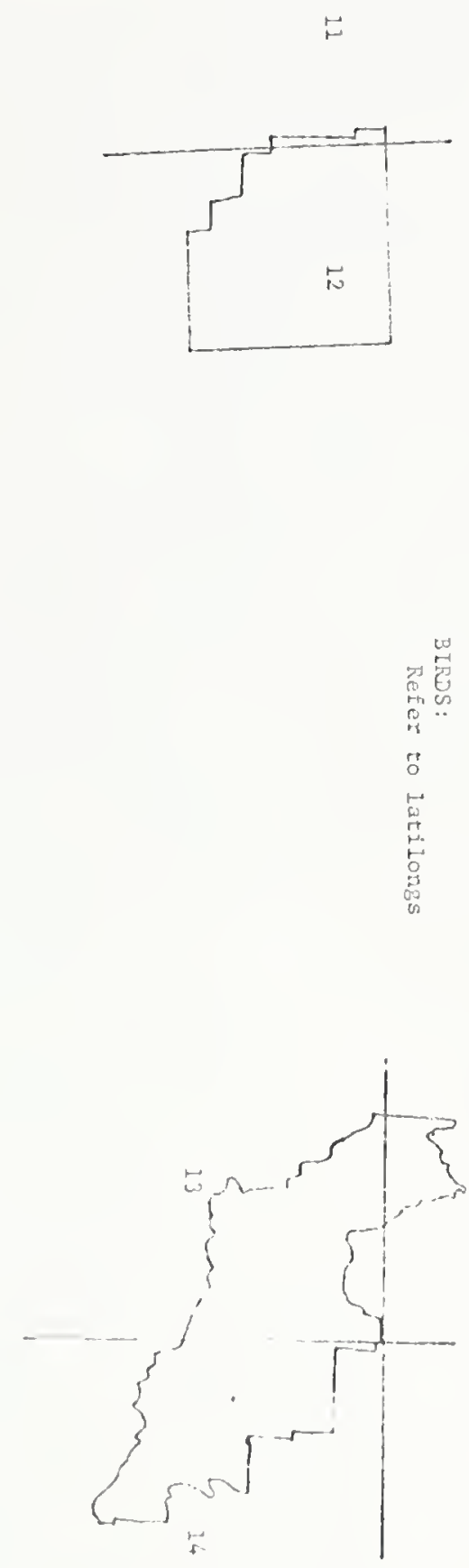
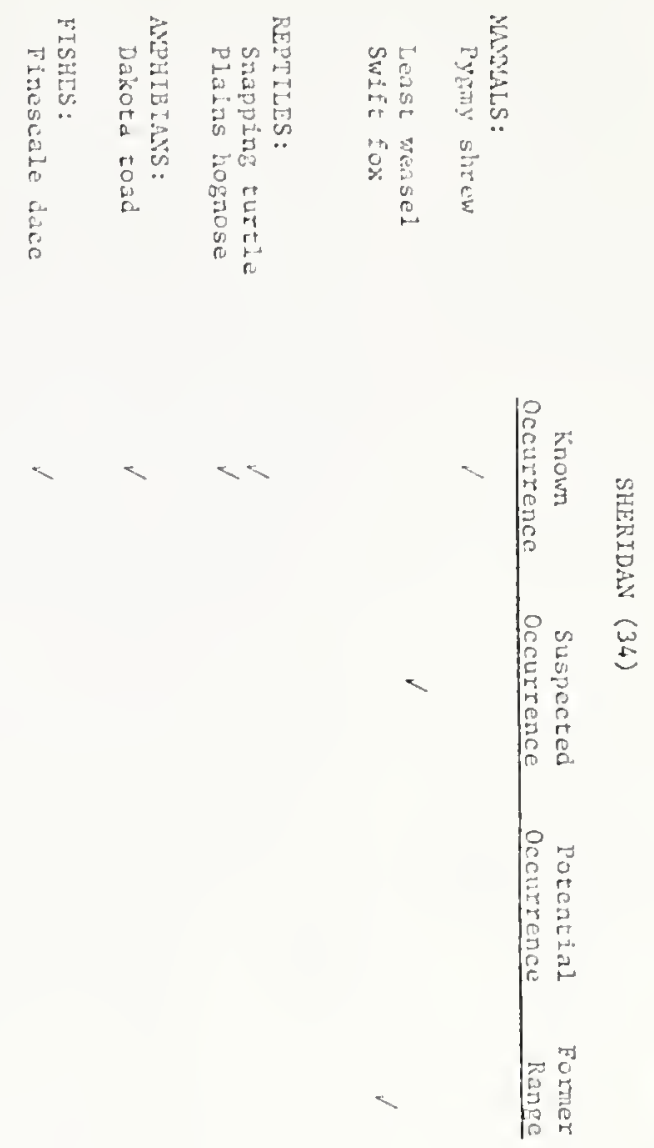

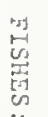

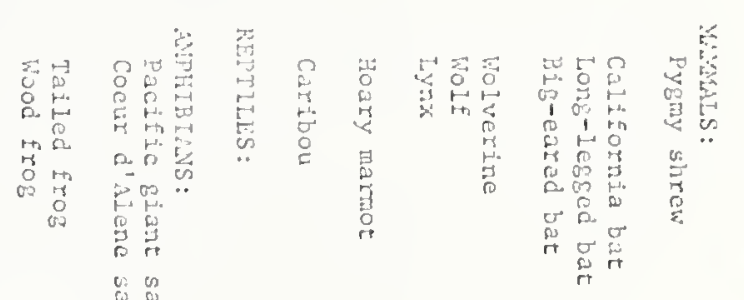

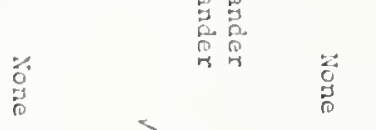
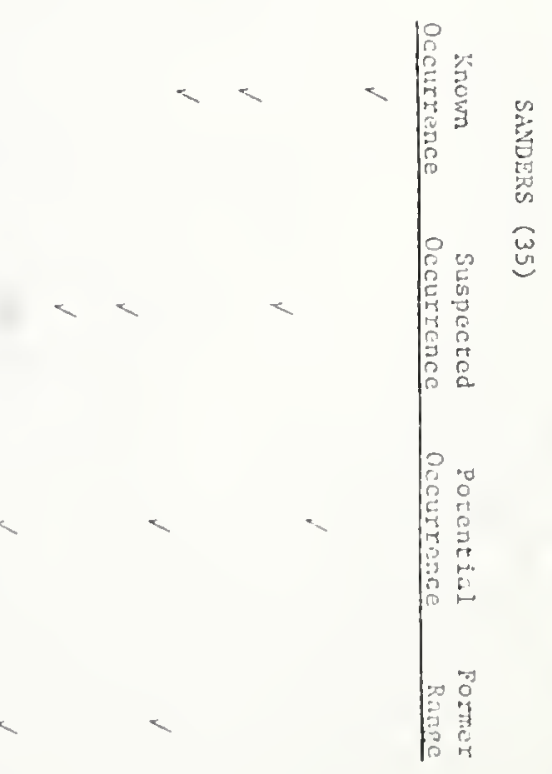


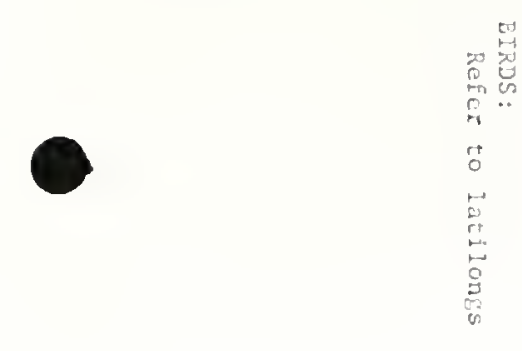

HenEm

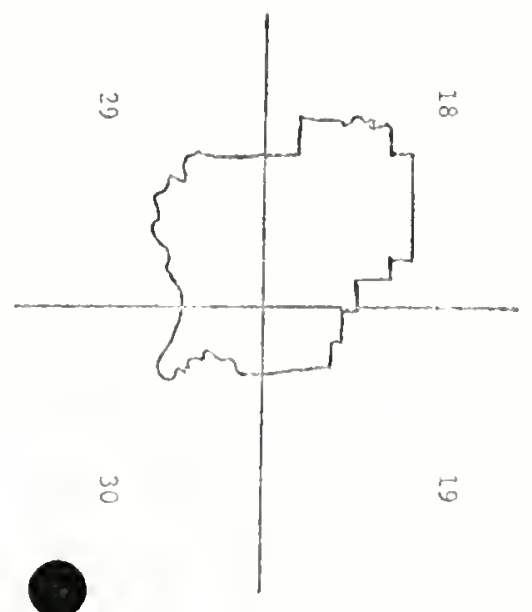

旁
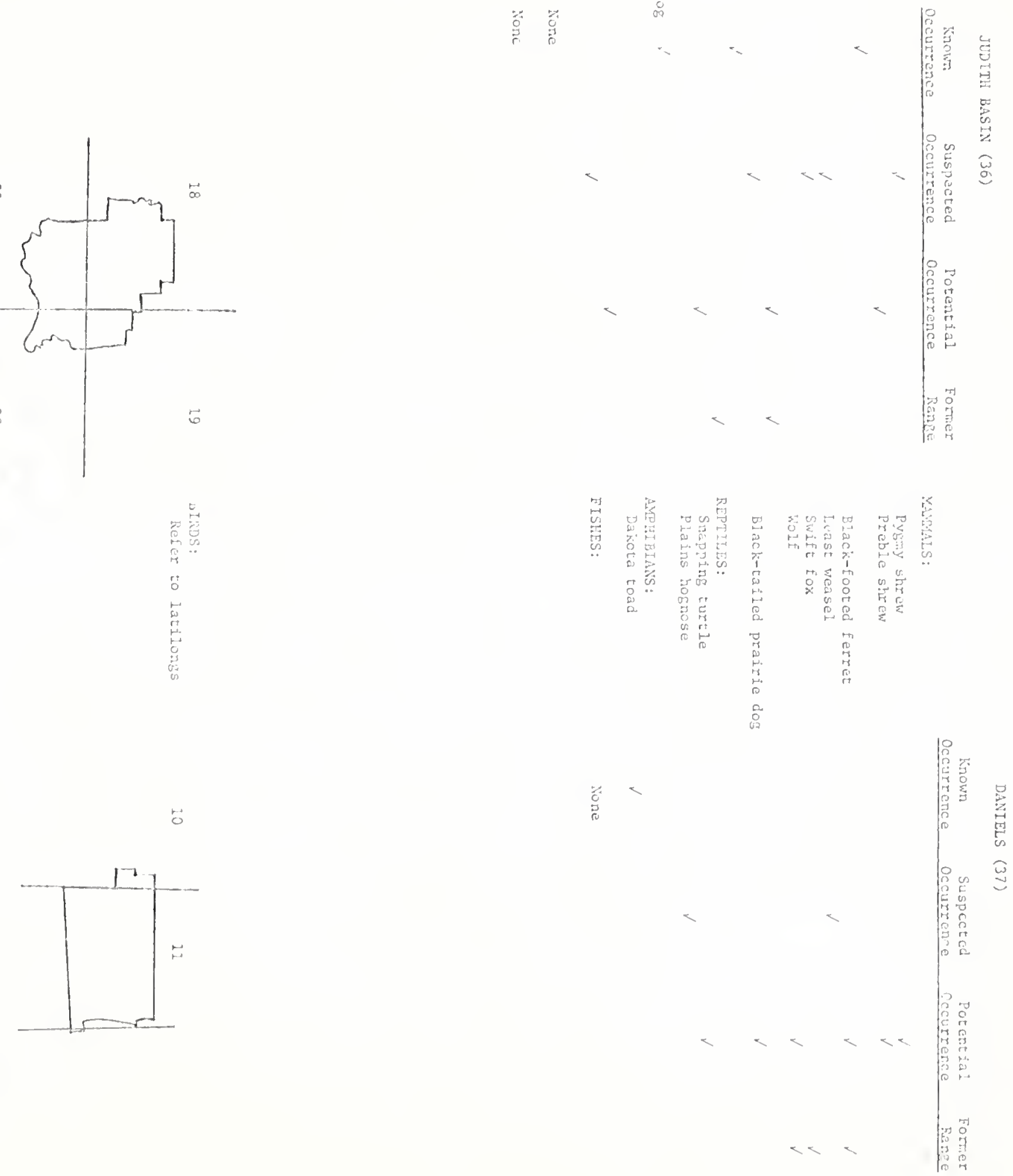

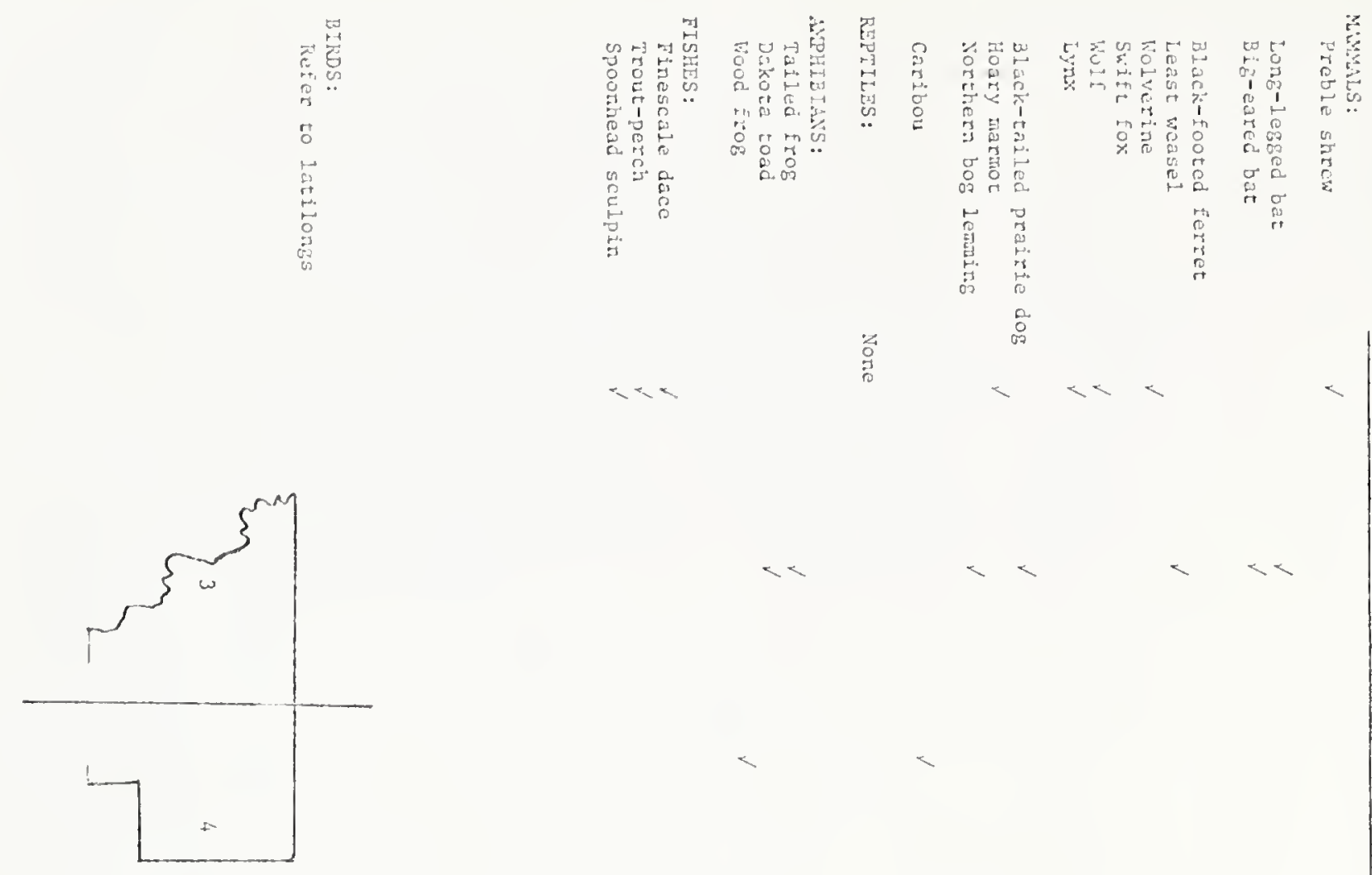

3
0
0
0
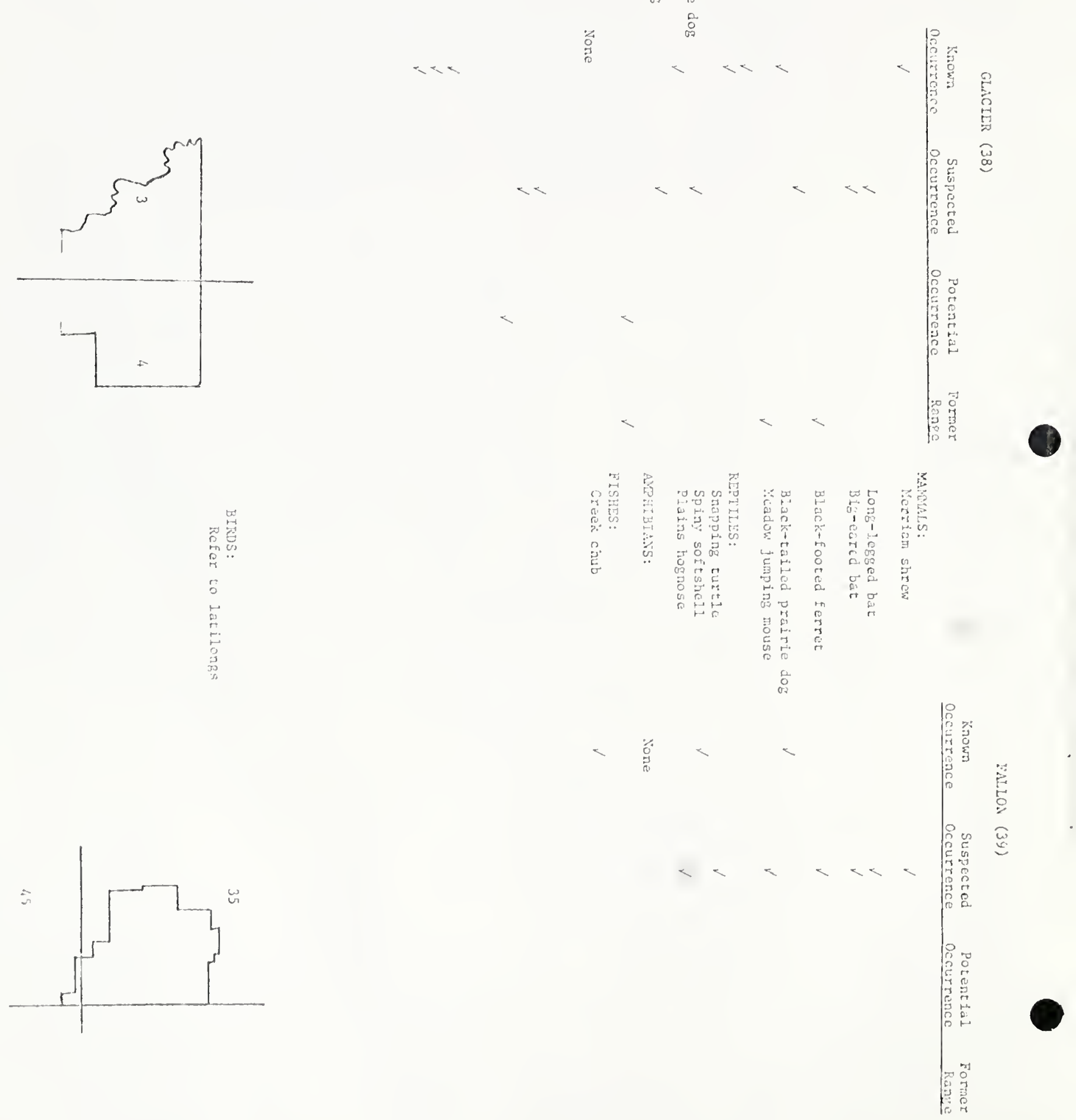


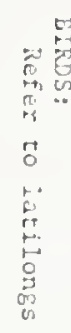
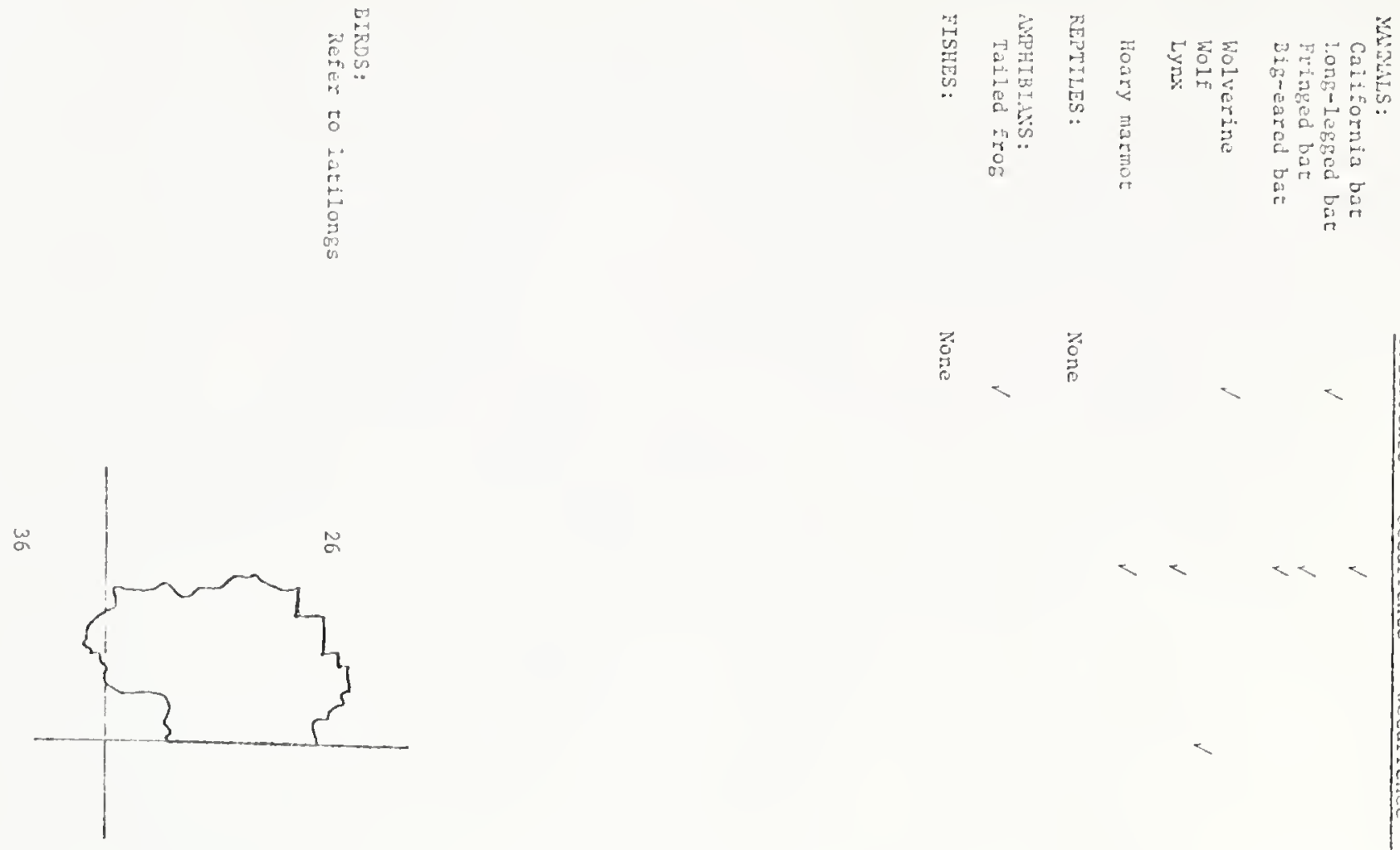

亳
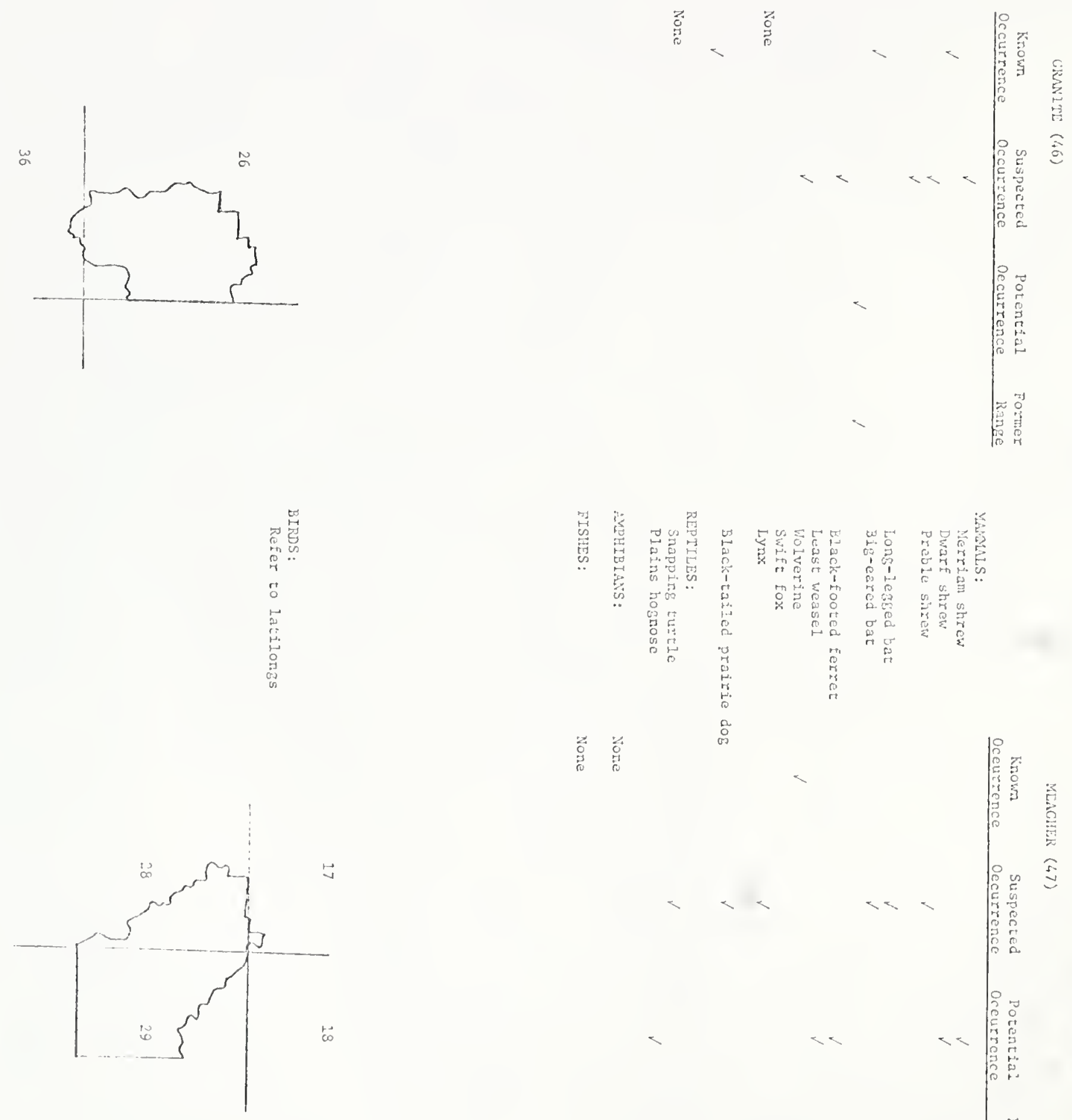

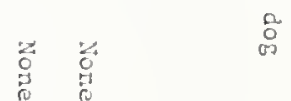

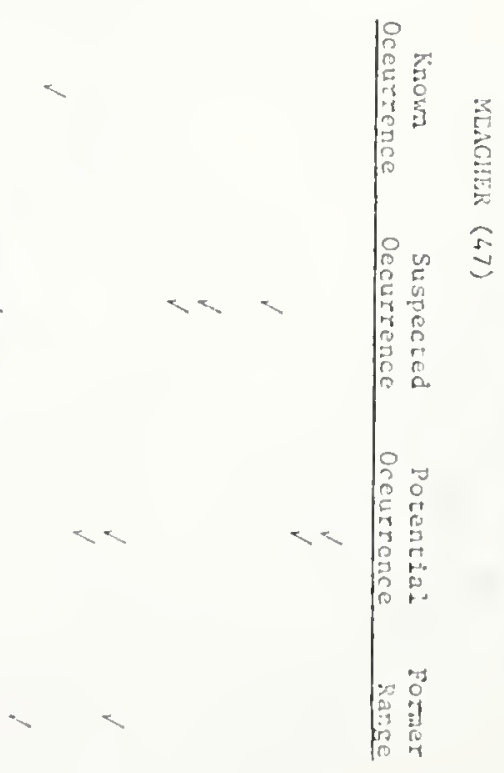



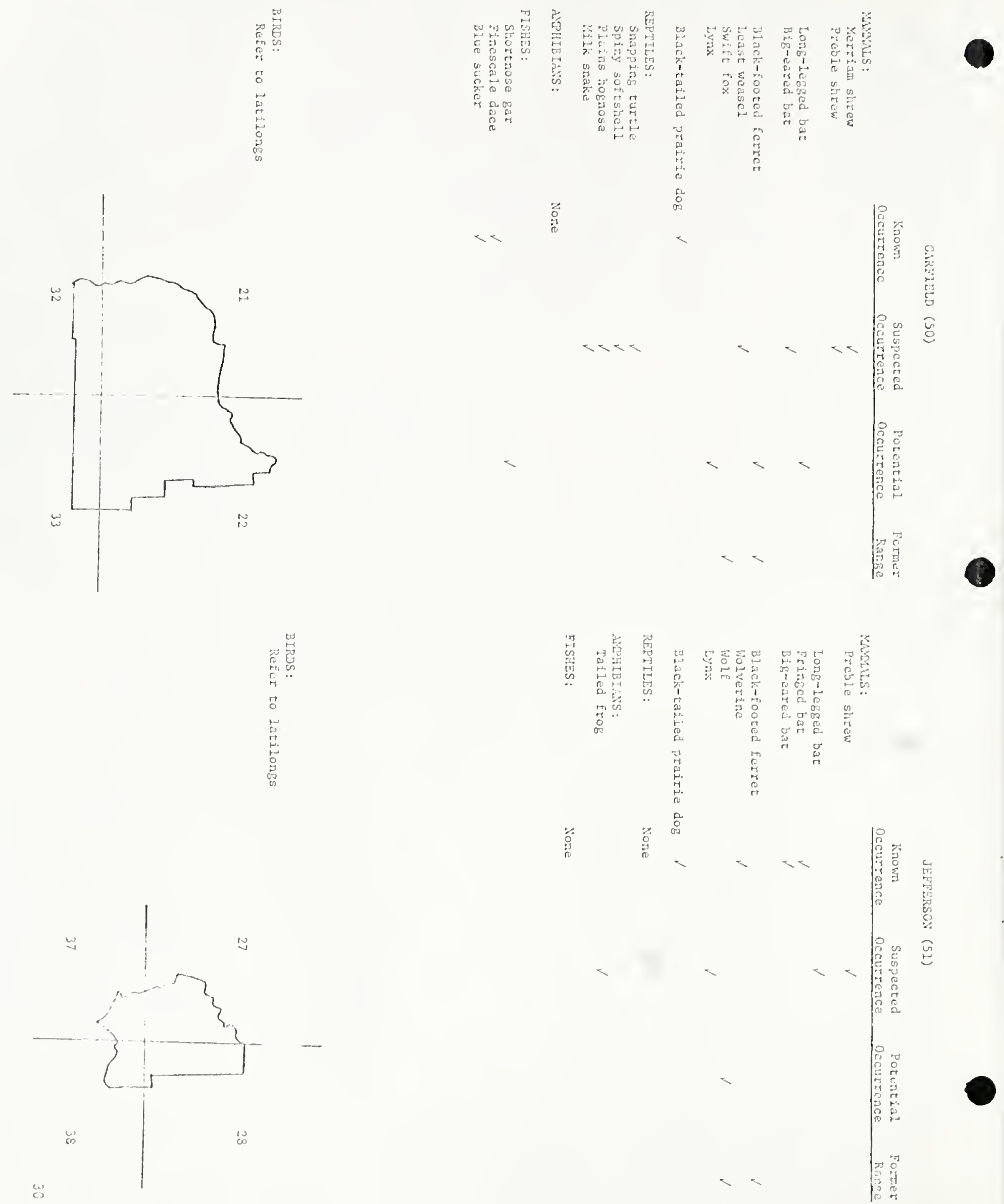

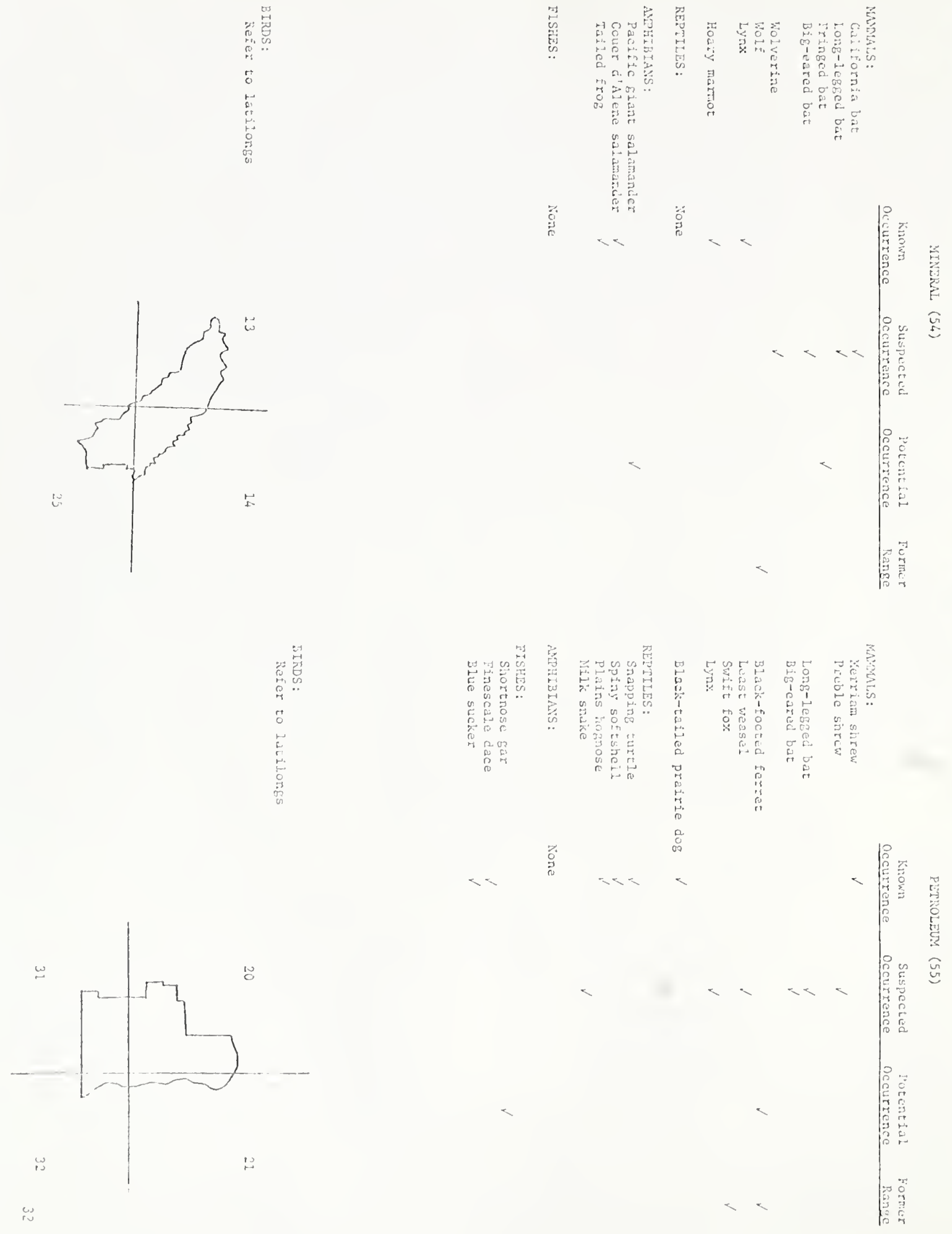


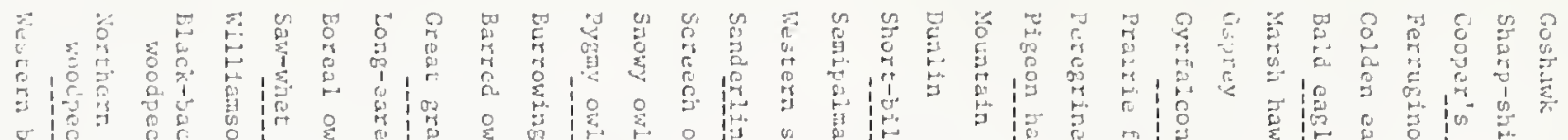

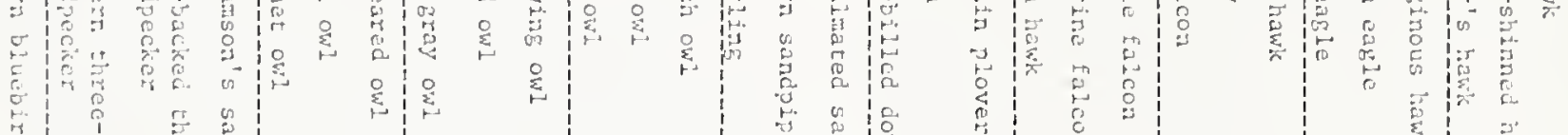
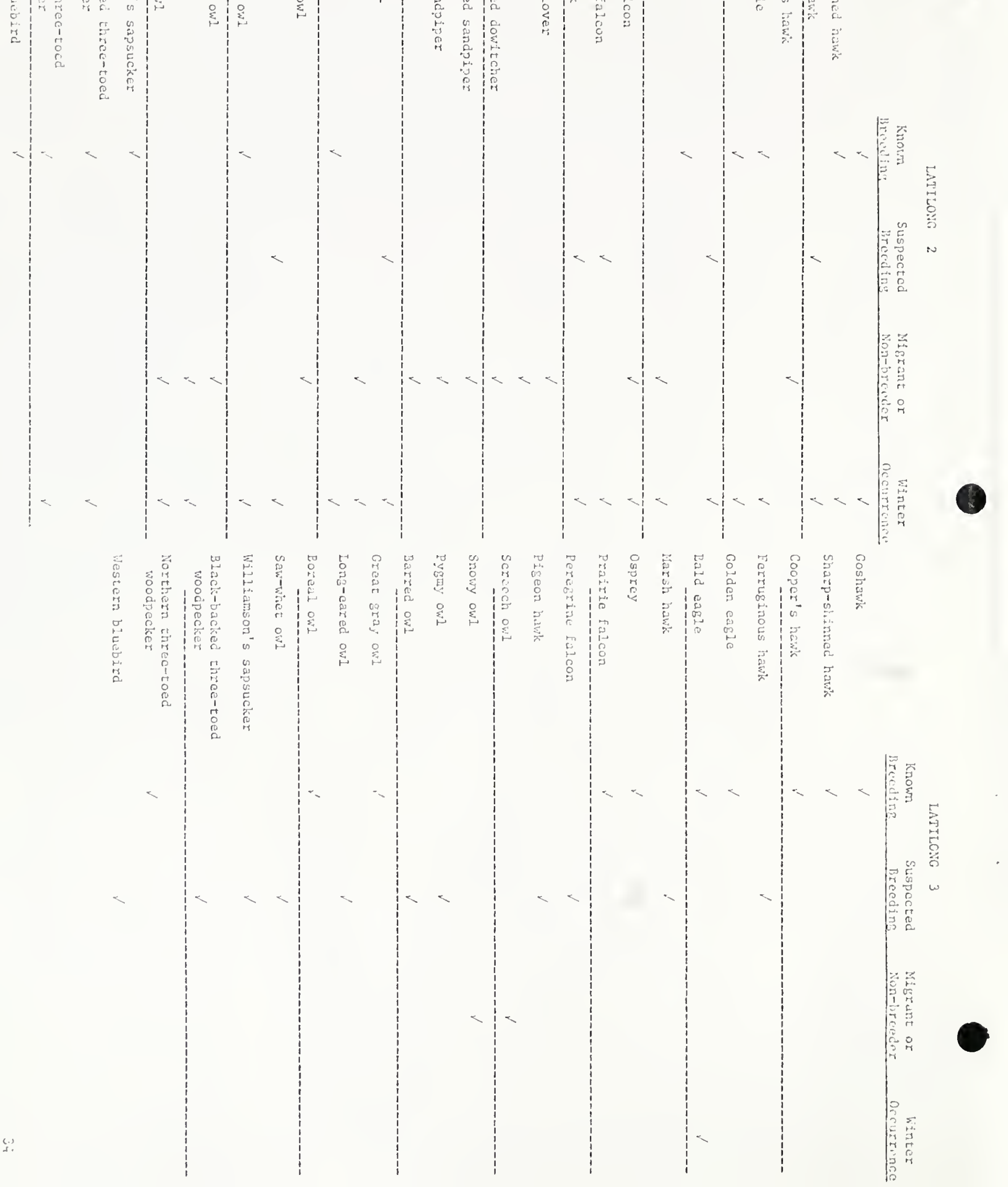

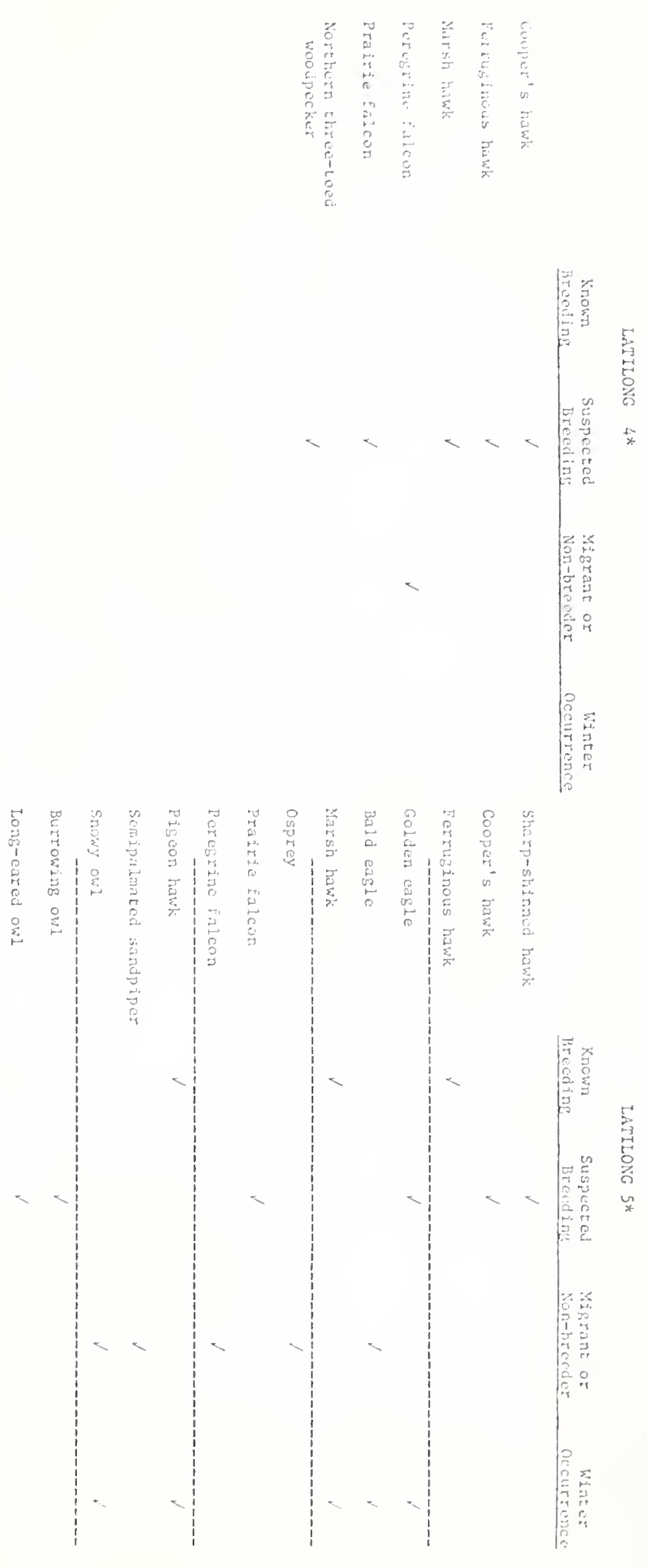


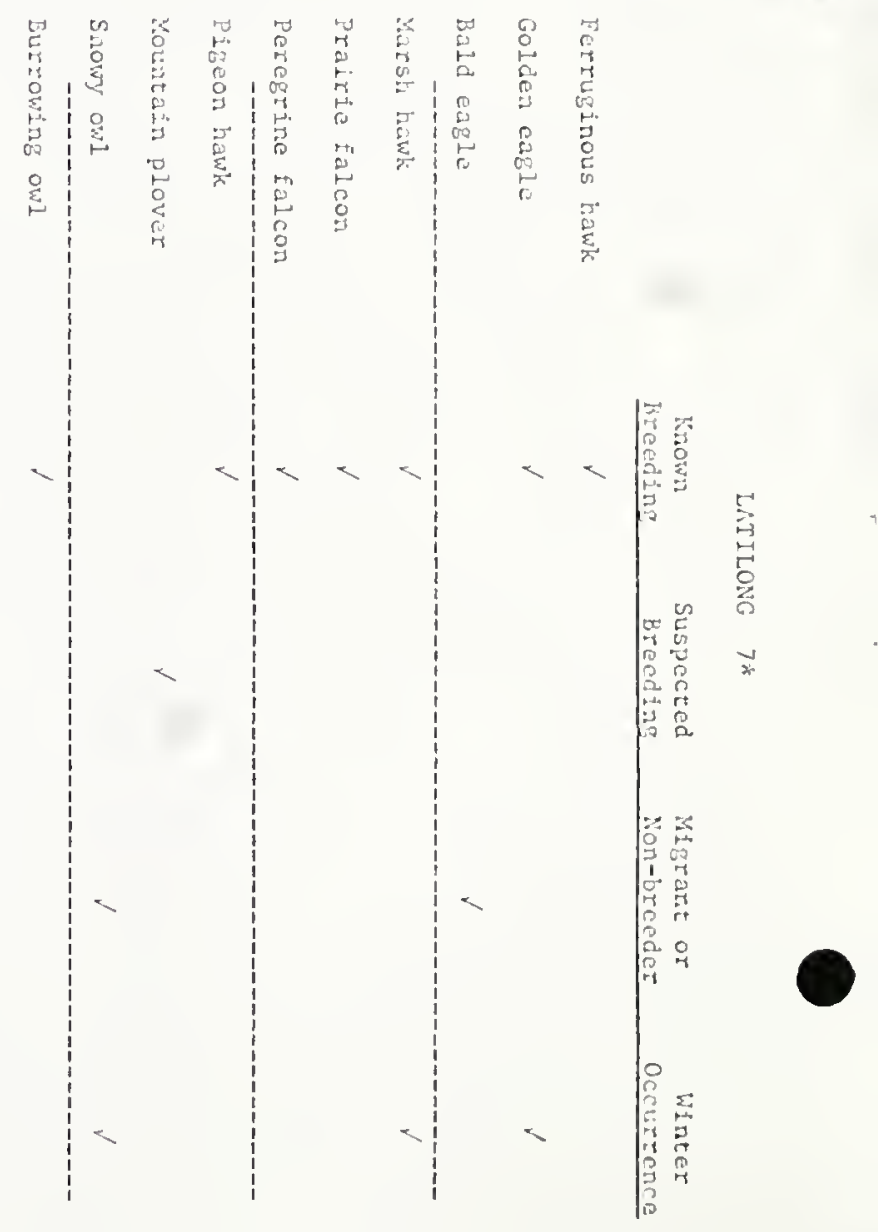



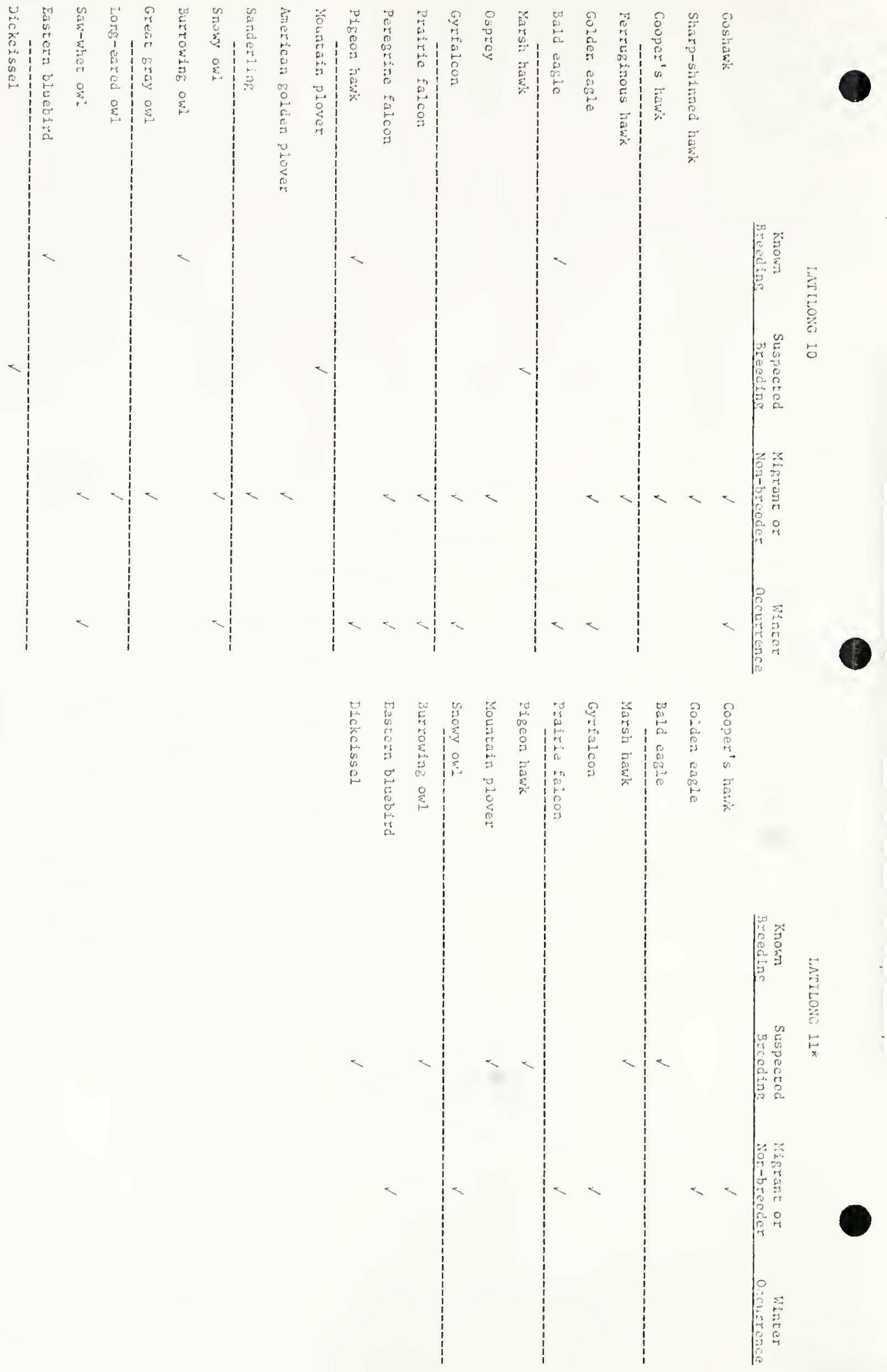

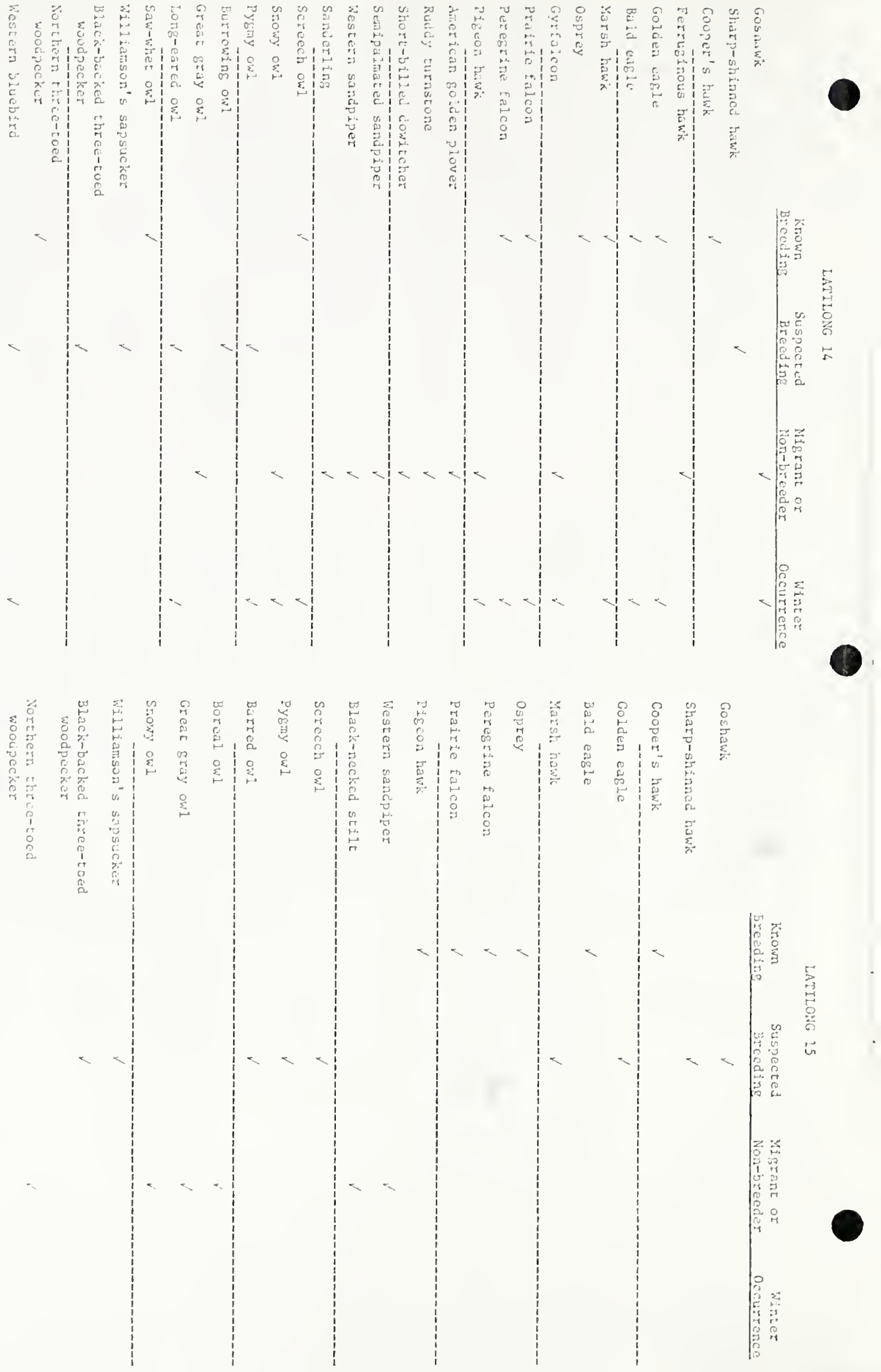


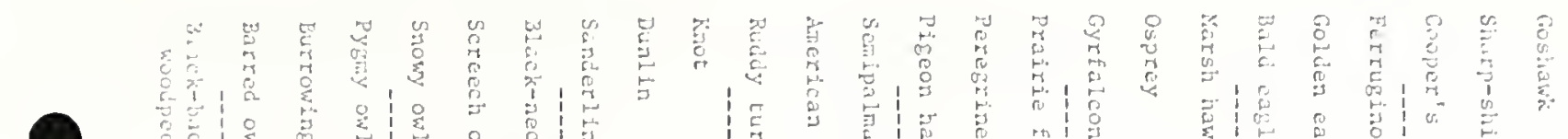

-
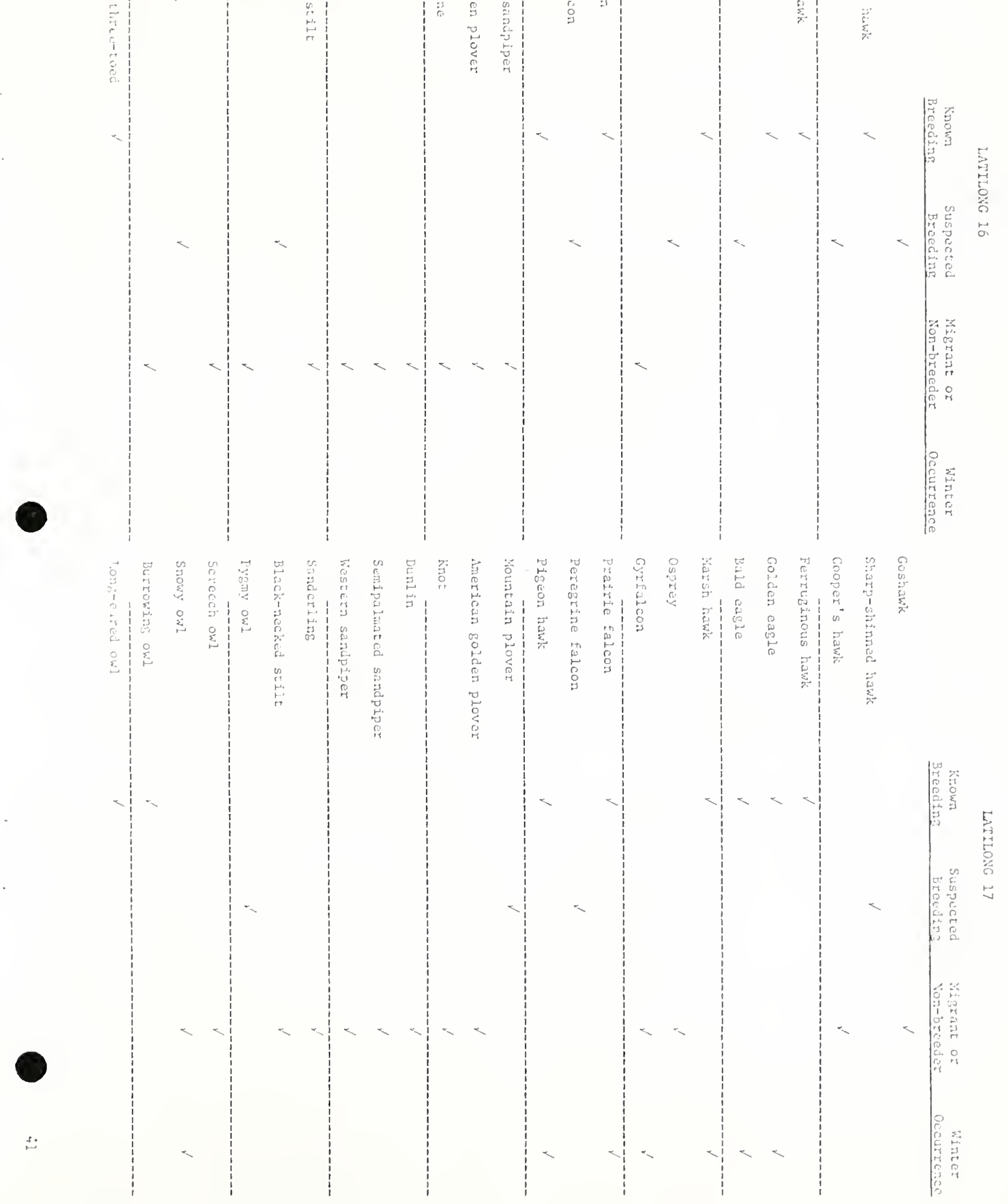

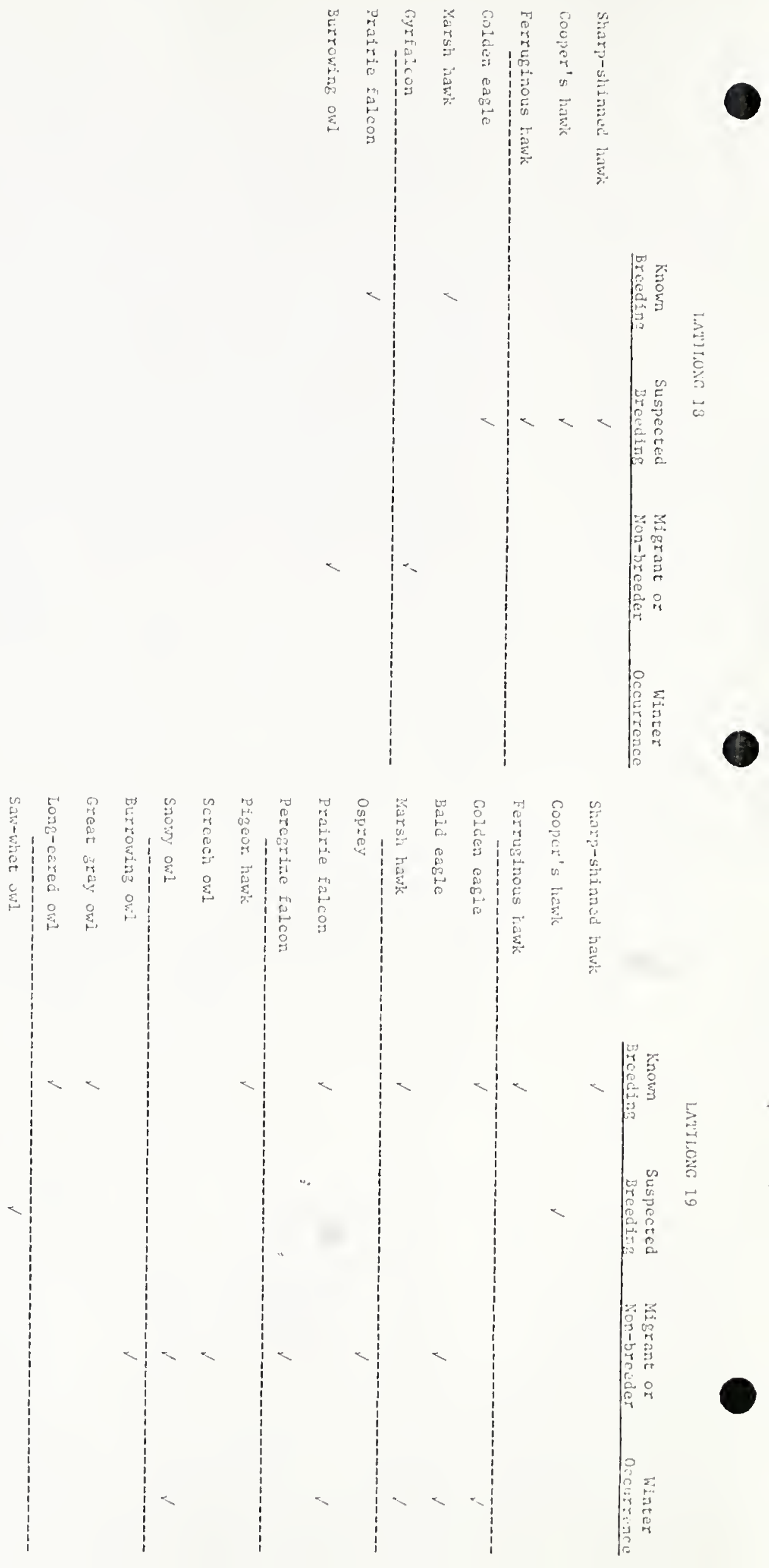

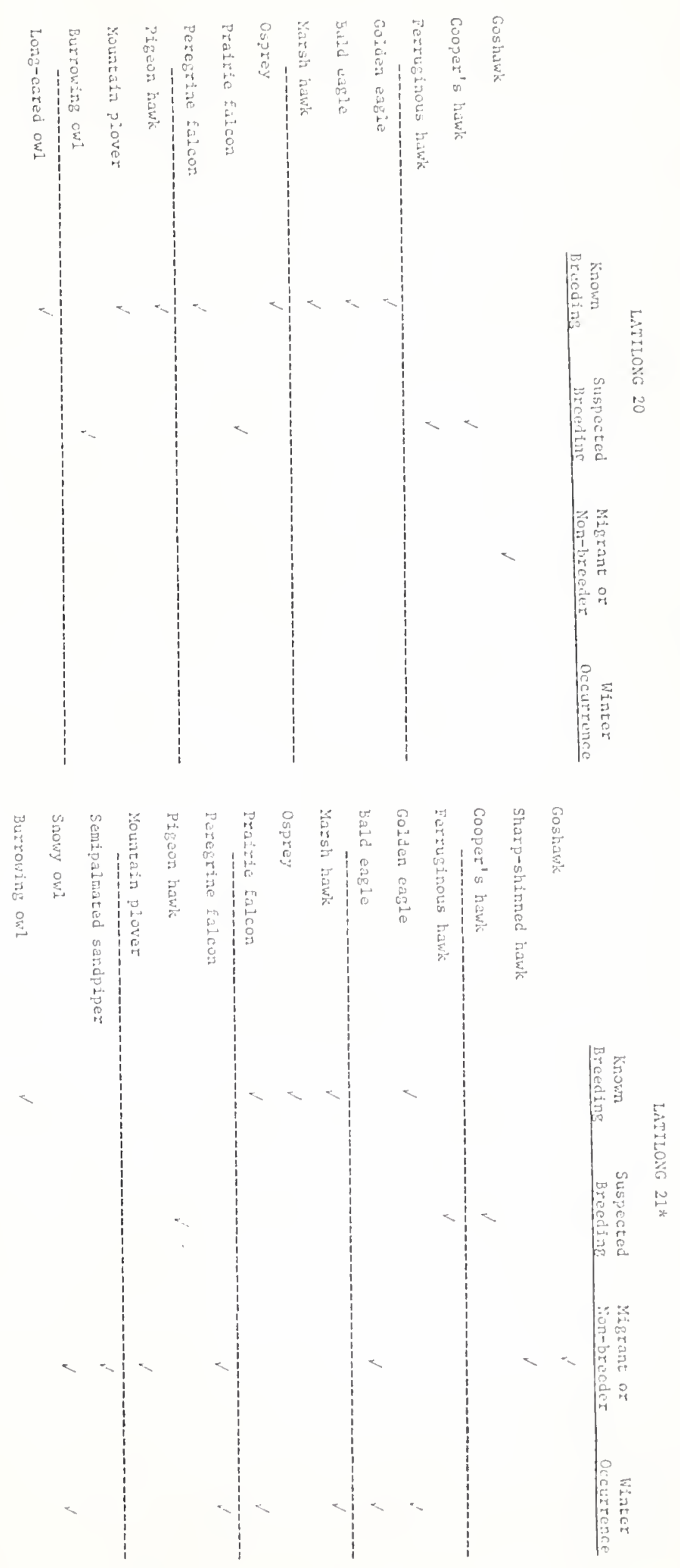


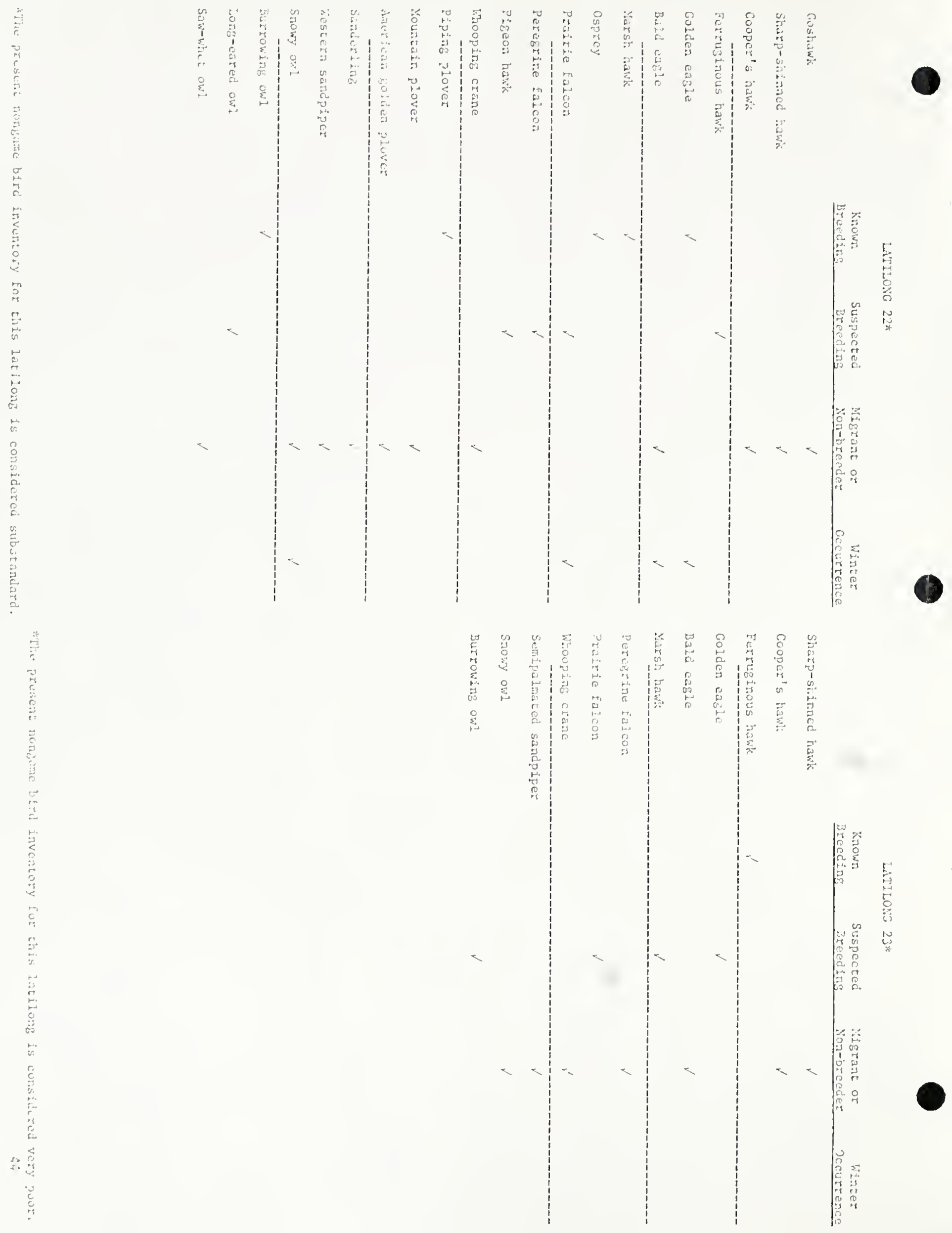


(1)
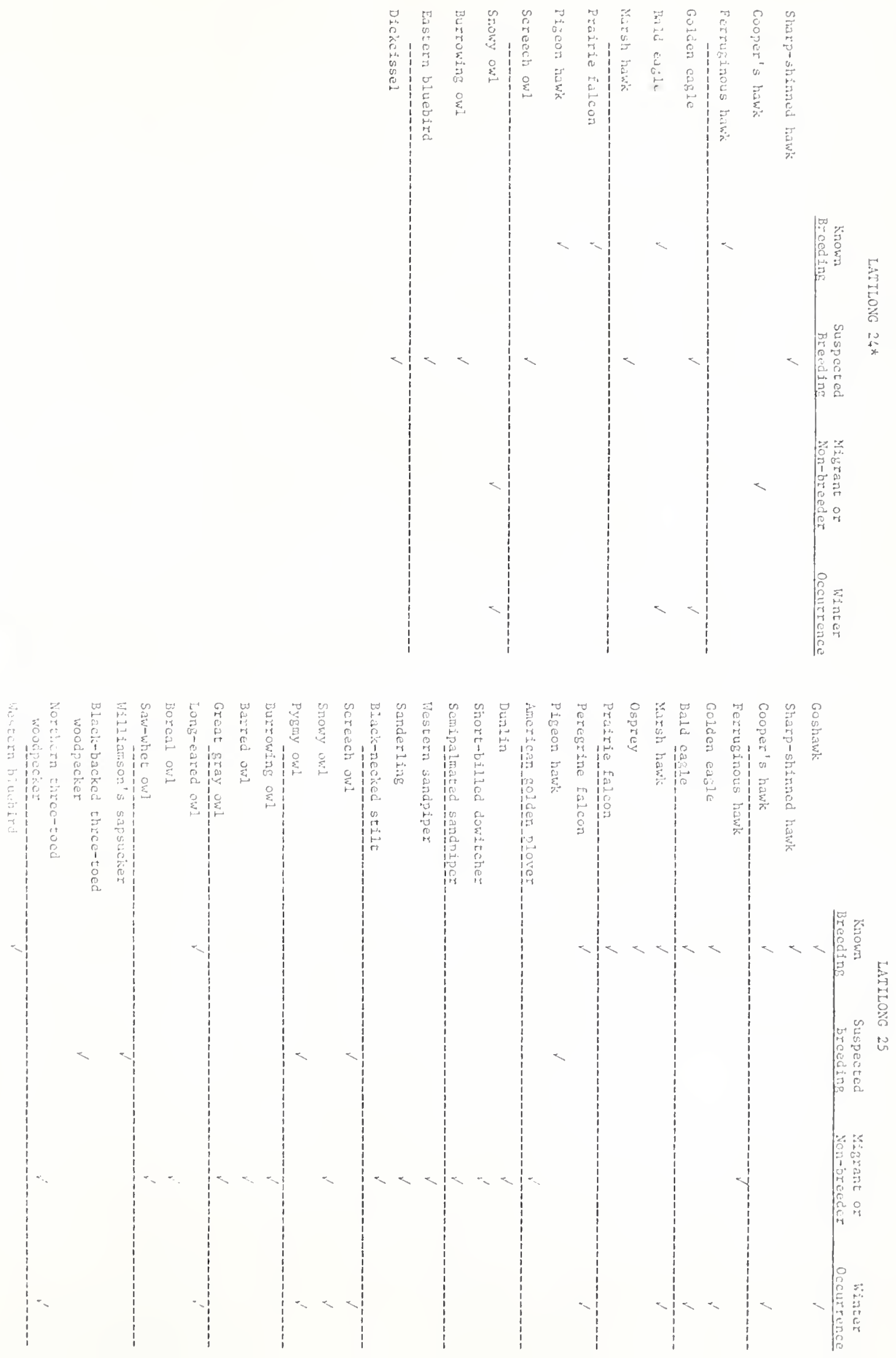


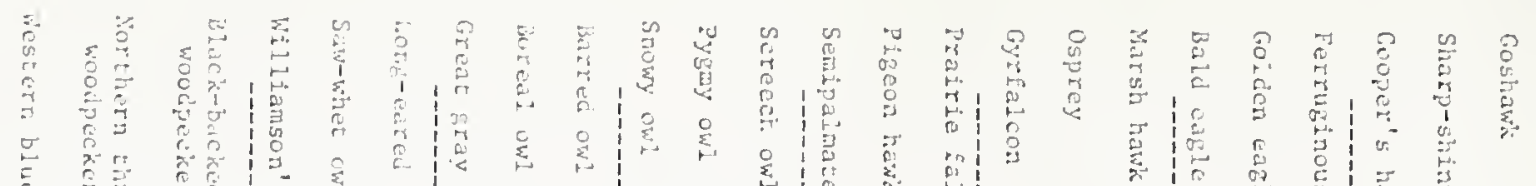

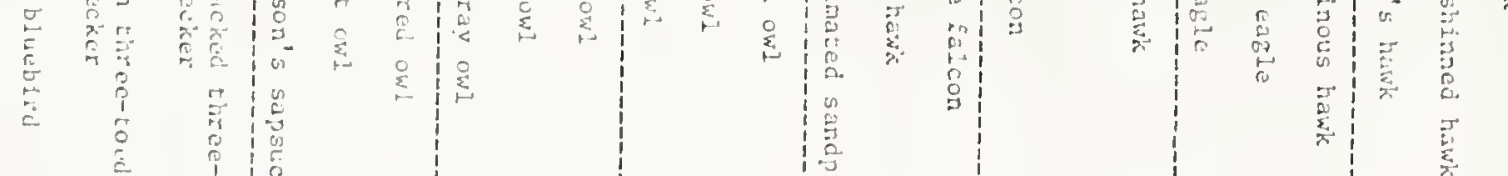

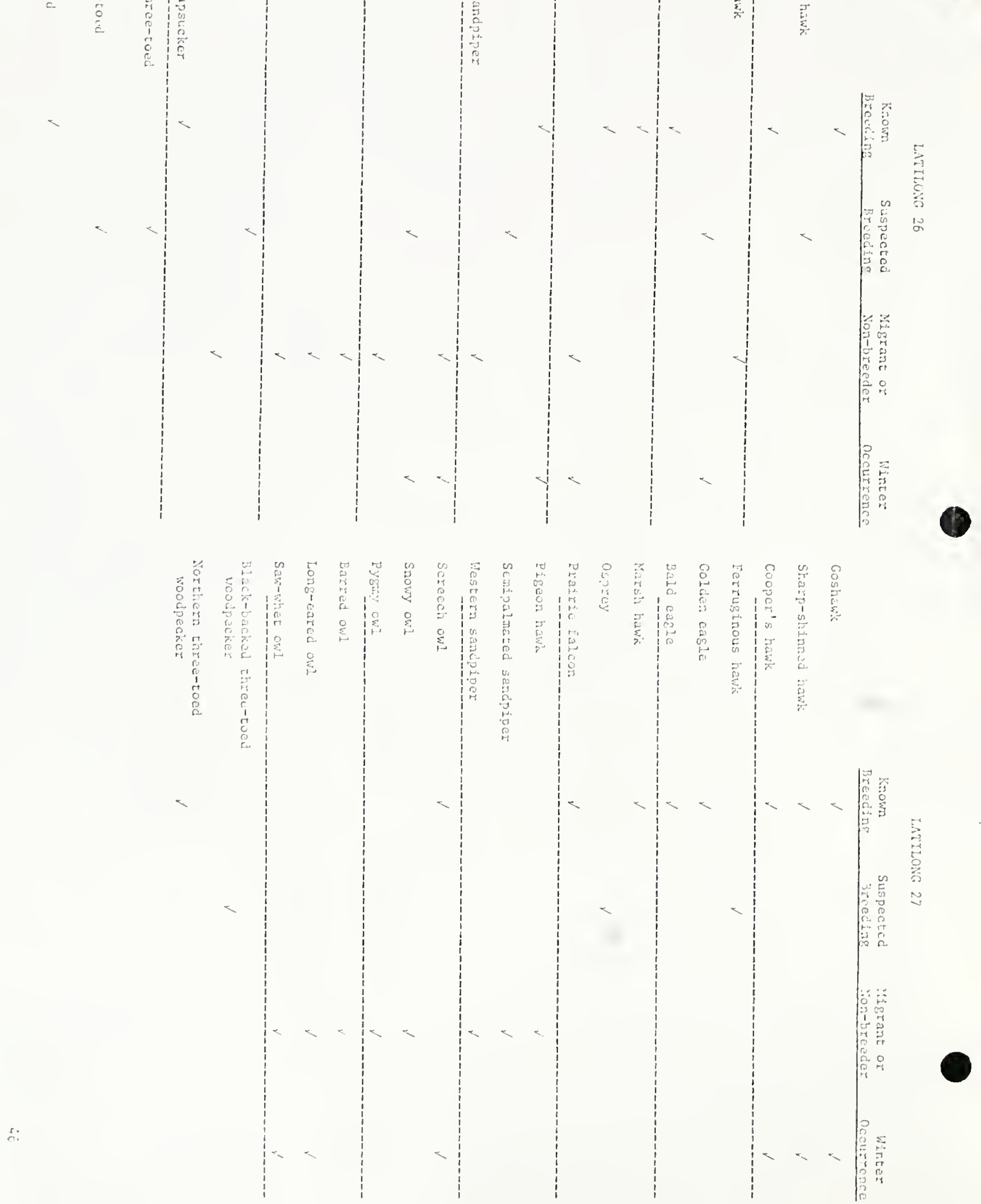



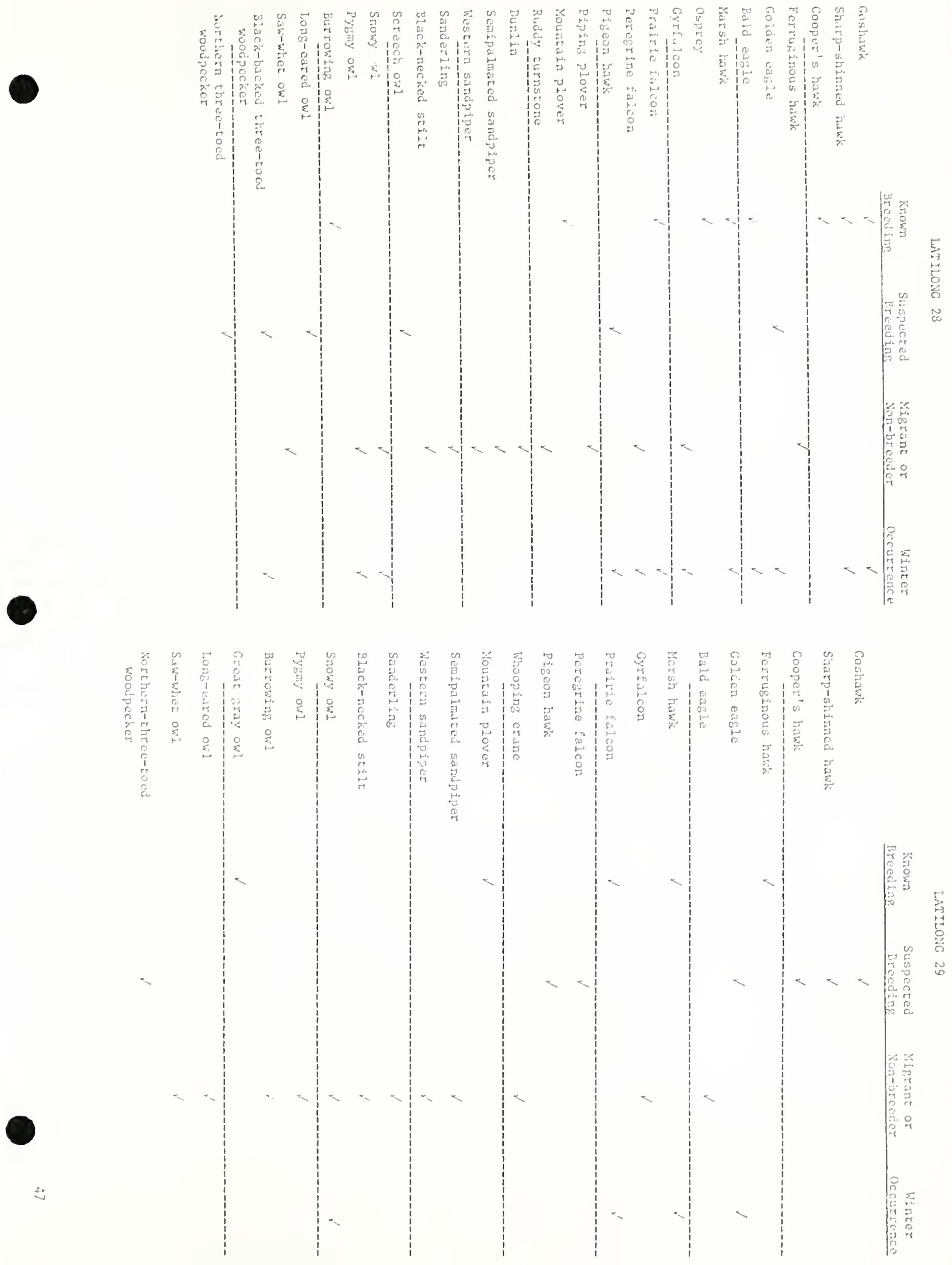


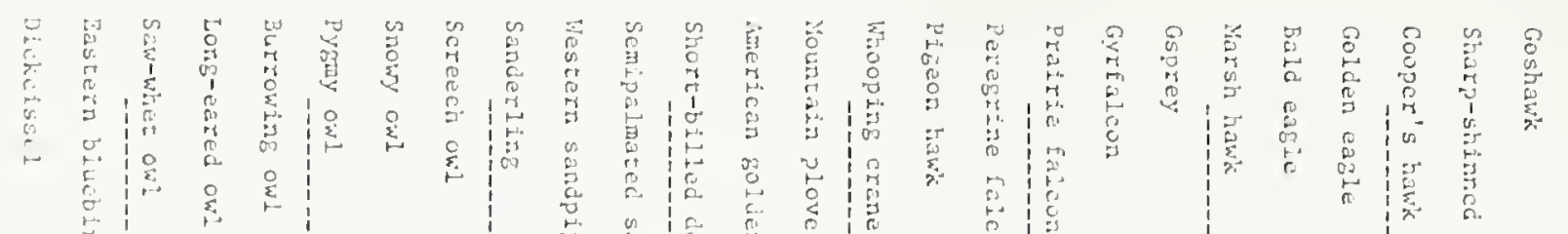
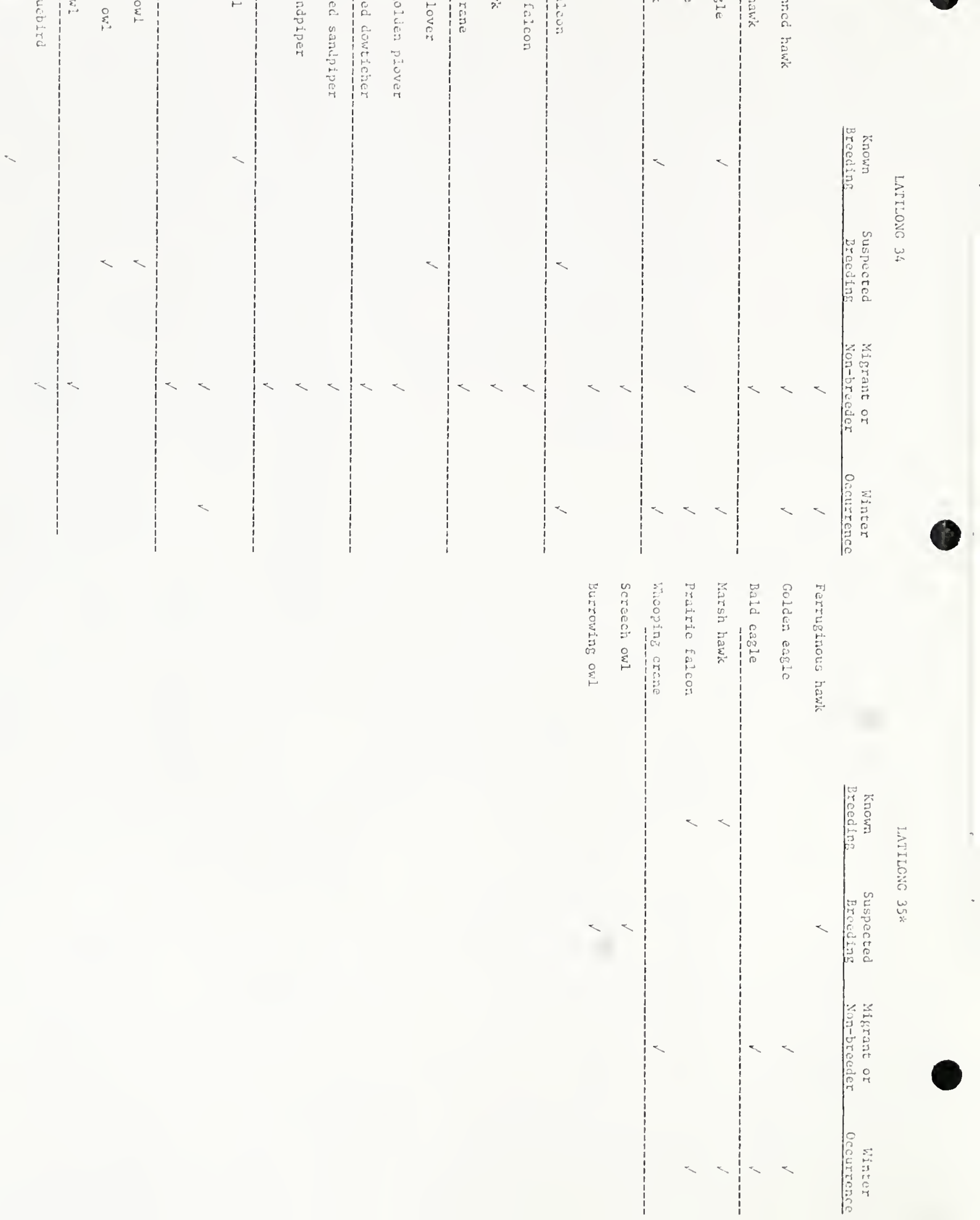

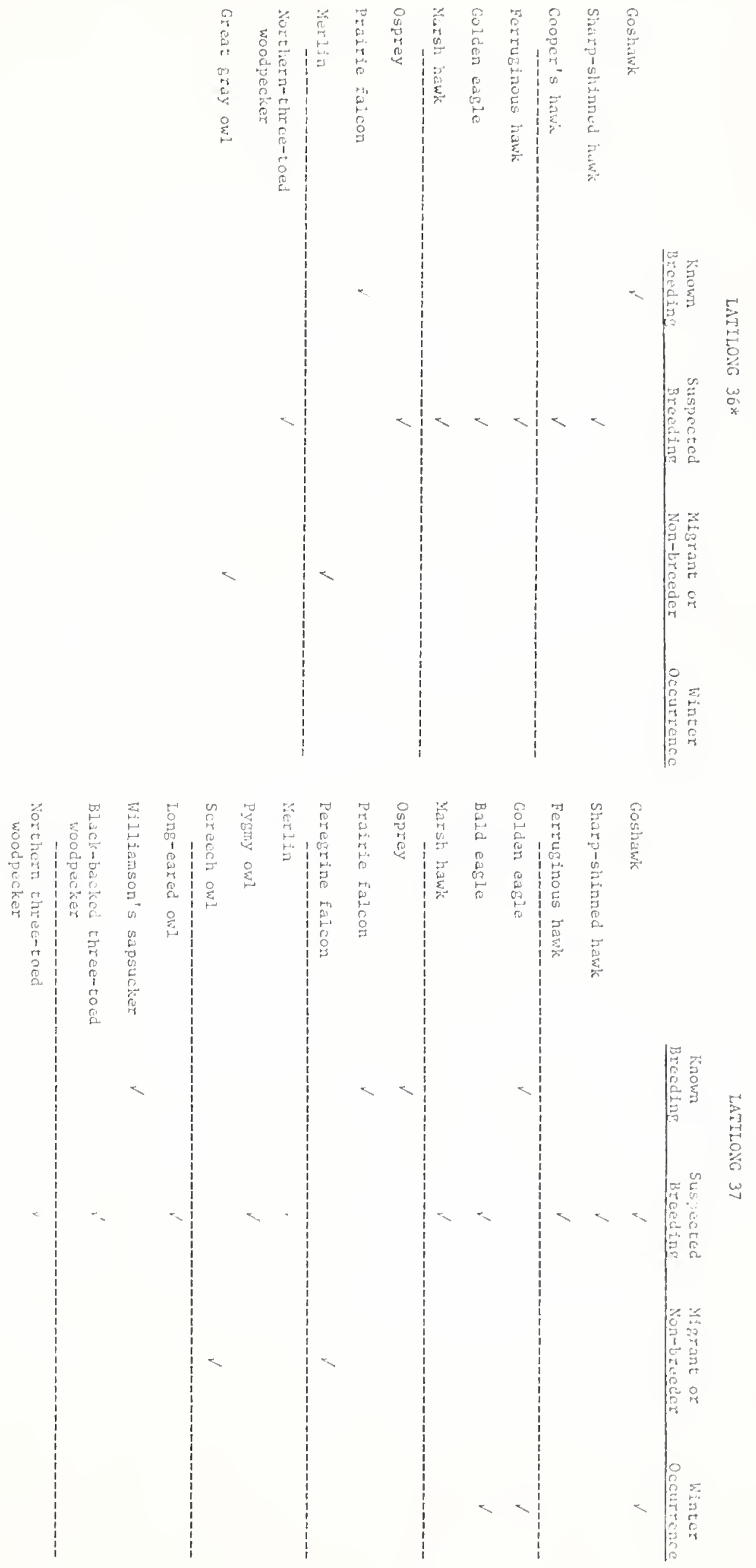
HOH D.

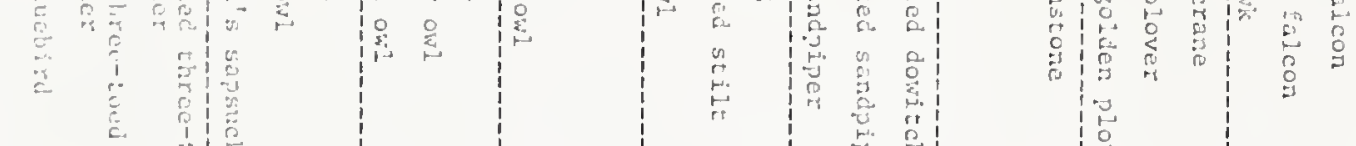
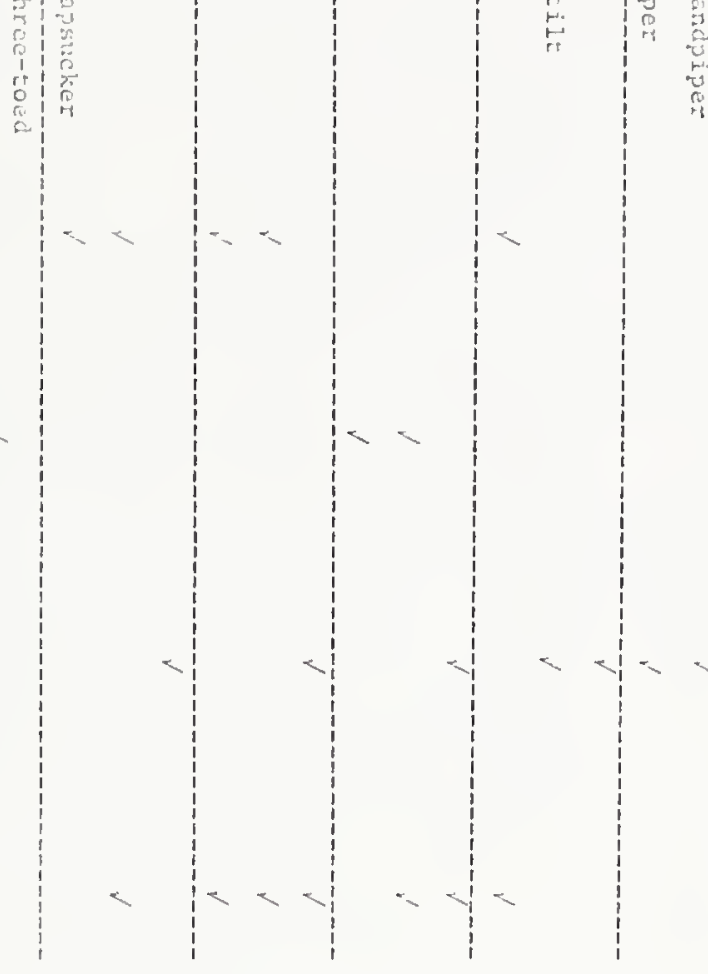

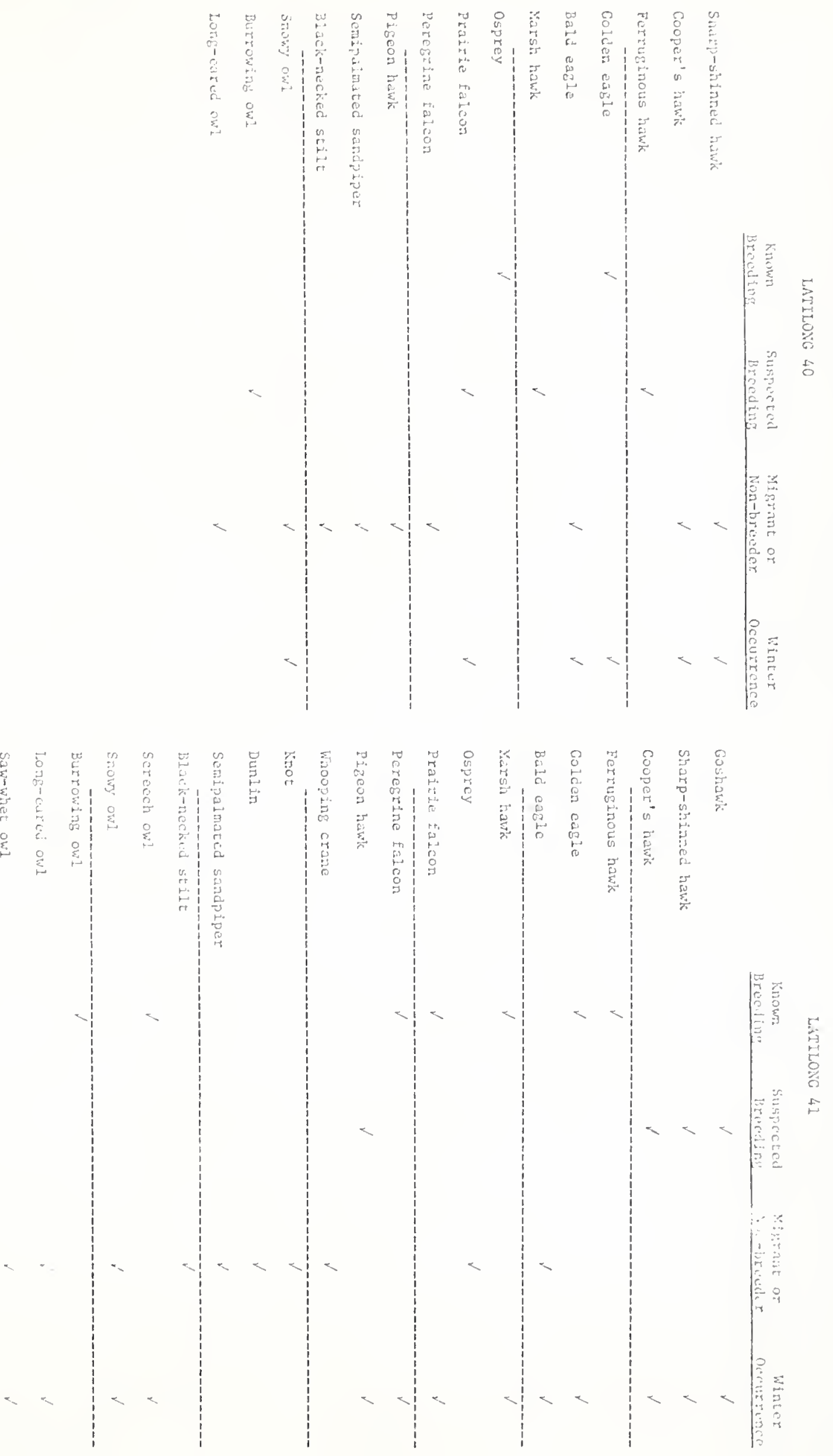

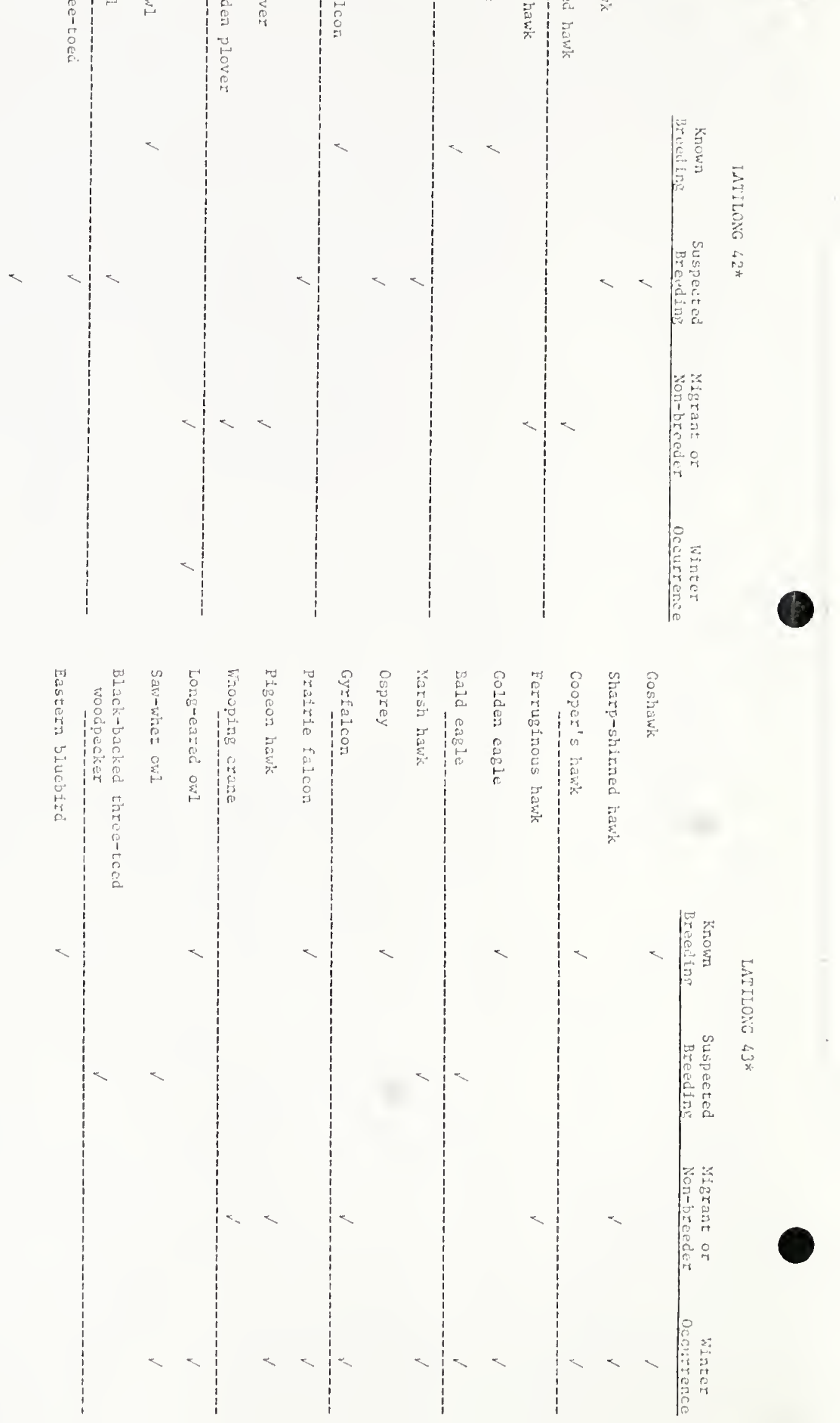


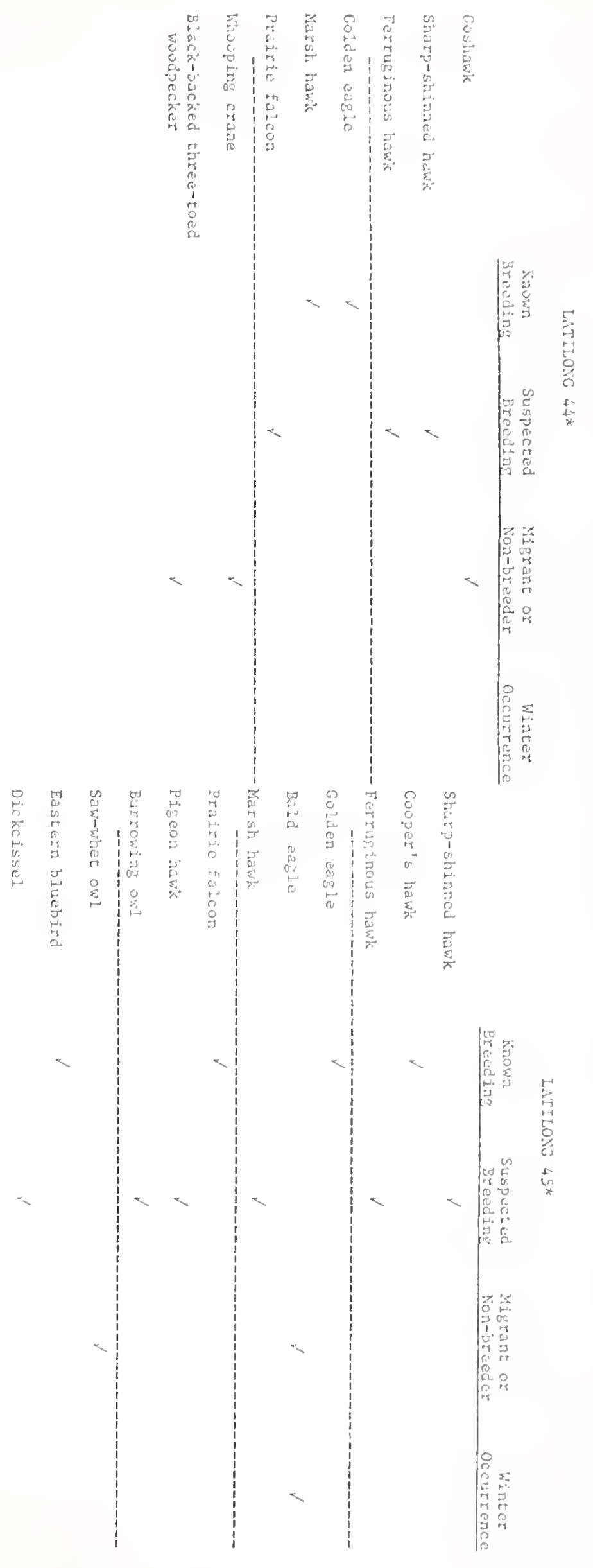




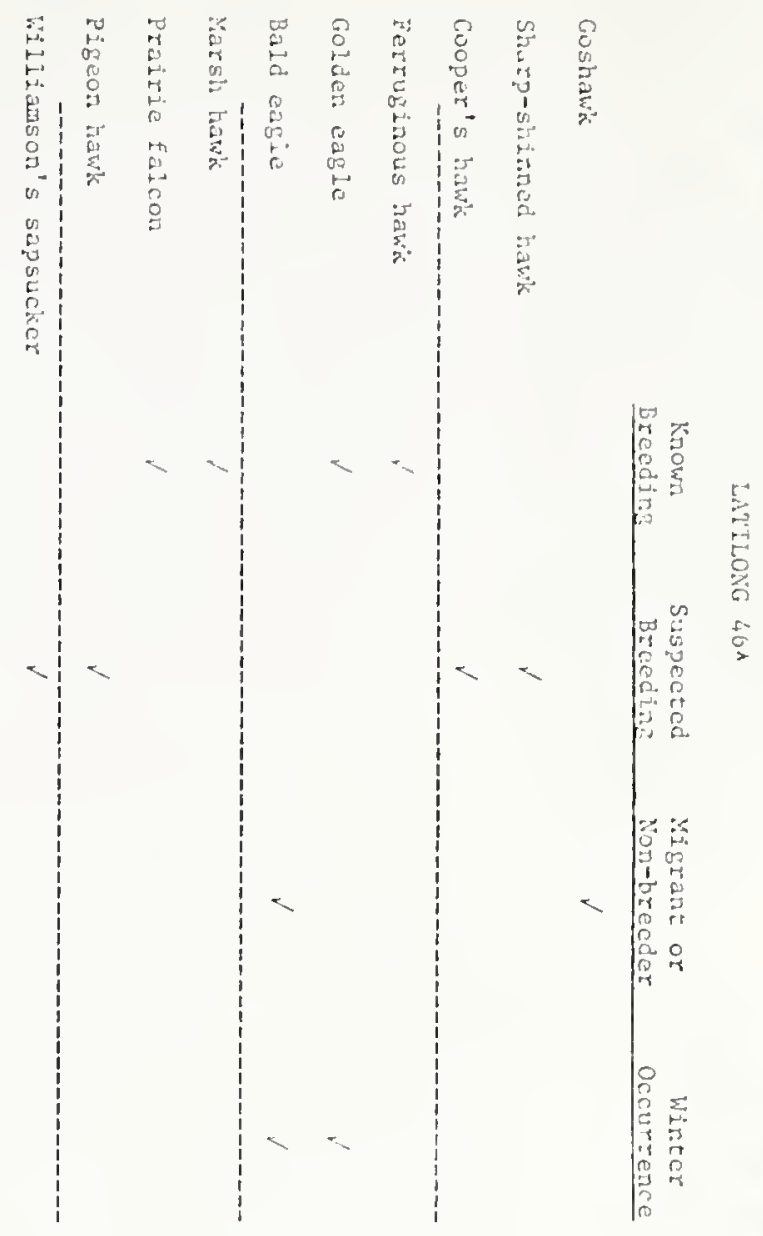

•

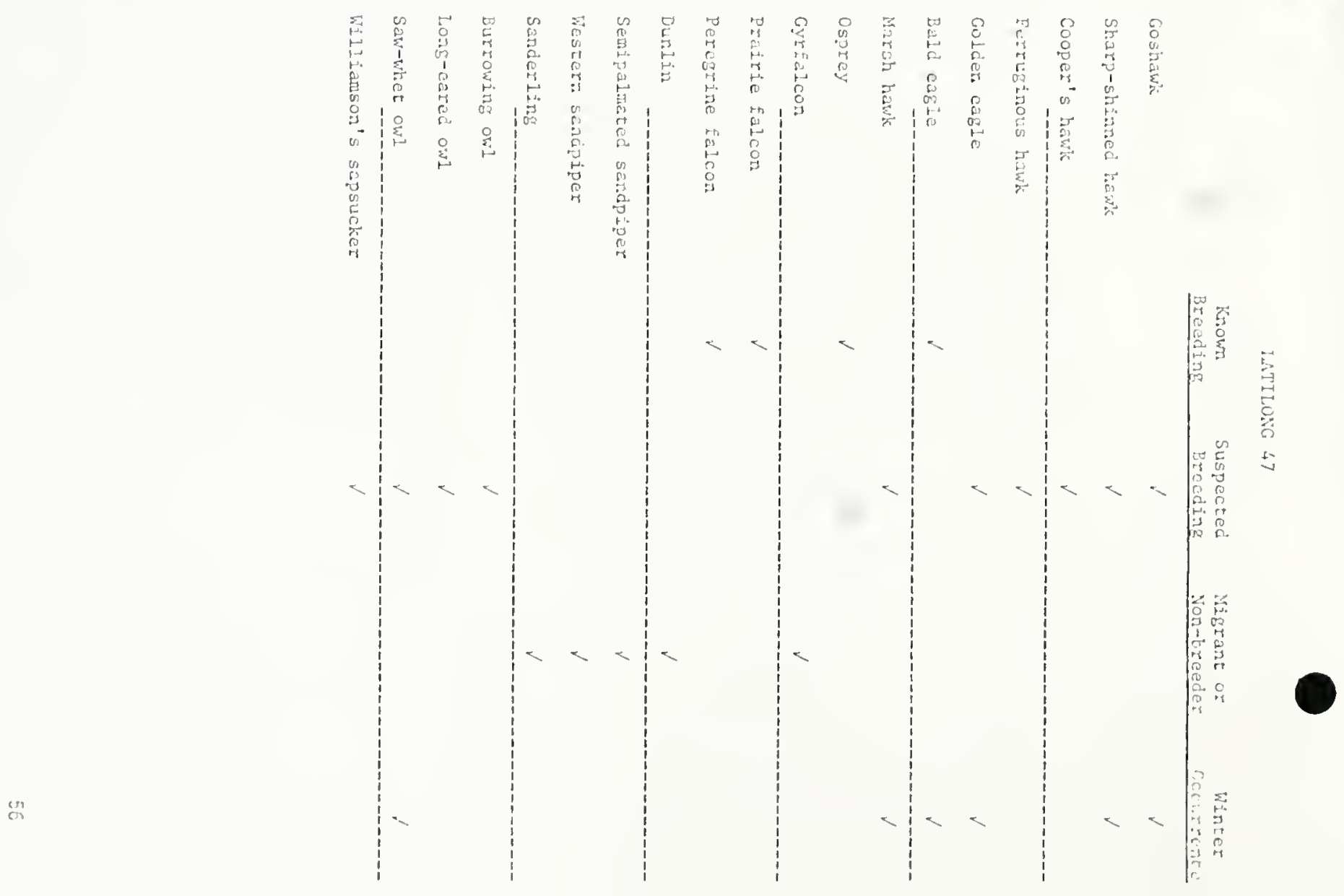


-

-

焉

• 
可 $\widehat{3} \widehat{\mathrm{g}}$

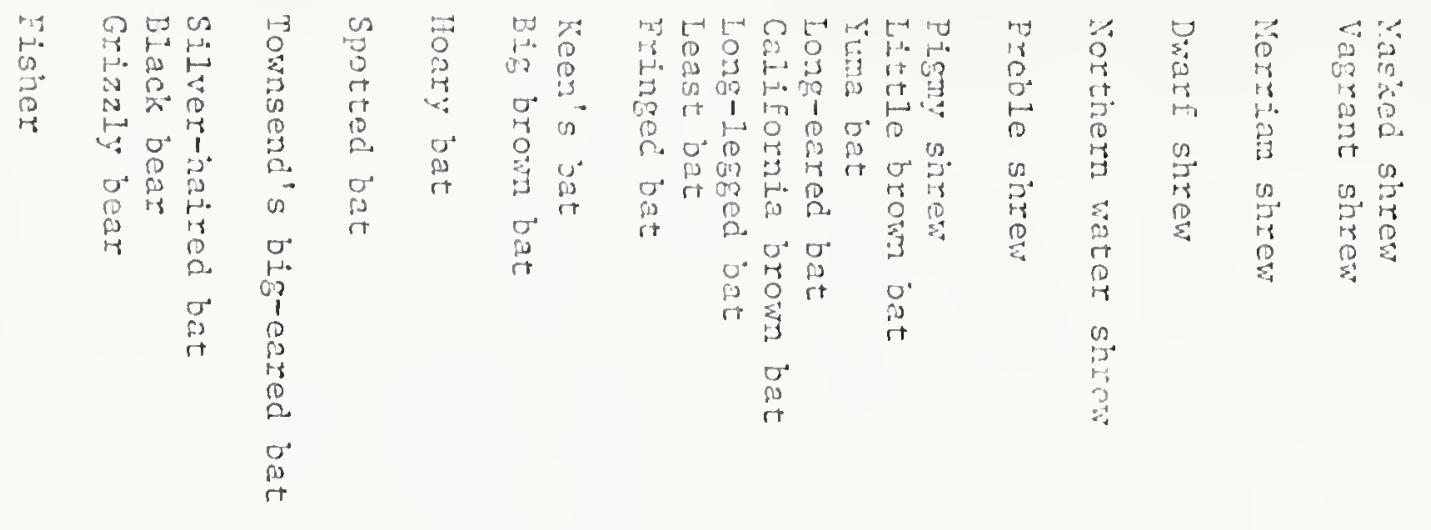

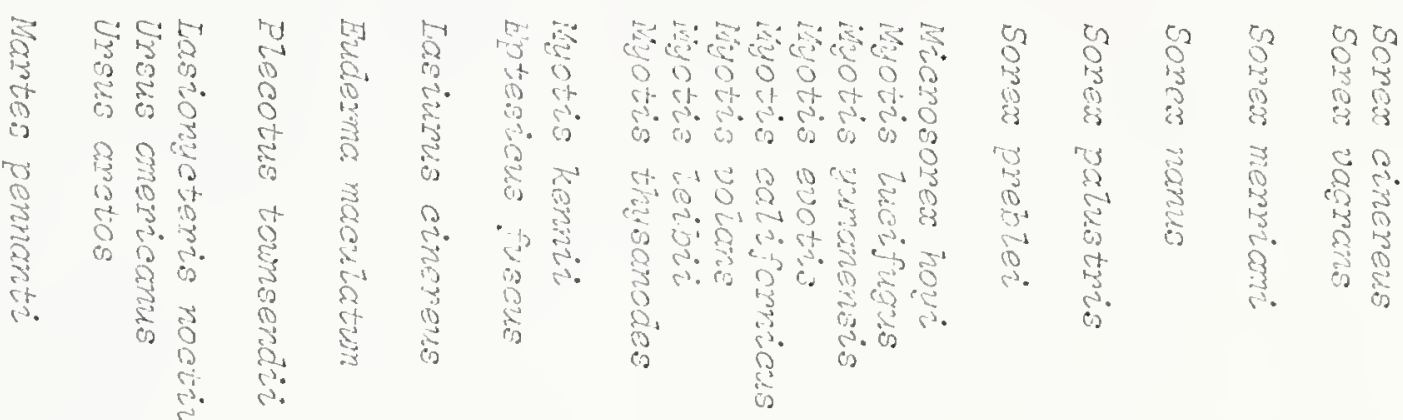

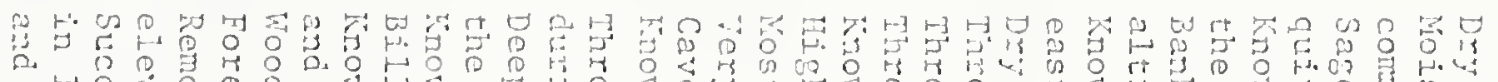
十0

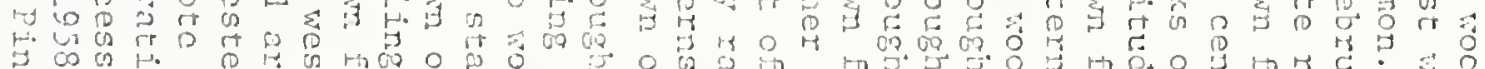

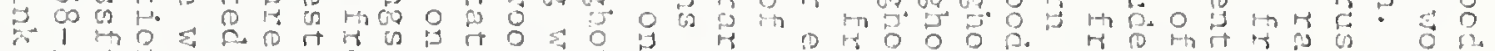

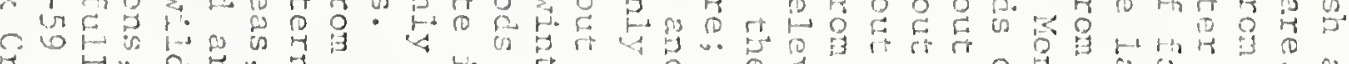

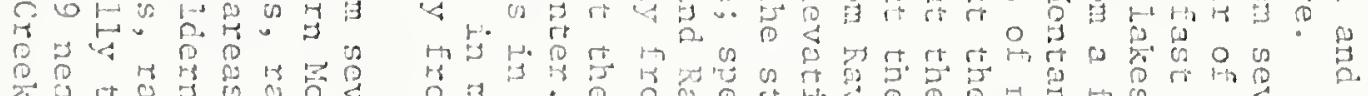

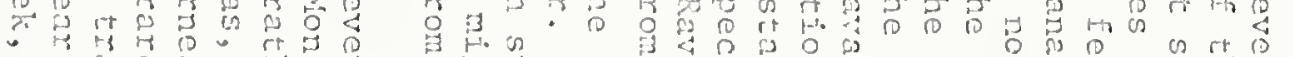

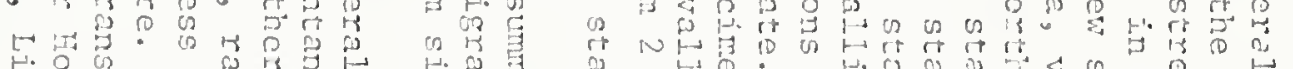

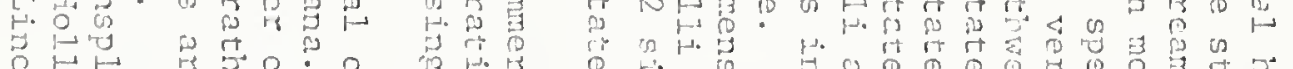

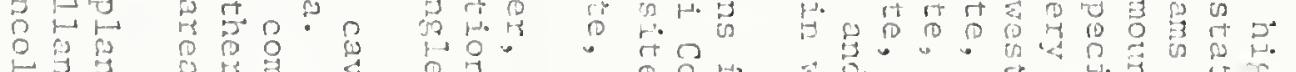

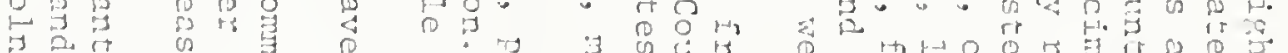

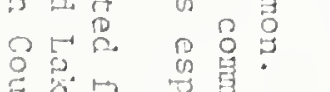




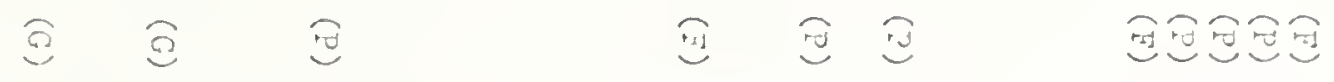

- H

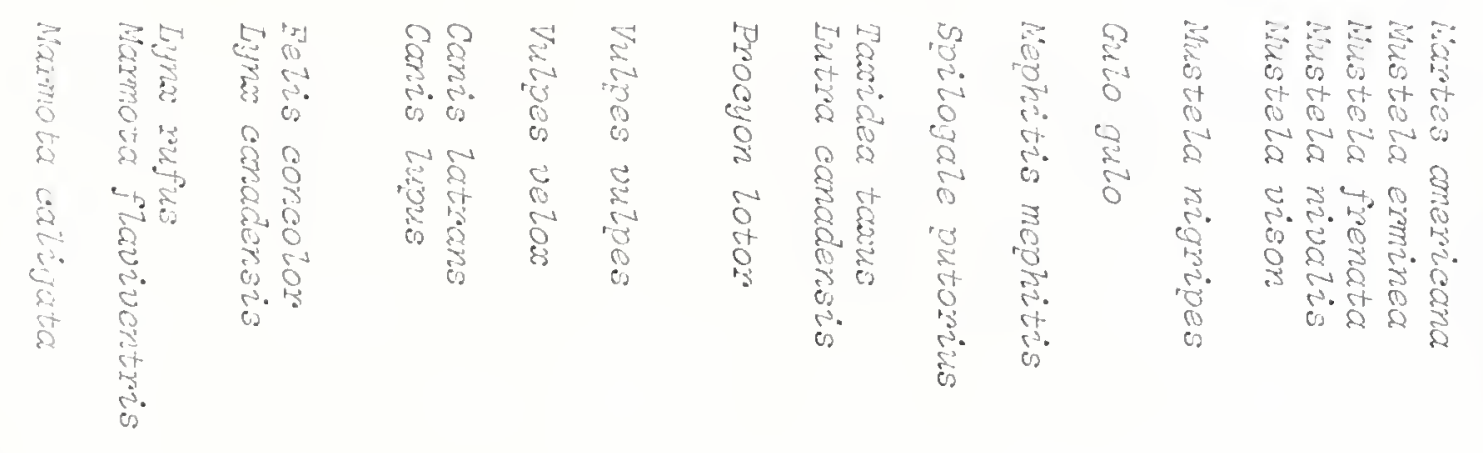

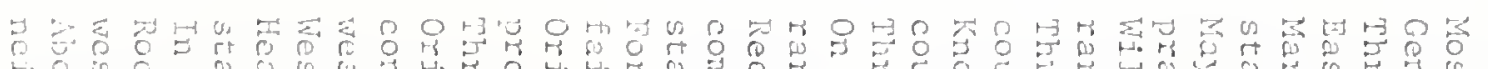

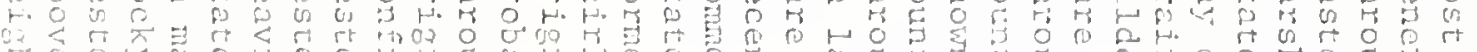

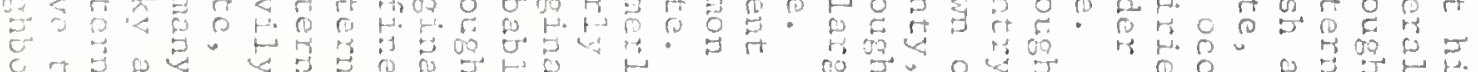

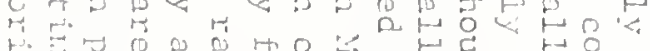

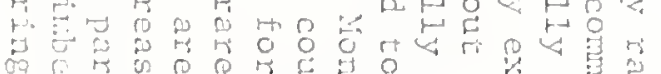

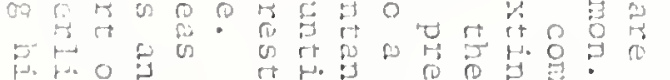
ars.

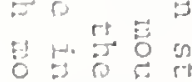

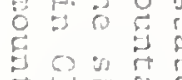
(rige

s. 20.

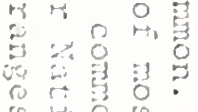

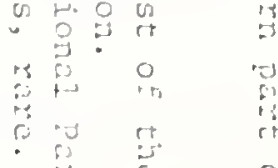

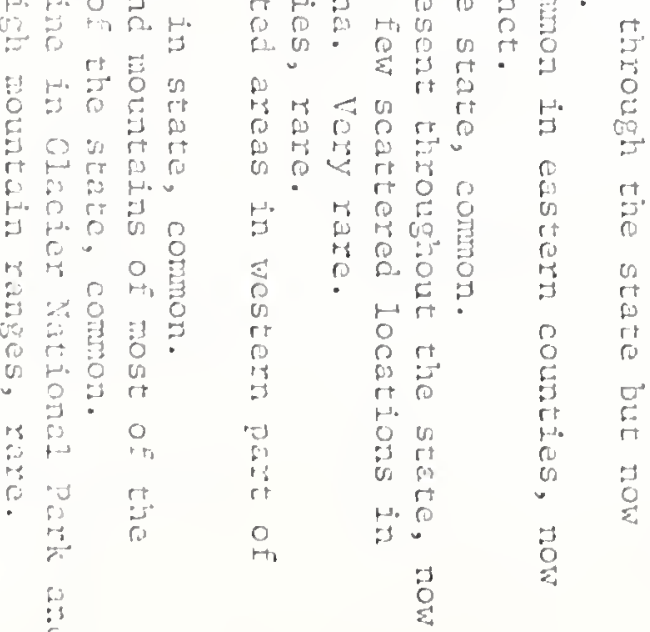
$\stackrel{1}{6}$

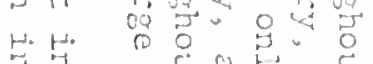
$ت$
$\cdots$
0 00 i

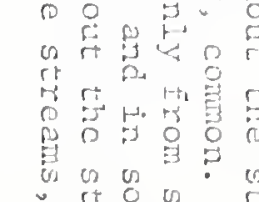

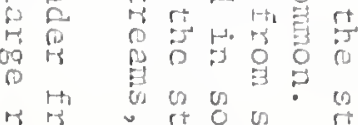

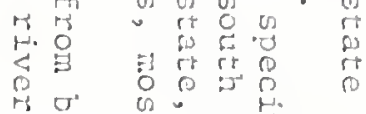

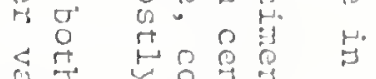

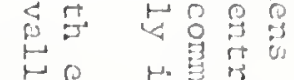
40 o
อ

8

㸵

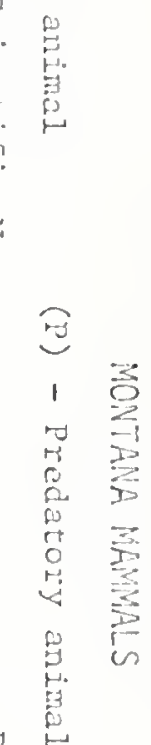



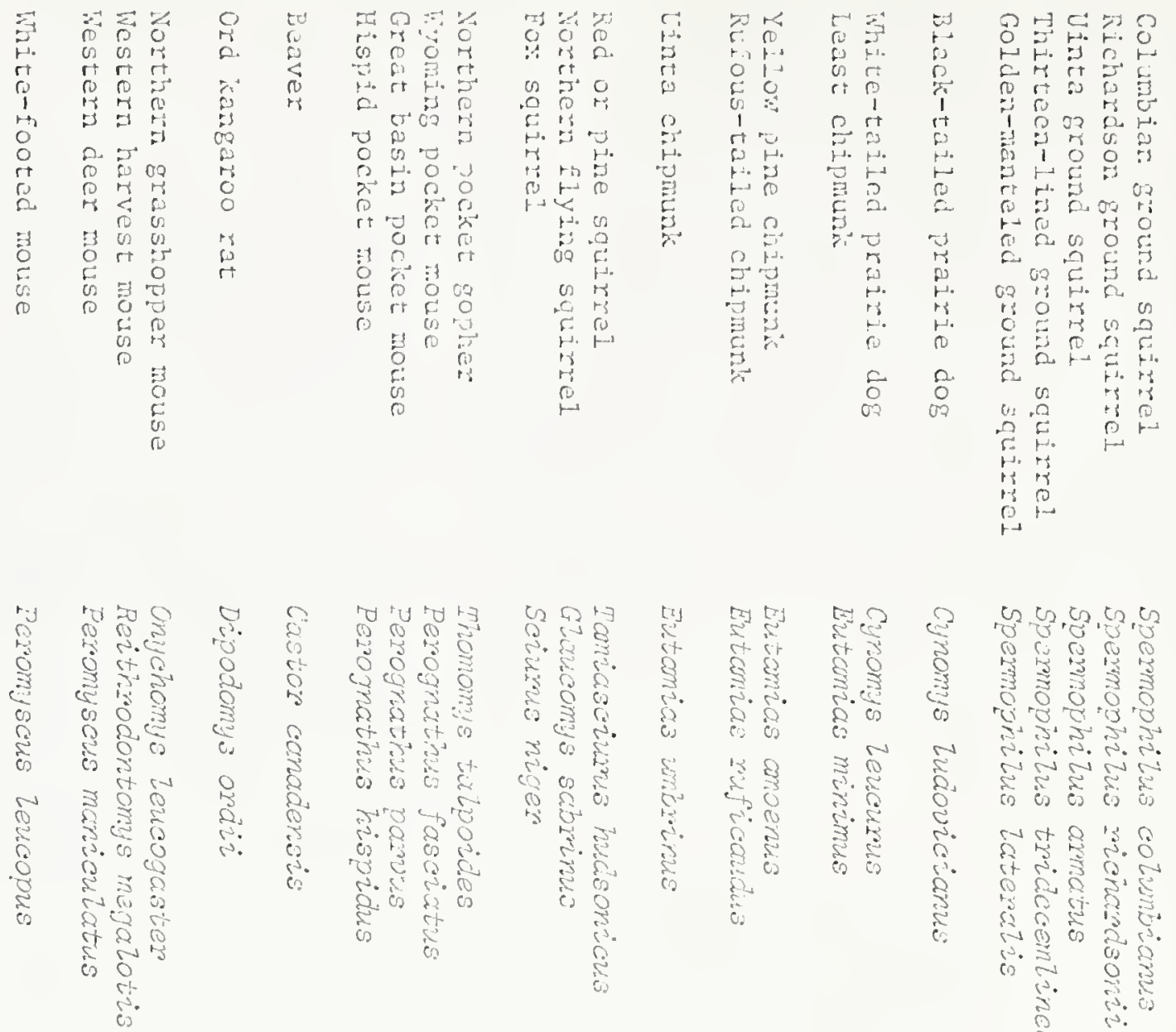

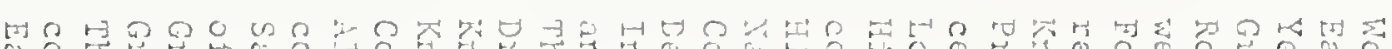

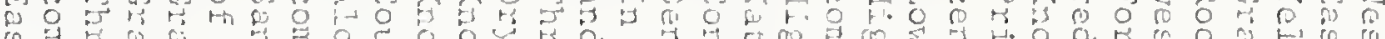
r 900 क

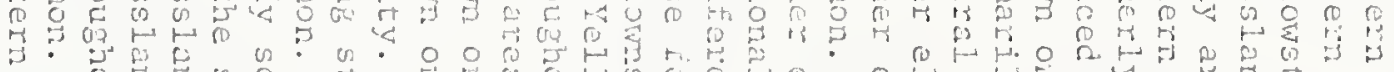
?

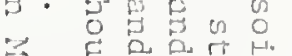

- $\begin{gathered}1 \\ 0\end{gathered}$

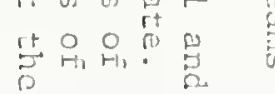

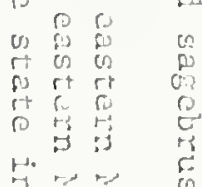
H.

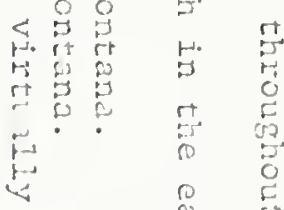

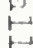<smiles>[C+]#[C+]C</smiles>

施

t. $\ddot{0}$

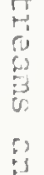
H a

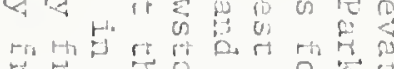

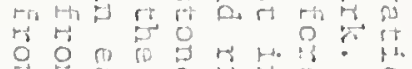

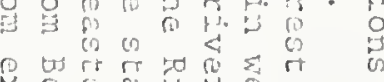
$\begin{array}{lllllll}4 & 0 & 0\end{array}$

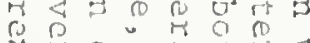

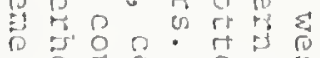

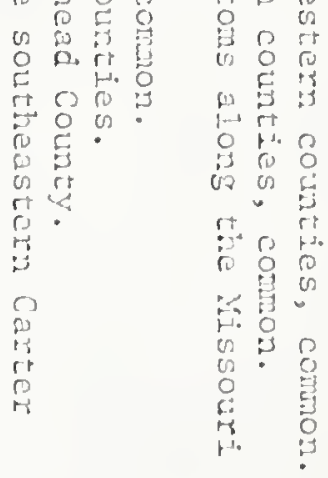
$\frac{0}{3}$ 

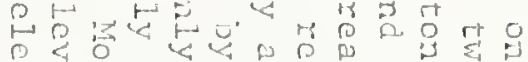
दि क

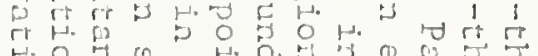

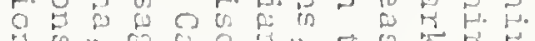

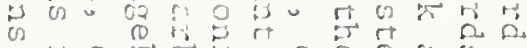

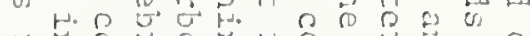

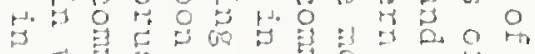
$\begin{array}{llll}0 & 5 & 0 \\ 0 & 0 & 0 & 0 \\ 0 & 0 & 0\end{array}$

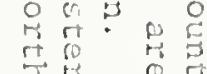

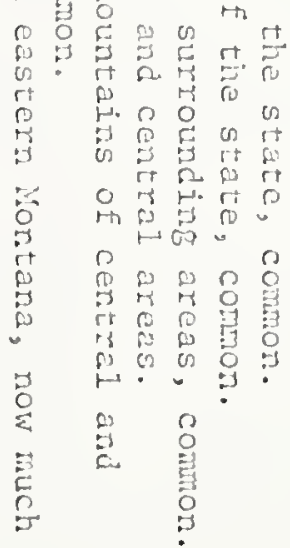
$\mid \begin{array}{lll}0 \\ 0 \\ 0 \\ 0 \\ 0 \\ 0 \\ 0 \\ 0\end{array}$ Q 1 量

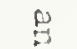




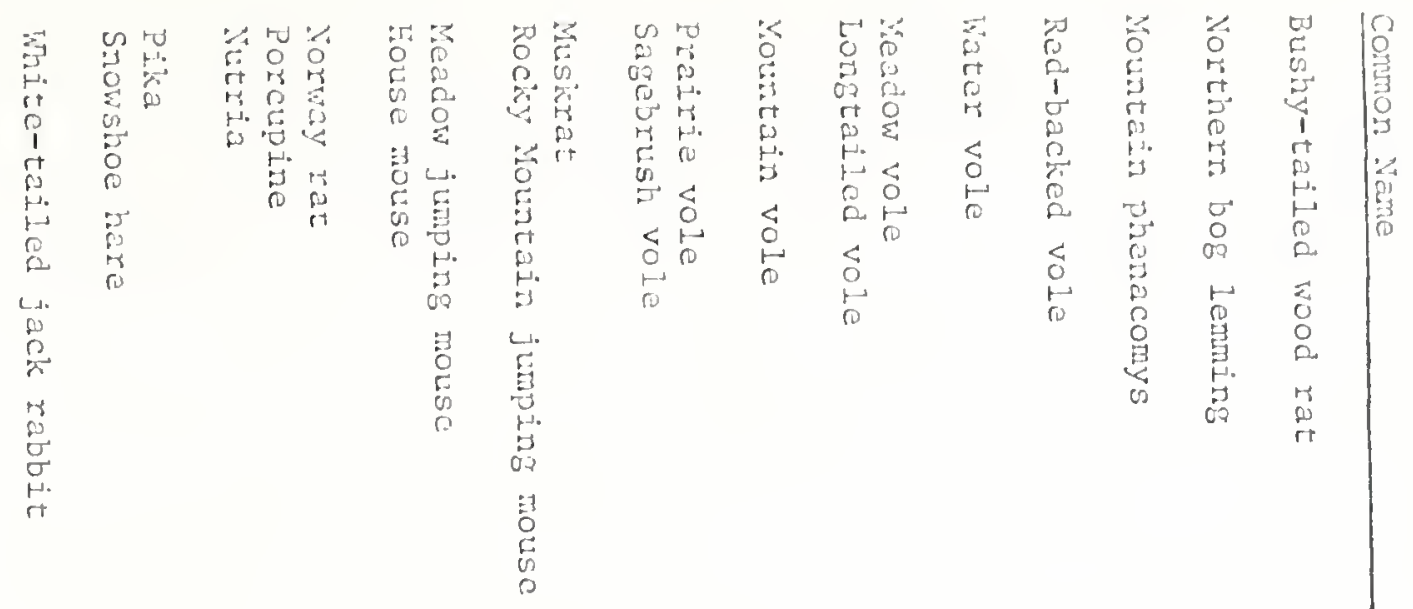

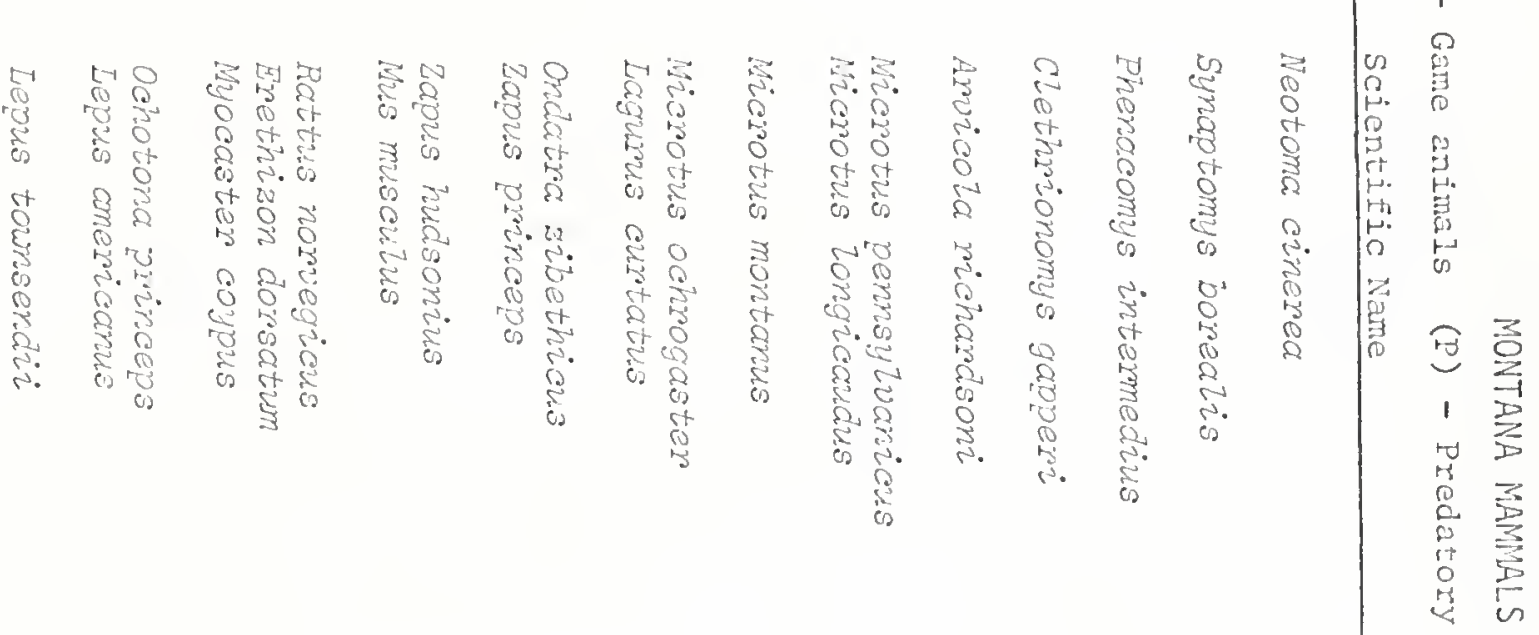

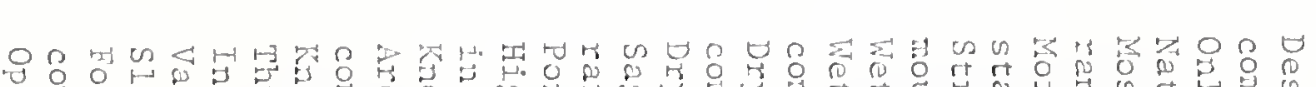

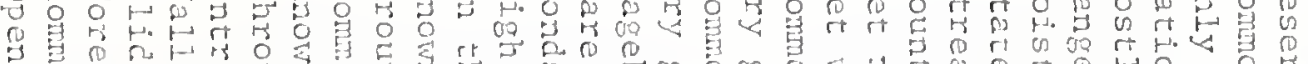

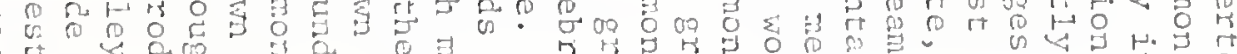

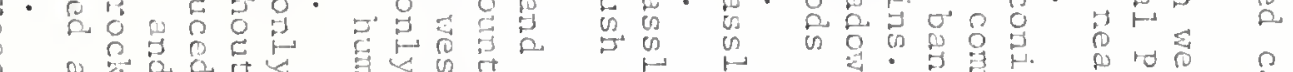

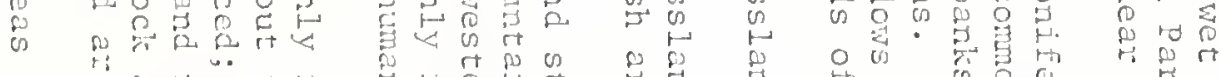

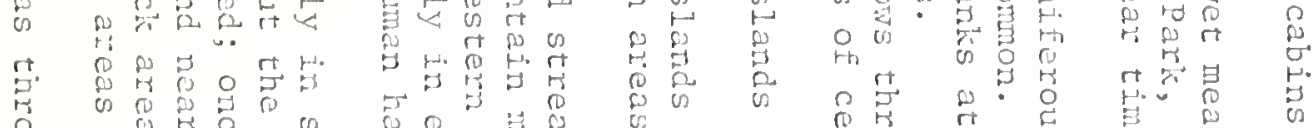

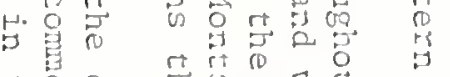



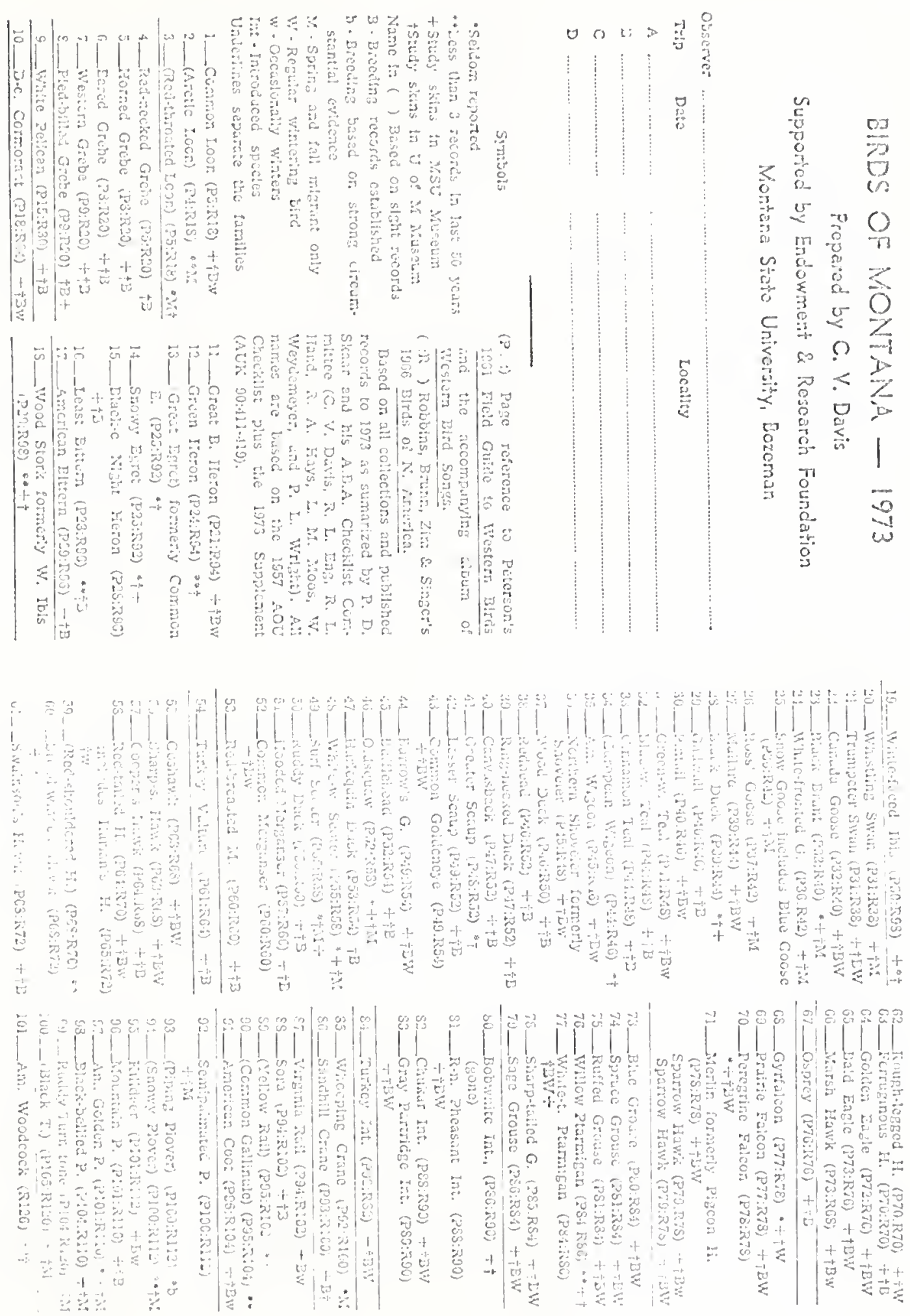

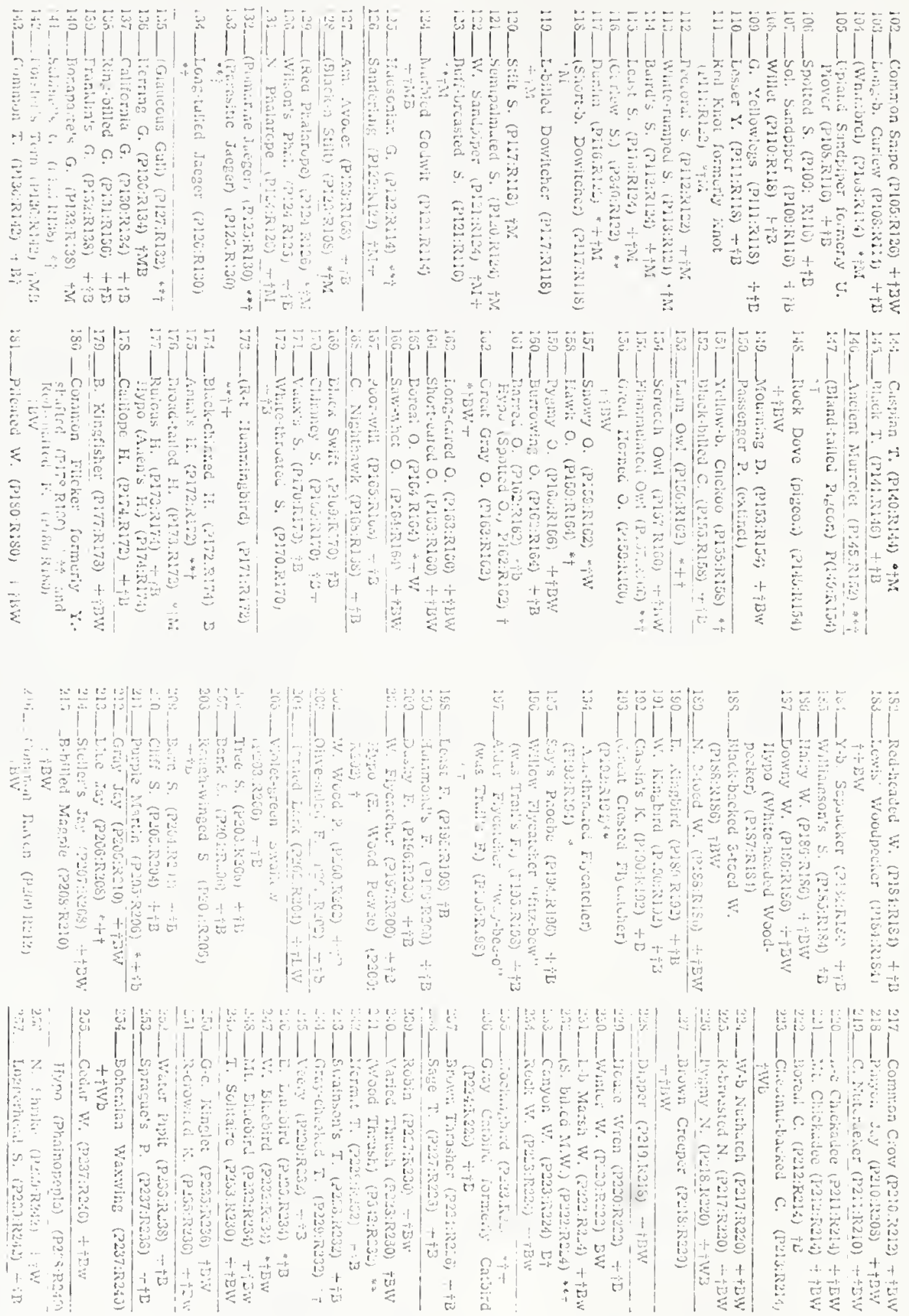

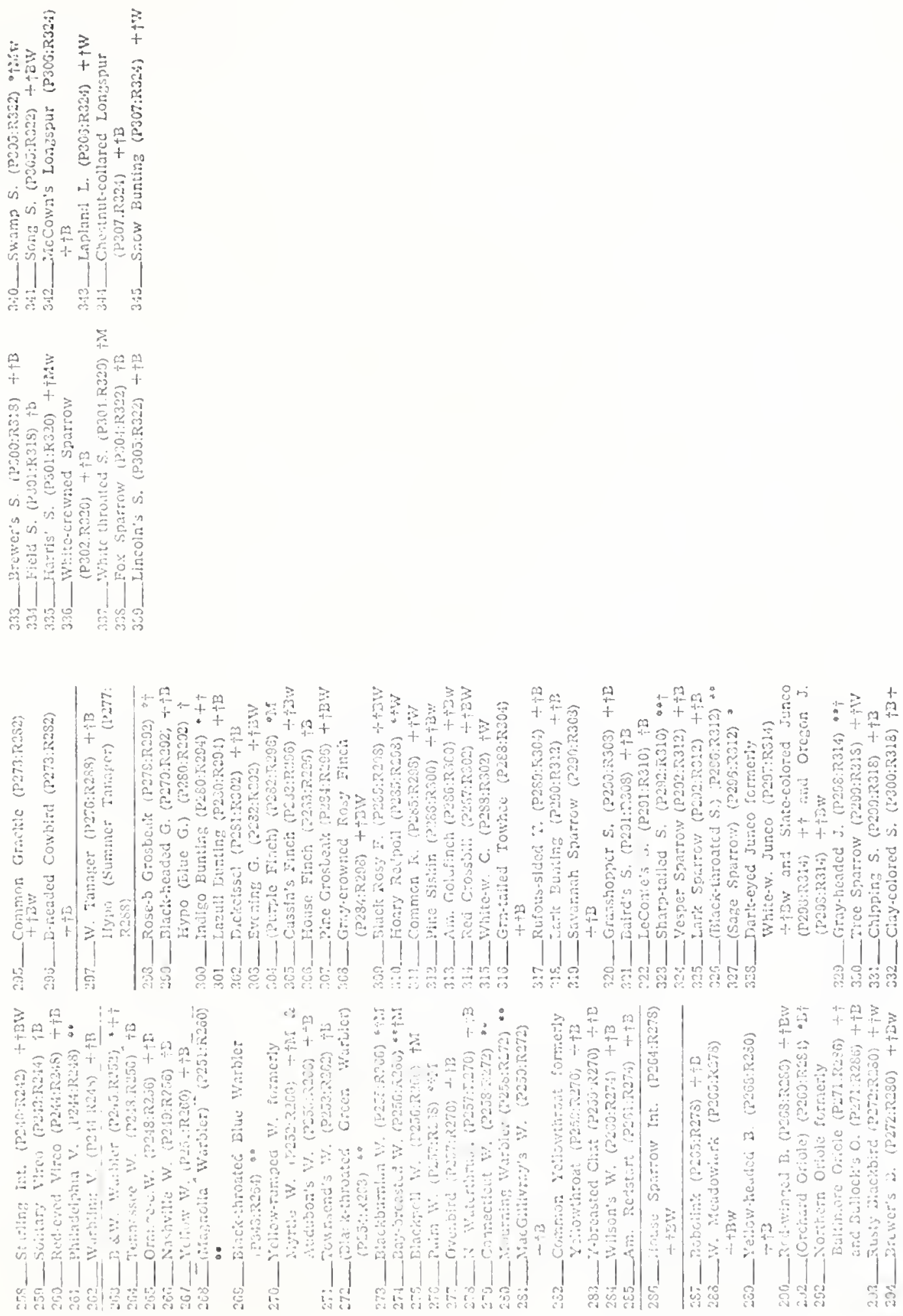

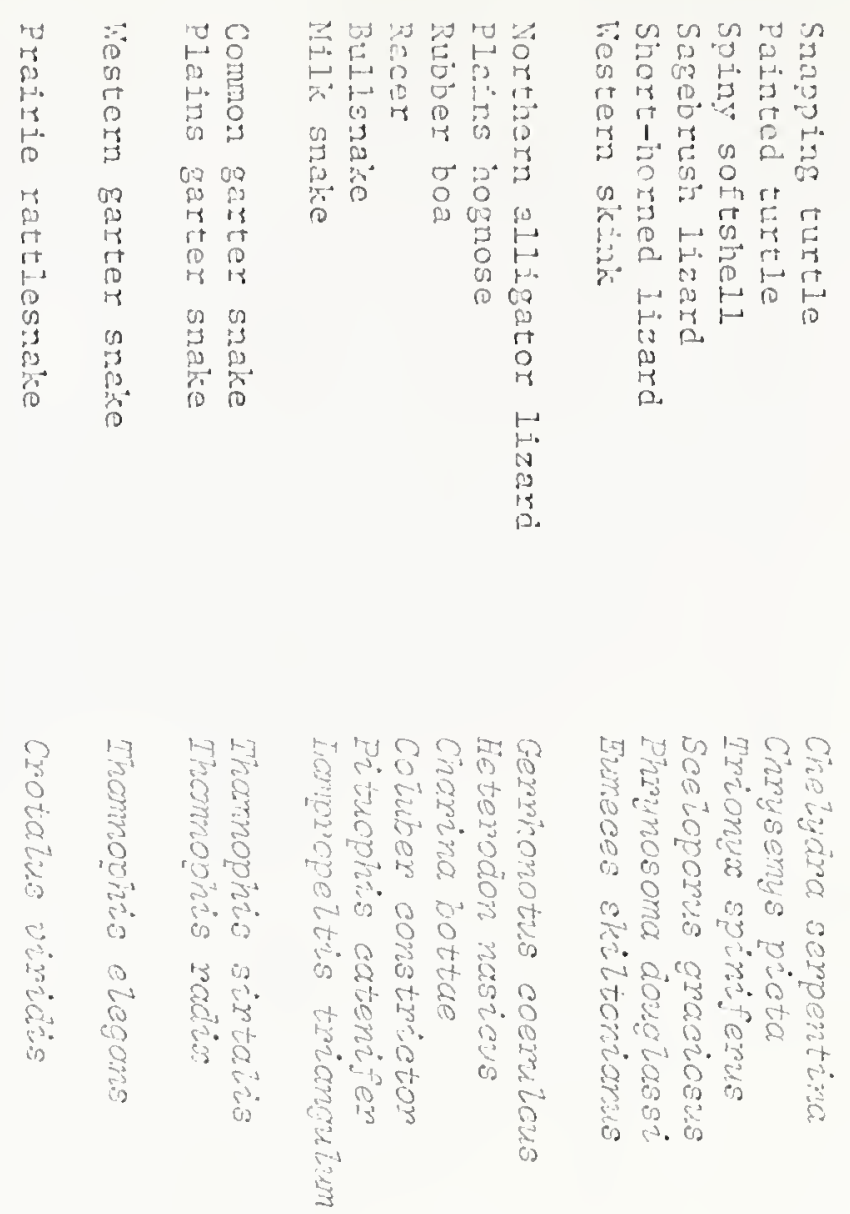

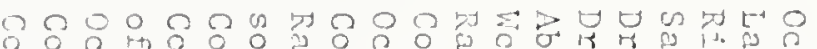
㝵学?

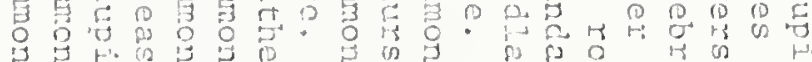

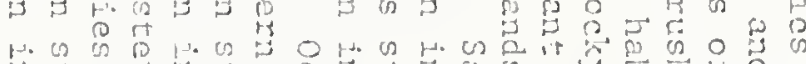

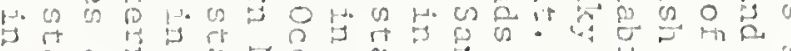

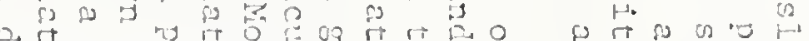

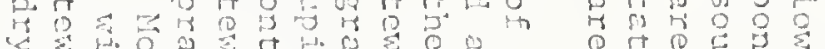
त.

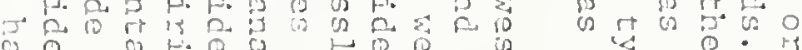

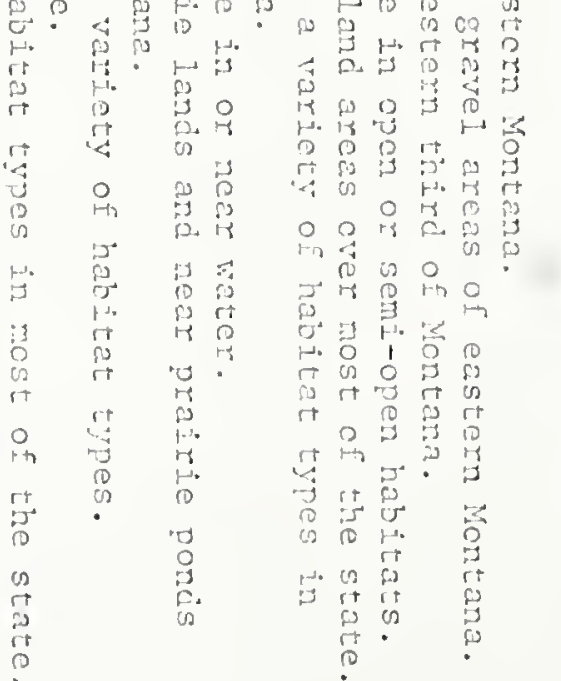




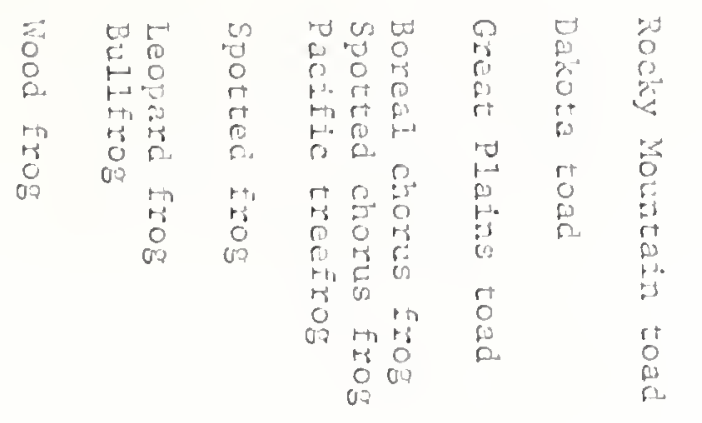

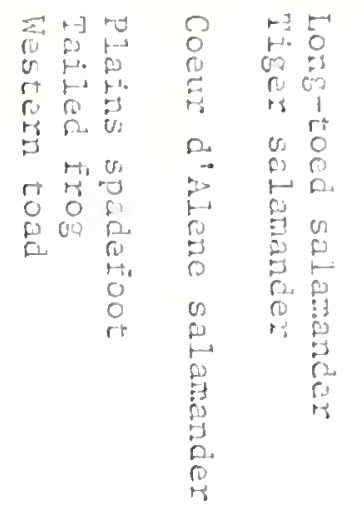

$n$
0
0
0
0
0
$r$
0
0
0
0
0
0
0
$r$
0
0
0
0
0
0
0
0
0
0
0
0
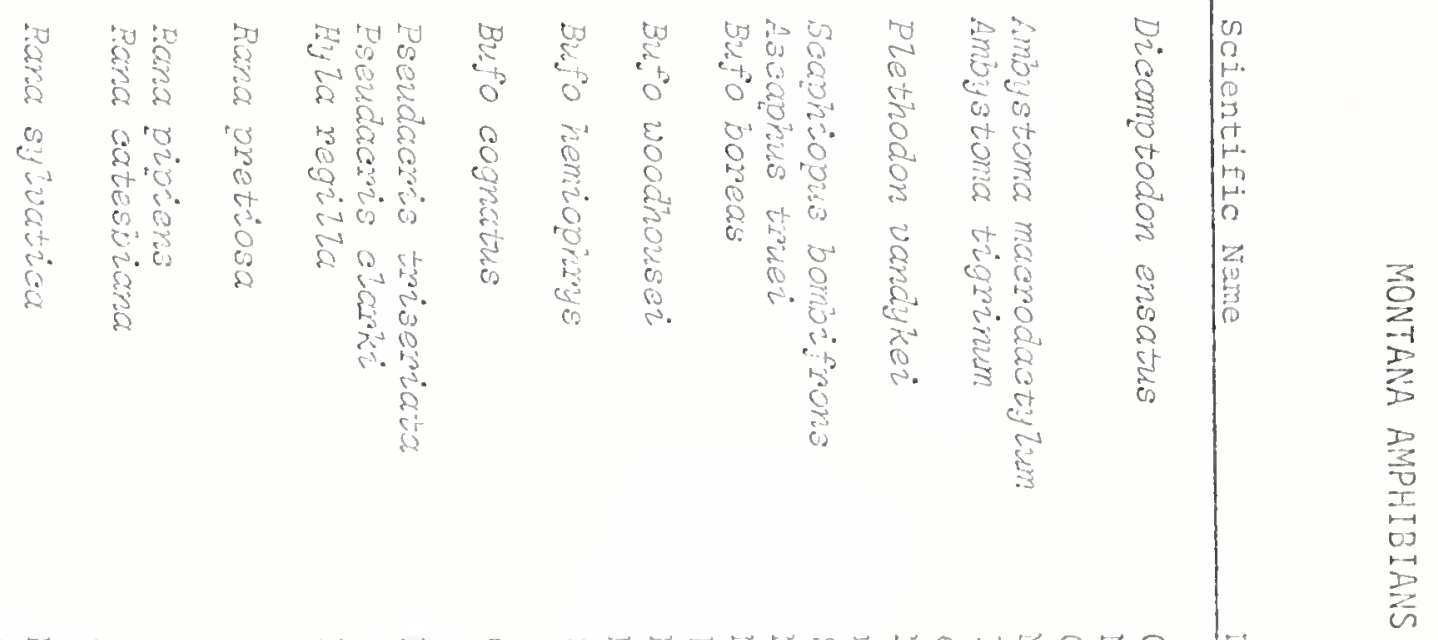

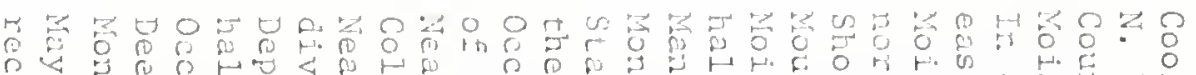

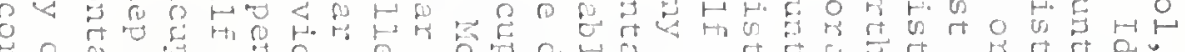

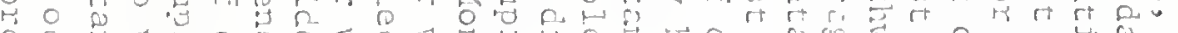

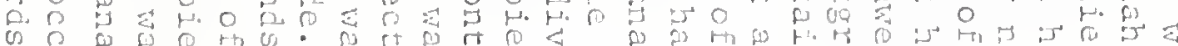

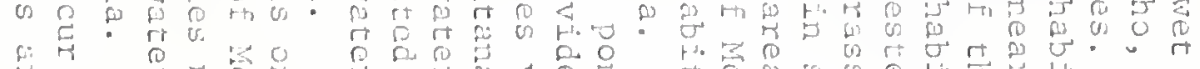

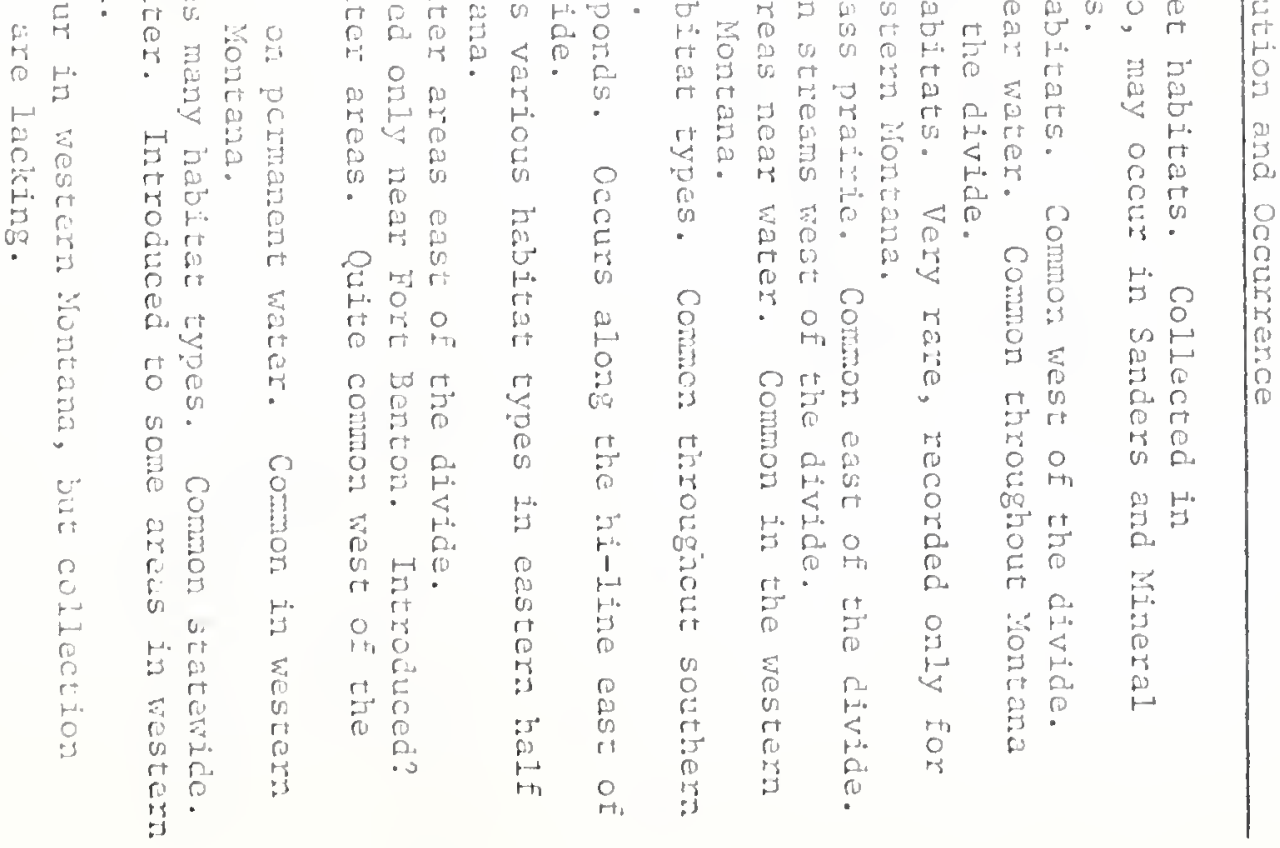


ล

Pling
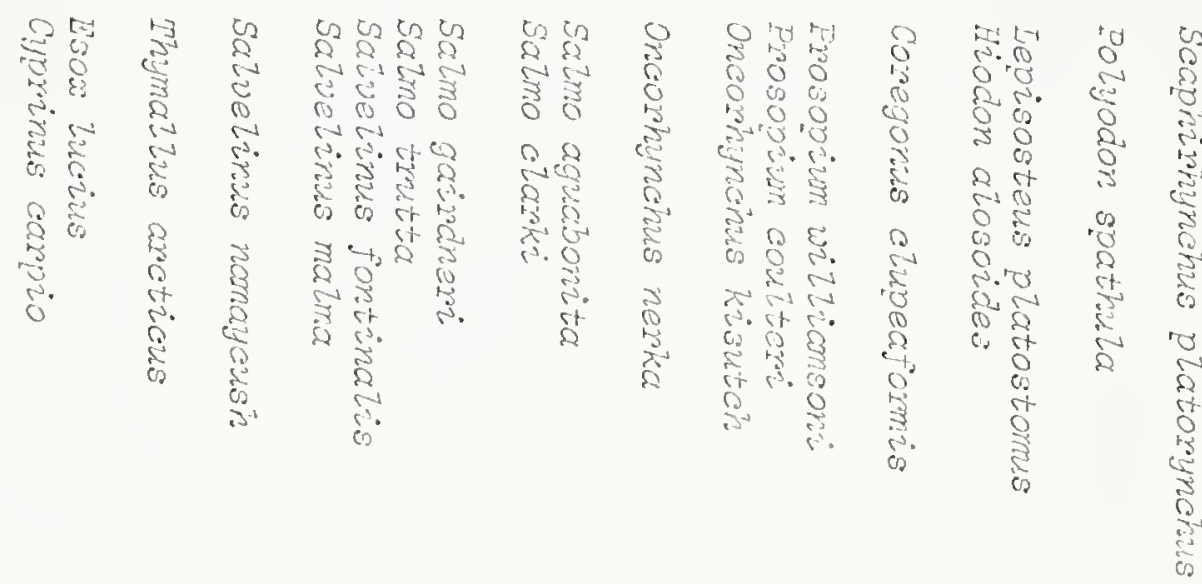

3
3
3
3
7
0
$\vdots$
0

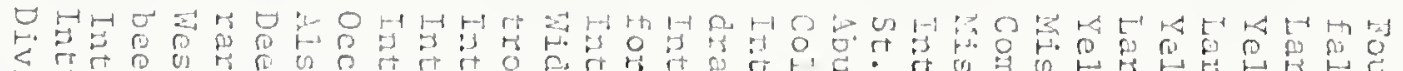

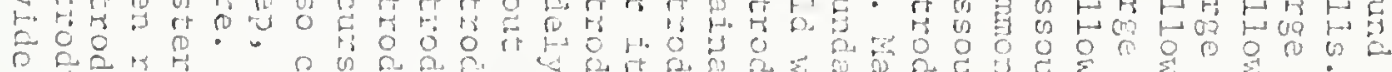

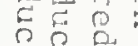

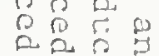

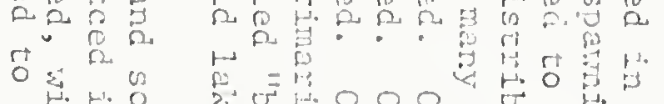

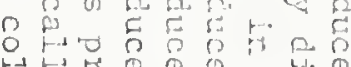

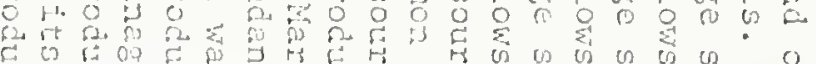

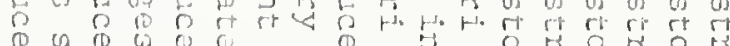

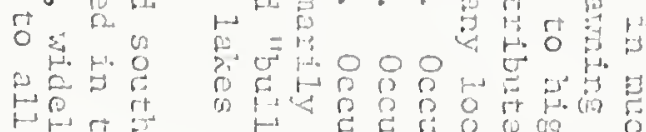

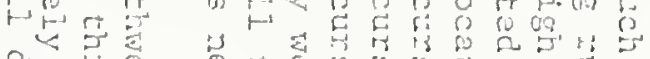

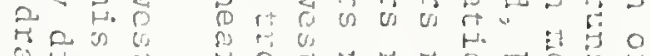

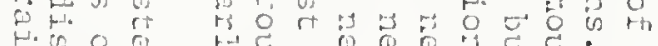

750

o

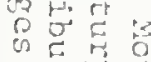

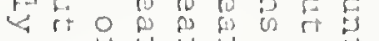

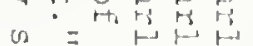

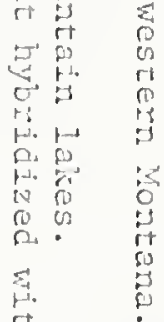

C)

०

it $r \varphi^{4}<4$

it.

it 0 on un

8 i it it

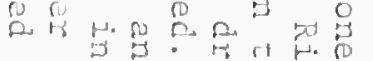

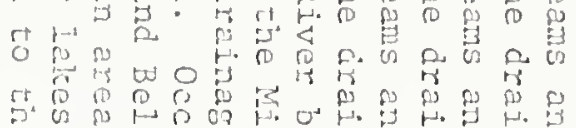

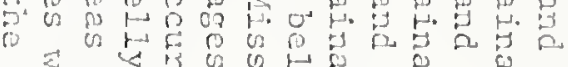

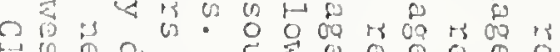

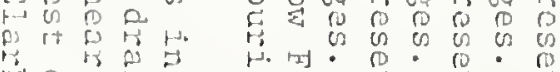

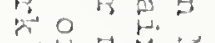

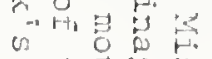

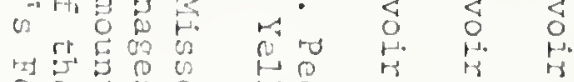

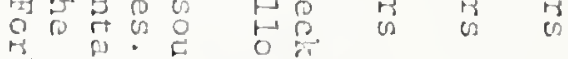

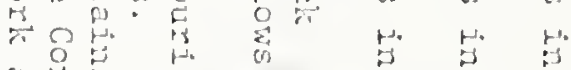

(2) 要

空得。

0 ?

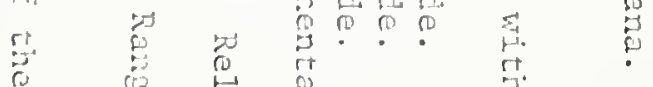

红落

on

然

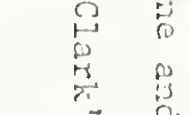

至

? 

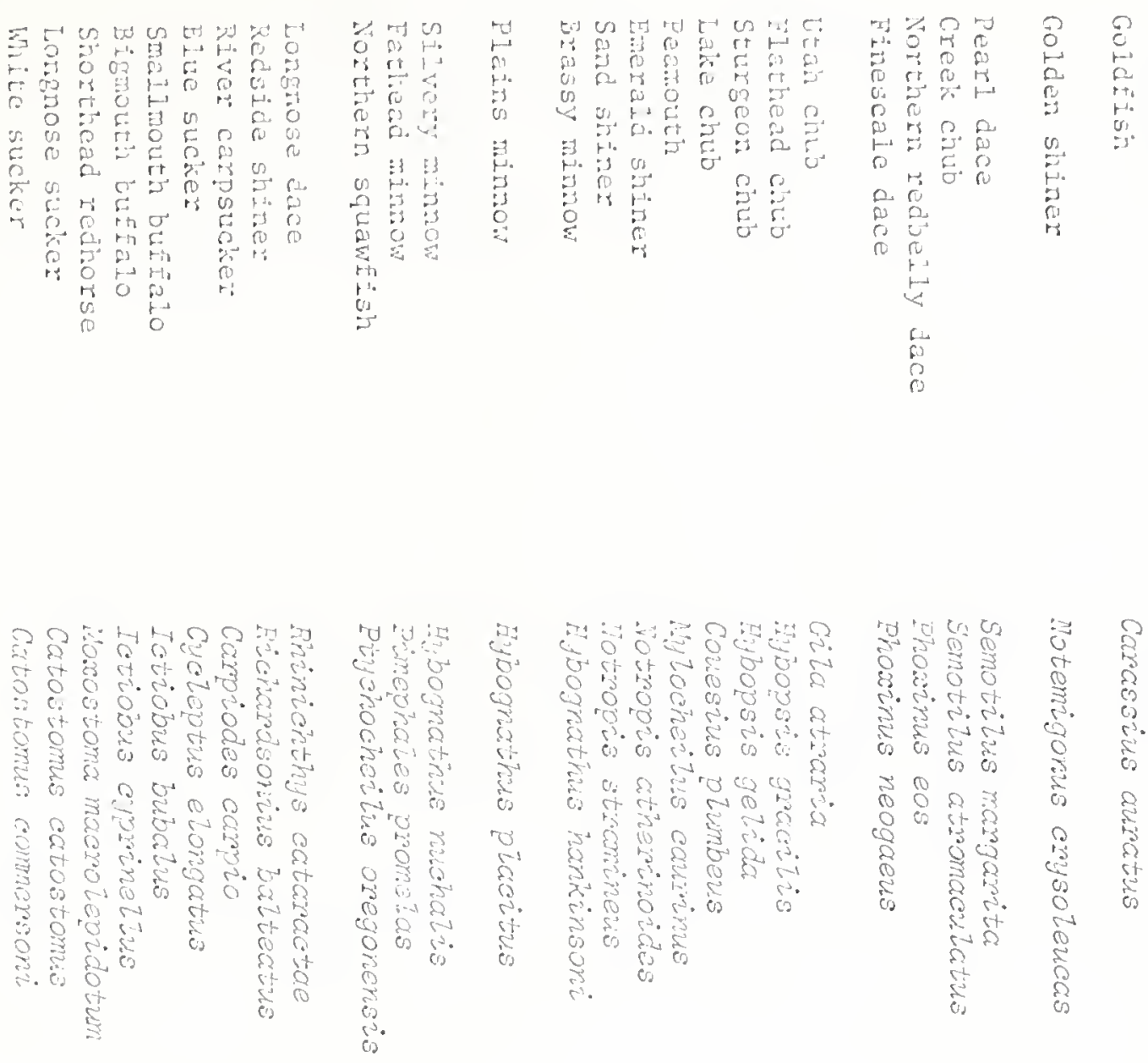

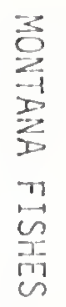

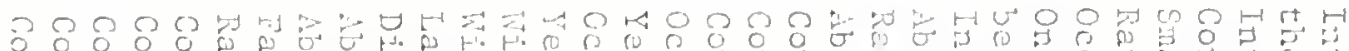

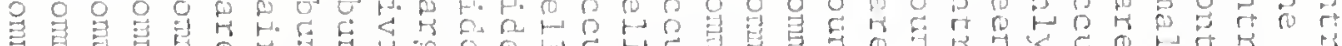

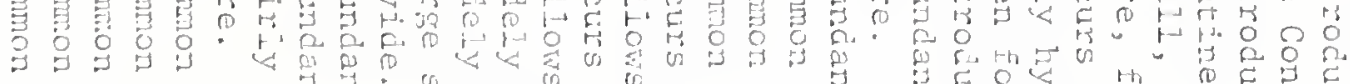

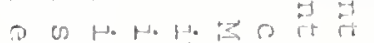

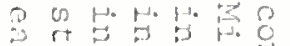

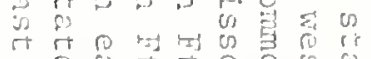
$\begin{array}{llllll}0 & 0 & 0 & 0 & 0 & 0\end{array}$

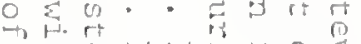

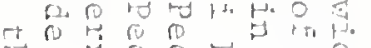

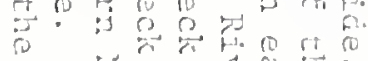

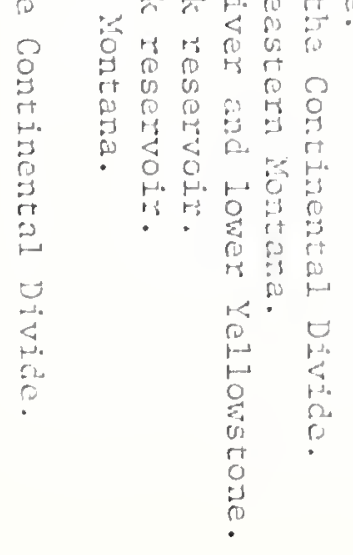

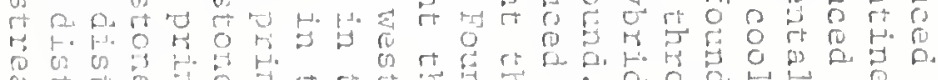

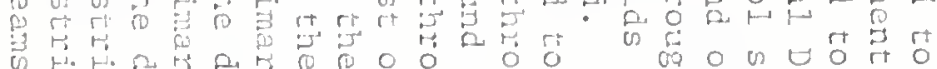

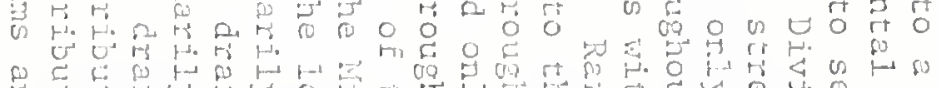

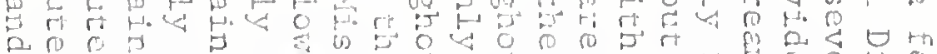

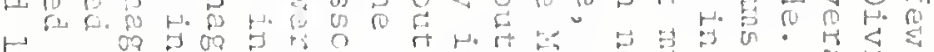

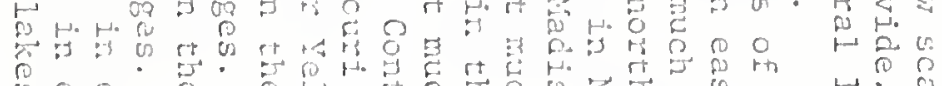

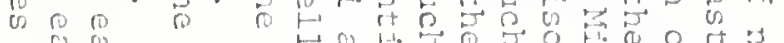
$\left\{\begin{array}{lllllllll}0 & 0 & 0 & 0\end{array}\right.$ $\begin{array}{llll}0 & 0 \\ 4 & 0 & 0\end{array}$

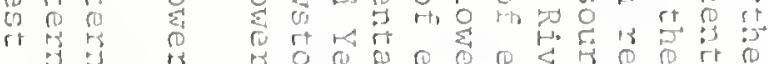

$$
\begin{aligned}
& 0 \\
& 5 \\
& 5 \\
& 0 \\
& 8 \\
& 0 \\
& 5 \\
& 50 \\
& 5 \\
& 5 \\
& 5 \\
& 6 \\
& 6
\end{aligned}
$$

(1)

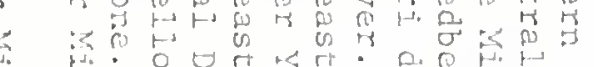

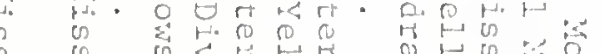

क क क स 0

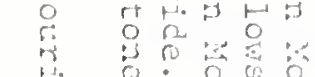

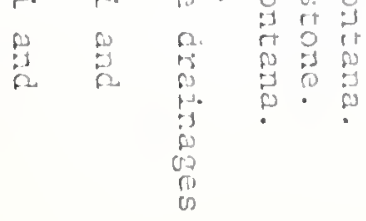

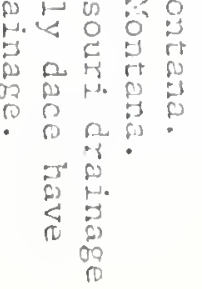



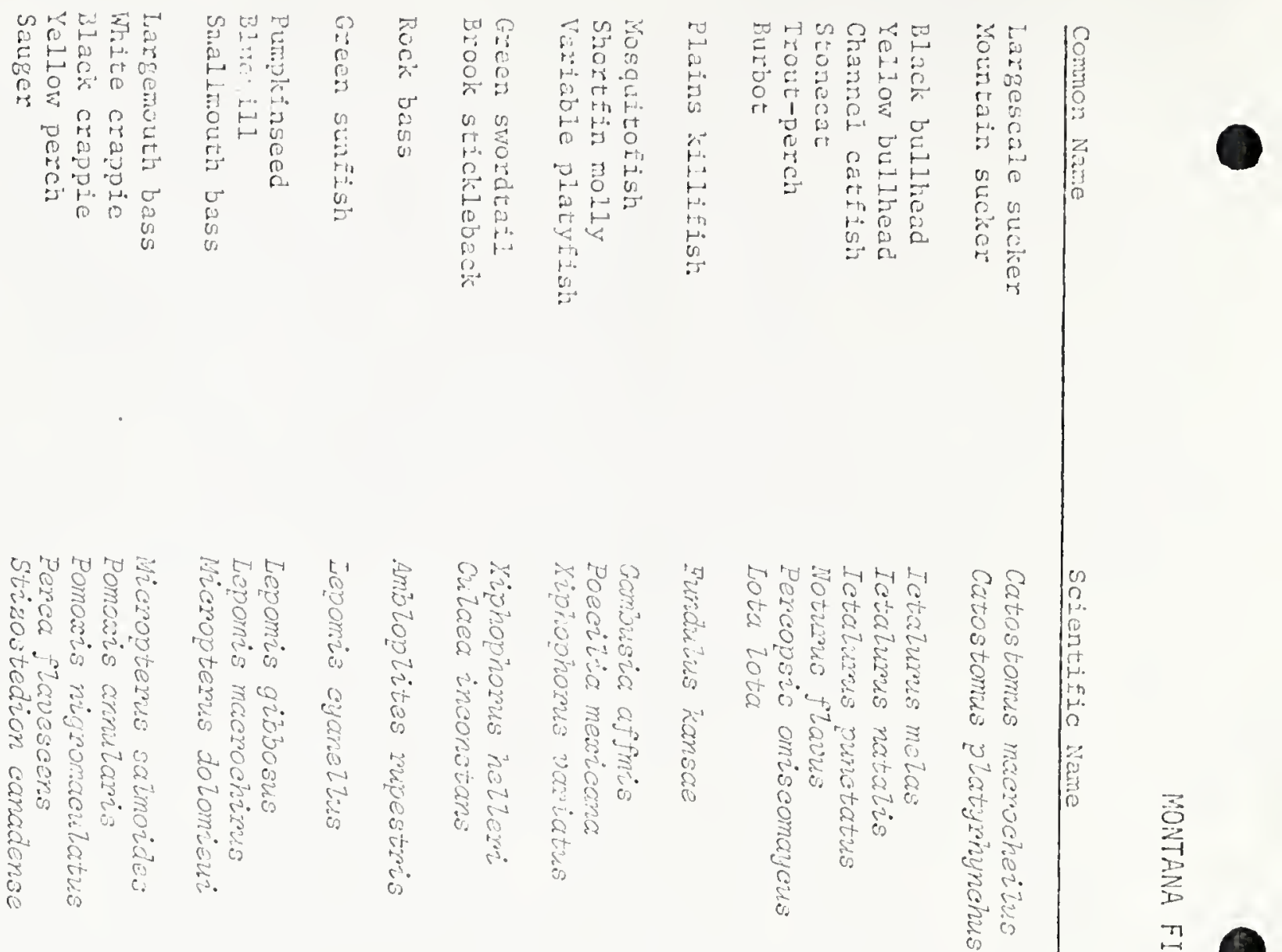

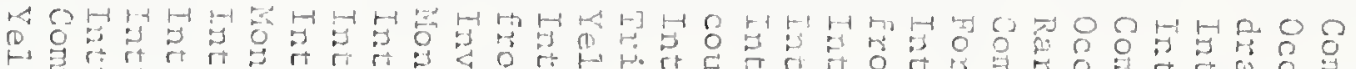

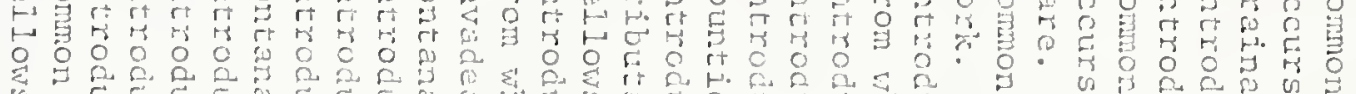

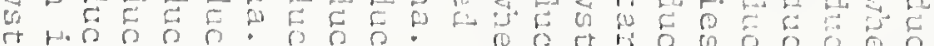

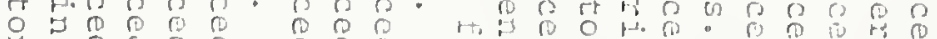

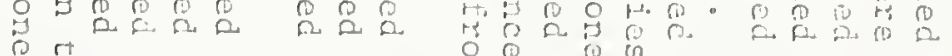

$\begin{array}{llllllll}0 & 0 & 0 & 0 & 0 & 0 & 0 & 0\end{array}$

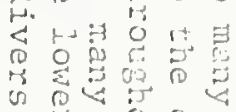

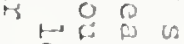

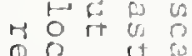
a) o 0 is is

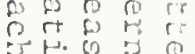
$\begin{array}{ccc}0 & 0 \\ 0 & 0 & 0\end{array}$

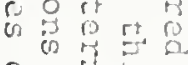

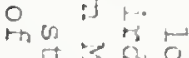

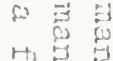
$H$
$\mathrm{C}$ $\begin{array}{lll}1+2 & 0\end{array}$ a) a b ?.A $r i t$

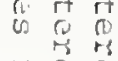
$\because 00$ ctin

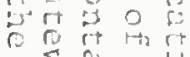

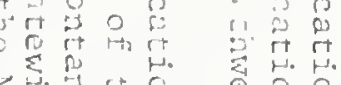
$\therefore$ t. 0 it 0 मे० 0

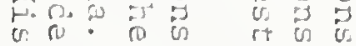

o.

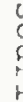

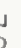

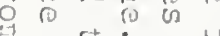
H.

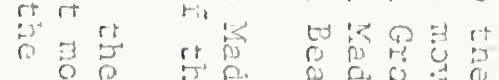
४द⿱乛龰

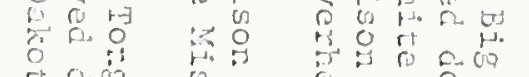

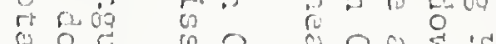

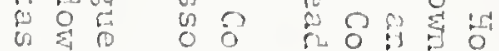
1

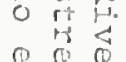
C.

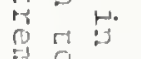

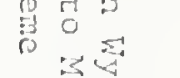

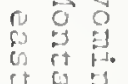

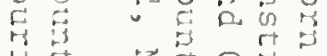

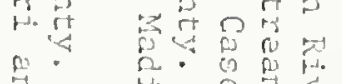
药

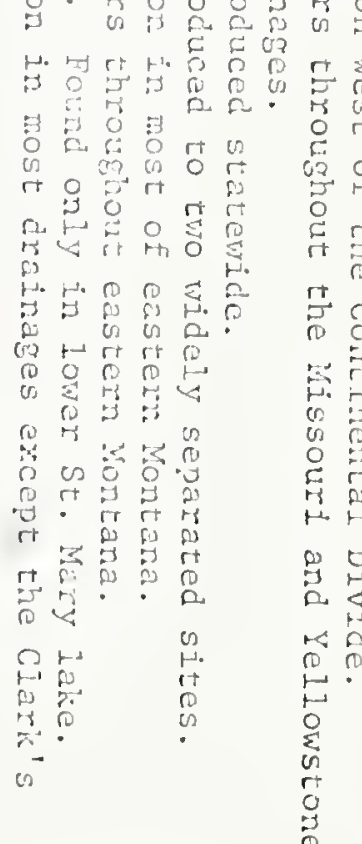

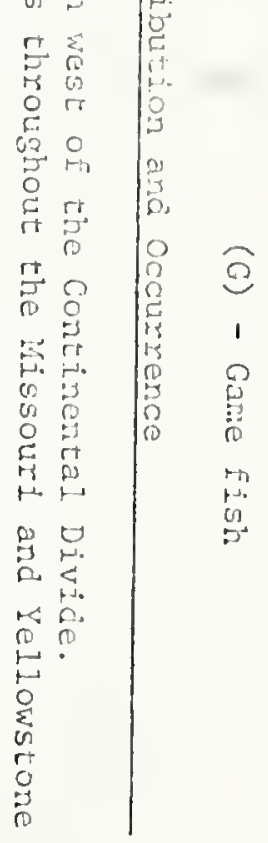

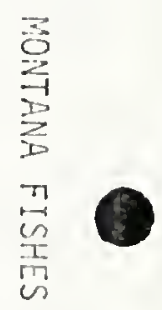
$\begin{array}{lllll}0 & 0 & 0 & 0 & 0 \\ 0 & 0 & 0 & 0 & 0\end{array}$

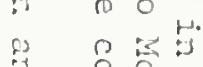

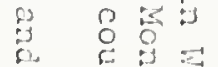
\&.

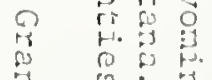
it $\begin{array}{cc}0 \\ 0\end{array}$ H.

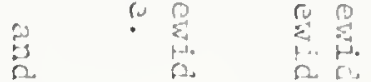

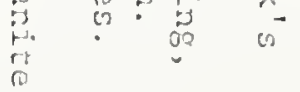
is 


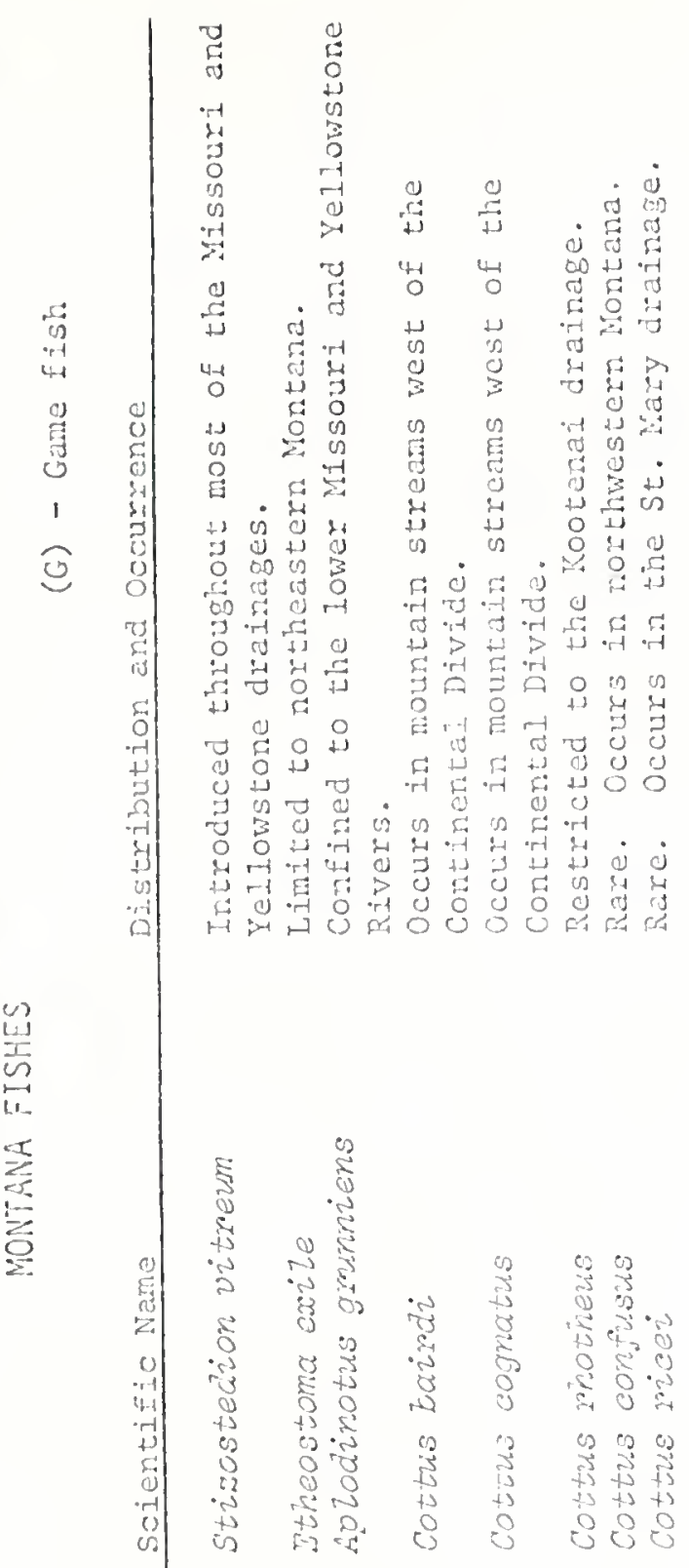

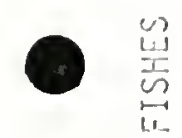

势

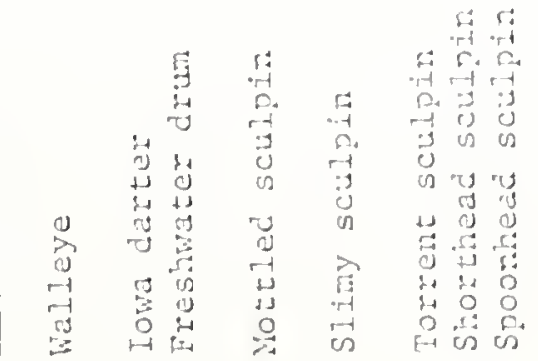

0 
-

○

- 